\title{
Cosmic Ray Interactions in Shielding Materials
}

\author{
E Aguayo RT Kouzes \\ AS Ankney ${ }^{1} \quad J L$ Orrell \\ TJ Berguson ${ }^{1}$ MD Troy ${ }^{2}$
}

July 2011

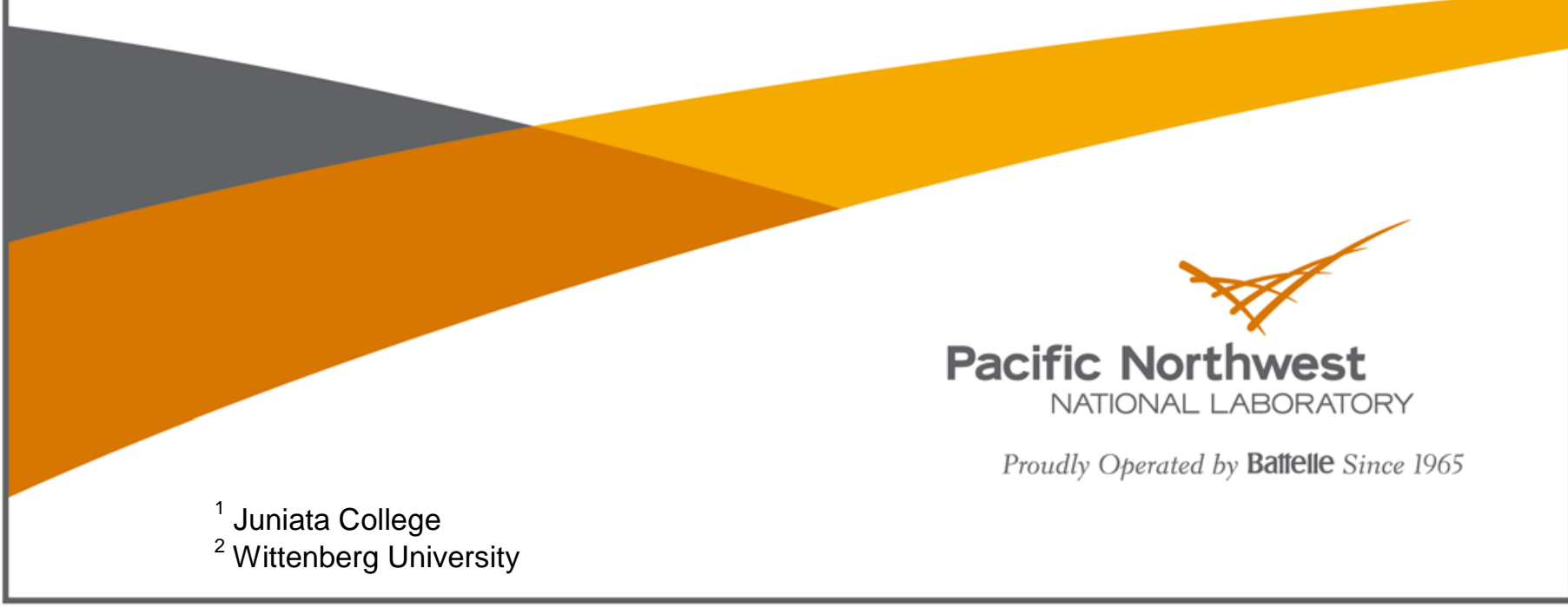




\title{
DISCLAIMER
}

This report was prepared as an account of work sponsored by an agency of the United States Government. Neither the United States Government nor any agency thereof, nor Battelle Memorial Institute, nor any of their employees, makes any warranty, express or implied, or assumes any legal liability or responsibility for the accuracy, completeness, or usefulness of any information, apparatus, product, or process disclosed, or represents that its use would not infringe privately owned rights. Reference herein to any specific commercial product, process, or service by trade name, trademark, manufacturer, or otherwise does not necessarily constitute or imply its endorsement, recommendation, or favoring by the United States Government or any agency thereof, or Battelle Memorial Institute. The views and opinions of authors expressed herein do not necessarily state or reflect those of the United States Government or any agency thereof.

\author{
PACIFIC NORTHWEST NATIONAL LABORATORY \\ operated by \\ BATTELLE \\ for the \\ UNITED STATES DEPARTMENT OF ENERGY \\ under Contract DE-AC05-76RL01830
}

Printed in the United States of America
Available to DOE and DOE contractors from the Office of Scientific and Technical Information,
P.O. Box 62, Oak Ridge, TN 37831-0062;
ph: (865) 576-8401
fax: $(865) 576-5728$
email: reports@adonis.osti.gov
Available to the public from the National Technical Information Service 5301 Shawnee Rd., Alexandria, VA 22312 ph: (800) 553-NTIS (6847)
email: orders@ntis.gov <http://www.ntis.gov/about/form.aspx> Online ordering: http://www.ntis.gov

This document was printed on recycled paper. 


\title{
Cosmic Ray Interactions in Shielding Materials
}

\author{
E Aguayo RT Kouzes \\ AS Ankney ${ }^{1} \quad$ JL Orrell \\ TJ Berguson ${ }^{1}$ MD Troy ${ }^{2}$
}

July 2011

Prepared for

the U.S. Department of Energy

under Contract DE-AC05-76RL01830

Pacific Northwest National Laboratory

Richland, Washington 99352

\footnotetext{
${ }^{1}$ Juniata College

${ }^{2}$ Wittenberg University
} 



\section{Summary}

This document provides a detailed study of materials used to shield against the hadronic particles from cosmic ray showers at Earth's surface. This work was motivated by the need for a shield that minimizes activation of the enriched germanium during transport for the MAJORANA collaboration. The materials suitable for cosmic-ray shield design are materials such as lead and iron that will stop the primary protons, and materials like polyethylene, borated polyethylene, concrete and water that will stop the induced neutrons. The interaction of the different cosmic-ray components at ground level (protons, neutrons, muons) with their wide energy range (from kilo-electron volts to giga-electron volts) is a complex calculation. Monte Carlo calculations have proven to be a suitable tool for the simulation of nucleon transport, including hadron interactions and radioactive isotope production. The Monte Carlo simulation tool Geant4 was used for this study.

This document is structured to explicitly present the data and its analysis for the six different materials considered. Each material is analyzed according to it geometry, considering ten different thicknesses of each material plus no material. The intent of this document is to provide practical guidance in the choice of shielding material for the energy range of interest (20 MeV to $10 \mathrm{GeV}$ ) and its particular configuration. The hydrogenous materials modeled for this study were polyethylene (PE), borated polyethylene (BPE), and water. The effectiveness of each of these materials in shielding cosmic neutrons, protons and muons was similarly poor. None of these is therefore recommended as a material to consider in shielding the detector materials in transport from cosmic rays.

The result of this study is the assertion that activation at Earth's surface is a result of the neutronic and protonic components of the cosmic-ray shower. The best material to shield against these cosmic-ray components is iron, which has the best combination of primary shielding and minimal secondary neutron production. 

PNNL-20693

\title{
Acronyms and Abbreviations
}

\author{
ov $\beta \beta \quad$ Neutrinoless double-beta decay \\ $2 v \beta \beta \quad$ Two-neutrino double beta decay \\ BPE Borated polyethylene \\ CERN The European Organization for Nuclear Research (French: Organisation Européenne \\ pour la Recherche Nucléaire) \\ Geant4 Geometry and Transport 4 \\ HPGe High-purity germanium \\ MJD MAJORANA DEMONSTRATOR \\ PE Polyethylene \\ PEEK Polyether ether ketone \\ PNNL Pacific Northwest National Laboratory
}





\section{Contents}

1.0

2.0

2.1

2.2

2.3

3.0

3.1

3.1.1

3.1.2

3.1.3

3.2

3.2.1

3.2.2

3.2.3

3.3

3.3.1

3.3.2

3.3.3

3.4

3.4.1

3.4 .2

3.4 .3

3.5

3.5.1

3.5.2

3.5 .3

3.6

3.6.1

3.6.2

3.6 .3

4.0

4.1

Cosmic Flux

5.0

6.0

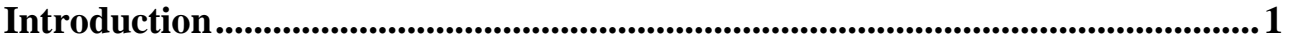

Monte Carlo Tool Description ............................................................................................. 4

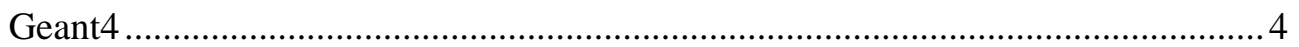

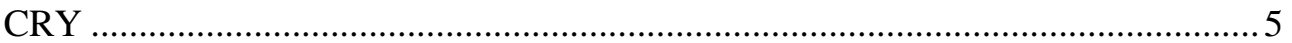

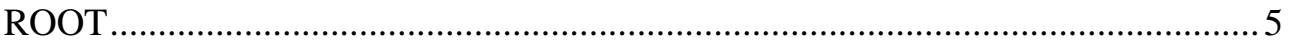

Material characterization.....................................................................................6

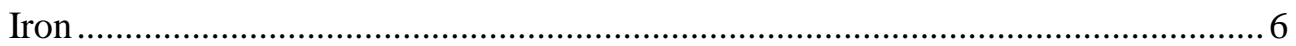

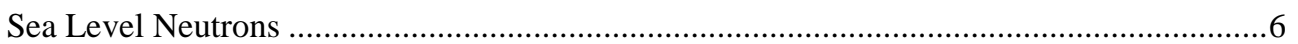

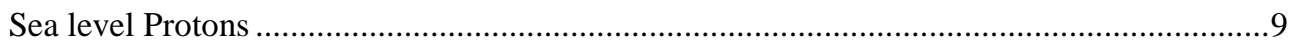

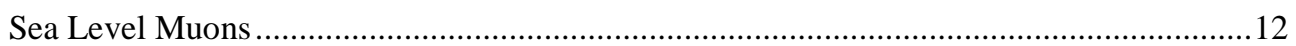

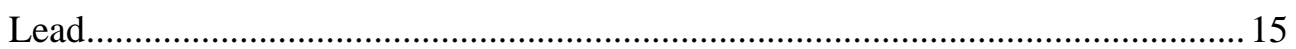

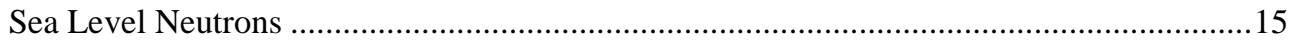

Sea level Protons ........................................................................................................18

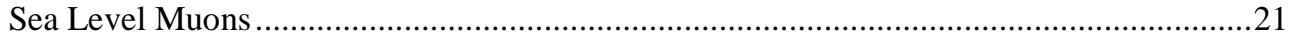

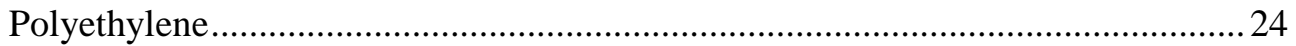

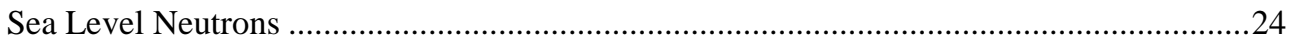

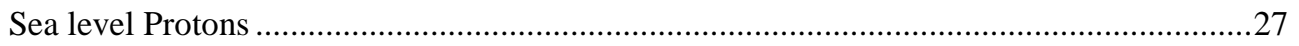

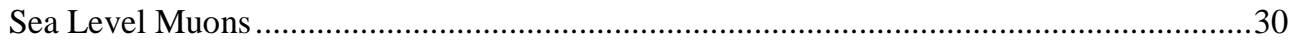

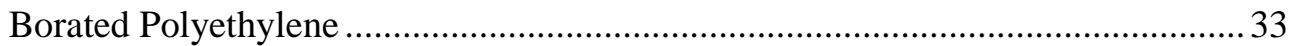

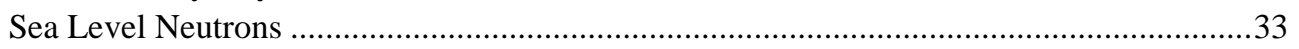

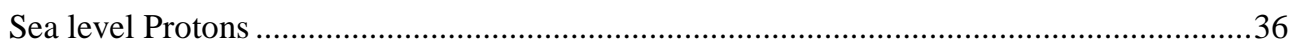

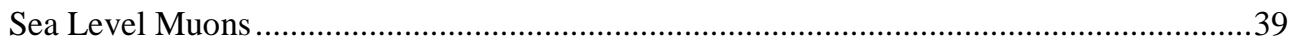

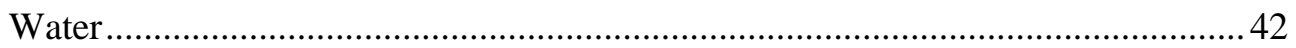

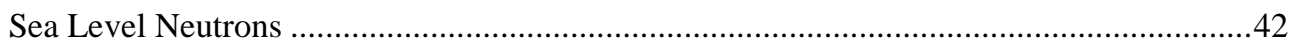

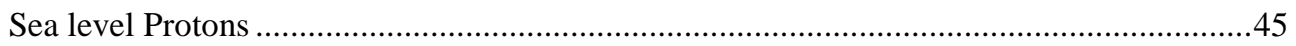

Sea Level Muons ....................................................................................48

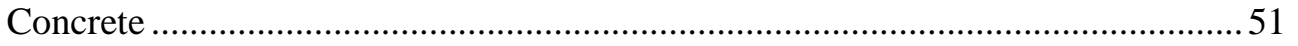

Sea Level Neutrons ……………………………………............................................5

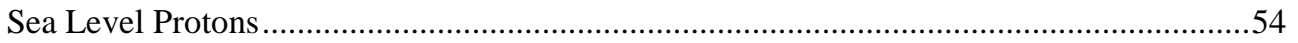

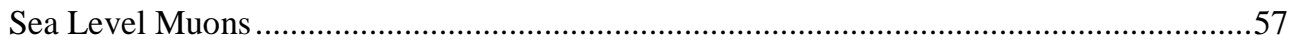

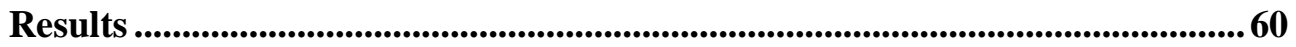

Twenty Mega-Electron Volt to Ten Giga-Electron Volt Energy Range of the 60

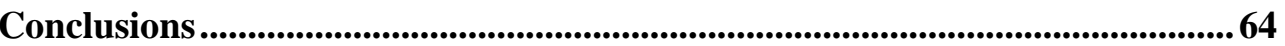

References ................................................................................................................................. 66

Appendix A : Low- and Very High-Energy Ranges......................................................................... A.1 


\section{Figures}

Figure 1: Cosmic Neutron Flux through Iron 7

Figure 2: Simulated Spectra for Cosmic Neutrons through $0 \mathrm{~cm}$ to $100 \mathrm{~cm}$ of Iron .......................8

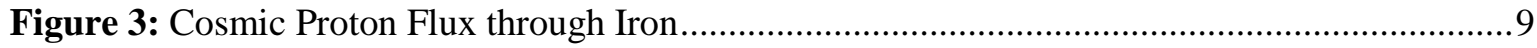

Figure 4: Simulated Spectra for Cosmic Protons through $0 \mathrm{~cm}$ to $100 \mathrm{~cm}$ of Iron.........................11

Figure 5: Cosmic Muon Flux through Iron.............................................................................12

Figure 6: Simulated Spectra for Cosmic Muons through $0 \mathrm{~cm}$ to $100 \mathrm{~cm}$ of Iron.........................14

Figure 7: Cosmic Neutron Flux through Lead .........................................................................15

Figure 8: Simulated Spectra for Cosmic Neutrons through $0 \mathrm{~cm}$ to $100 \mathrm{~cm}$ of Lead....................17

Figure 9: Cosmic Proton Flux through Lead .............................................................................18

Figure 10: Simulated Spectra for Cosmic Protons through $0 \mathrm{~cm}$ to $100 \mathrm{~cm}$ of Lead ....................20

Figure 11: Cosmic Muon Flux through Lead …........................................................................21

Figure 12: Simulated Spectra for Cosmic Muons through $0 \mathrm{~cm}$ to $100 \mathrm{~cm}$ of Lead .....................23

Figure 13: Cosmic Neutron Flux through Polyethylene ..........................................................24

Figure 14: Simulated Spectra for Cosmic Neutrons through $0 \mathrm{~cm}$ to $100 \mathrm{~cm}$ of Polyethylene......26

Figure 15: Cosmic Proton Flux through Polyethylene..............................................................2

Figure 16: Simulated Spectra for Cosmic Protons through $0 \mathrm{~cm}$ to $100 \mathrm{~cm}$ of Polyethylene ........29

Figure 17: Cosmic Muon Flux through Polyethylene.................................................................30

Figure 18: Simulated Spectra for Cosmic Muons through $0 \mathrm{~cm}$ to $100 \mathrm{~cm}$ of Polyethylene...........32

Figure 19: Cosmic Neutron Flux through Borated Polyethylene.................................................33

Figure 20: Simulated Spectra for Cosmic Neutrons through $0 \mathrm{~cm}$ to $100 \mathrm{~cm}$ of Borated

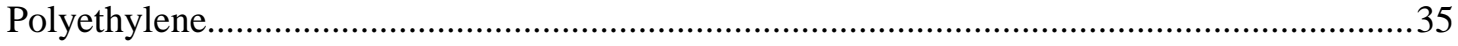

Figure 21: Cosmic Proton Flux through Borated Polyethylene...................................................36

Figure 22: Simulated Spectra for Cosmic Protons through $0 \mathrm{~cm}$ to $100 \mathrm{~cm}$ of Borated

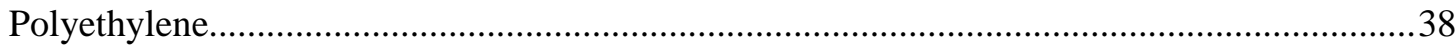

Figure 23: Cosmic Muon Flux through Borated Polyethylene .......................................................39

Figure 24: Simulated Spectra for Cosmic Muons through $0 \mathrm{~cm}$ to $100 \mathrm{~cm}$ of Borated

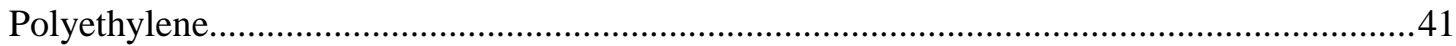

Figure 25: Cosmic Neutron Flux through Water ..................................................................42

Figure 26: Simulated Spectra for Cosmic Neutrons through $0 \mathrm{~cm}$ to $100 \mathrm{~cm}$ of Water .................44

Figure 27: Cosmic Proton Flux through Water............................................................................45

Figure 28: Simulated Spectra for Cosmic Protons through $0 \mathrm{~cm}$ to $100 \mathrm{~cm}$ of Water ....................47 


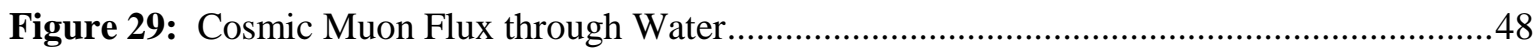

Figure 30: Simulated Spectra for Cosmic Muons through $0 \mathrm{~cm}$ to $100 \mathrm{~cm}$ of Water.....................50

Figure 31: Cosmic Neutron Flux through Concrete.................................................................51

Figure 32: Simulated Spectra for Cosmic Neutrons through $0 \mathrm{~cm}$ to $100 \mathrm{~cm}$ of Concrete ............53

Figure 33: Cosmic Proton Flux through Concrete ..................................................................54

Figure 34: Simulated Spectra for Cosmic Protons through $0 \mathrm{~cm}$ to $100 \mathrm{~cm}$ of Concrete...............56

Figure 35: Cosmic Muon Flux through Concrete .......................................................................57

Figure 36: Simulated Spectra for Cosmic Muons through $0 \mathrm{~cm}$ to $100 \mathrm{~cm}$ of concrete.................59

Figure 37: High-Energy Outbound Neutron Flux versus Material Thickness for All Materials

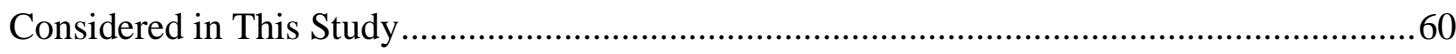

Figure 38: High-Energy Outbound Proton Flux versus Material Thickness for All Materials

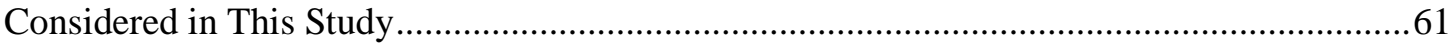

Figure 39: Outbound Total Neutron and Proton Flux through $100 \mathrm{~cm}$ of All Materials Considered in This Study

Figure 40: Low-Energy Outbound Neutron Flux versus Material Thickness for All Materials Considered in This Study

Figure 41: Low-Energy Outbound Proton Flux versus Material Thickness for All Materials Considered in This Study

Figure 42: Outbound Total Low-Energy Neutron and Proton Flux through $100 \mathrm{~cm}$ of All Materials Considered in This Study

Figure 43: High-Energy Outbound Neutron Flux versus Material Thickness for All Materials Considered in This Study 


\section{Tables}

Table 1: Calculated Energy Q-values for the Neutronic ${ }^{68}$ Ge Reactions ........................................

Table 2: Calculated Energy Q-values for the Neutronic ${ }^{60}$ Co Reactions ........................................2

Table 3: MAJORANA DEMOnSTRATOR Background Budget (Detwiler 2011) .................................

Table 4: Software Versions Used in This Work (Aguayo-Navarrete et al. 2010) ..........................4

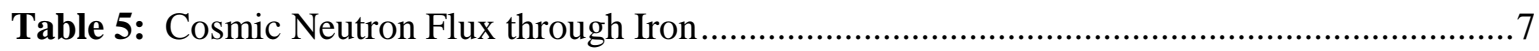

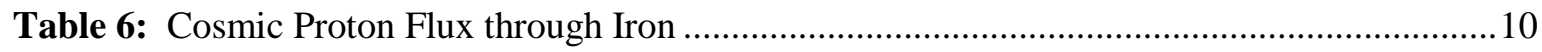

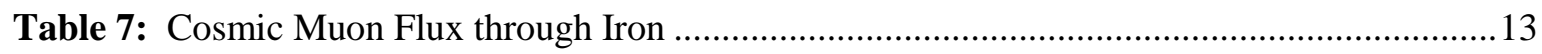

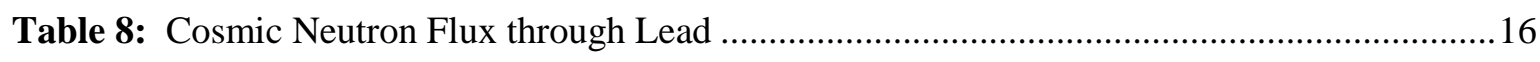

Table 9: Cosmic Proton Flux through Lead............................................................................. 19

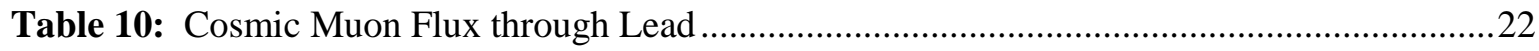

Table 11: Cosmic Neutron Flux through Polyethylene.............................................................25

Table 12: Cosmic Proton Flux through Polyethylene .............................................................28

Table 13: Cosmic Muon Flux through Polyethylene ............................................................... 31

Table 14: Cosmic Neutron Flux through Borated Polyethylene .................................................34

Table 15: Cosmic Proton Flux through Borated Polyethylene ......................................................37

Table 16: Cosmic Muon Flux through Borated Polyethylene.......................................................40

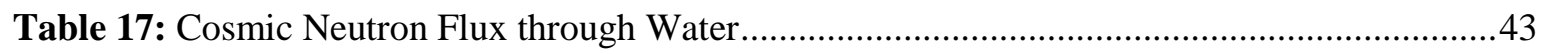

Table 18: Cosmic Proton Flux through Water ..........................................................................46

Table 19: Cosmic Muon Flux through Water ...........................................................................49

Table 20: Cosmic Neutron Flux through Concrete .......................................................................52

Table 21: Cosmic Proton Flux through Concrete …......................................................................55

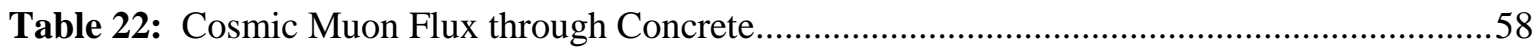

Table 23: High-Energy Cosmic Particle Flux through Different Materials per Primary Particle....62

Table 24: Low-Energy Cosmic Particle Flux through Different Materials per Primary Particle .A.4 
PNNL-20693

\subsection{Introduction}

The MAJORANA Project (Aalseth et al. 2009) will use high-purity germanium (HPGe) in an attempt to observe the rare nuclear decay process of neutrinoless double-beta decay $(0 v \beta \beta)$ and to determine the mass of the neutrino. To obtain the measurements necessary to complete these tasks, the experiment must have a low-background radiation environment. In other words, for the success of this experiment "it's all about the backgrounds" (Elliott 2011). The contributors to the background can be divided into categories:

- Natural radioactivity in detector components (potassium, uranium, thorium)

- Cosmogenic radioactivity $\left({ }^{68} \mathrm{Ge},{ }^{60} \mathrm{Co}\right)$

- $\quad$ Surface contaminants $(\alpha, \beta)$

- Muons, fast neutrons

- $2 v \beta \beta$ decay

- $\quad$ Neutrino scattering (reactor, solar, atmospheric, geoneutrinos, supernovae ...)

- $\quad$ Low-energy backgrounds $\left({ }^{3} \mathrm{H}\right.$; low-E Compton from potassium, uranium, thorium, etc.)

This study focuses on the minimization of the cosmogenic activation of the HPGe by analyzing different shielding materials in the energy range of interest. The cosmic rays generate unstable nuclei with both short (minutes) and long (years) half-lives. Therefore, the experiment will be carried out underground to shield against cosmic rays. However, during shipment, particles that would later be shielded by Earth's crust can reach the HPGe detector. This makes it necessary to use additional shielding material that can block these particles during shipment. The two distinct background issues in this type of experiment are ${ }^{68} \mathrm{Ge}$ with a half-life of 270 days, for which the cosmogenic production "clock" starts after enrichment in Russia and ${ }^{60}$ Co with a half-life of 5.27 years for which the cosmogenic production "clock" starts after zone refining and crystal pulling in Oak Ridge, TN. This is an important distinction in terms of managing cosmogenic activation as the longer half-life ${ }^{60} \mathrm{Co}$ is effectively eliminated after the overseas transport of the enriched germanium material.

To determine which particles need to be shielded against during transport, it is necessary to know what energy is required to activate the germanium, producing the radionuclides of concern, especially ${ }^{60} \mathrm{Co}$ and ${ }^{68} \mathrm{Ge}$. Table 1 shows the Q-values for the activation reactions in enriched germanium producing ${ }^{68} \mathrm{Ge}$. From these calculated values, one can derive that the energy region of interest for cosmogenic activation is above $20 \mathrm{MeV}$. In other words, cosmic ray particles — in particular neutrons — with energy of $20 \mathrm{MeV}$ or greater can generate ${ }^{68} \mathrm{Ge}$ in germanium, and in the case of ${ }^{60} \mathrm{Co}$ neutrons with energy greater than $80 \mathrm{MeV}$. The Q-values for the activation reactions in enriched germanium producing 60Co are shown in Table 2. Such unstable nuclei, and their short-lived daughter products, can subsequently create signals in the same energy regions as $0 v \beta \beta$. One hundred mega-electron volts for the source particle - in this case, neutrons - is the point where all reactions of concern can occur. Two factors impact the large uncertainty in production rate: firstly, the number of primary particles drops rapidly (Ziegler 1998), and secondly, the Geant4 cross section data, which is based on theoretical extrapolation of beam experiments (usually source neutrons with $20 \mathrm{MeV}$ maximum energy) is not as reliable, and the production rate calculation becomes more uncertain instead of being based on experimental data. Data for this energy range is presented in Appendix A. 
PNNL-20693

Table 1: Calculated Energy Q-values for the Neutronic ${ }^{68}$ Ge Reactions

\begin{tabular}{cc}
\hline Nuclear Reaction & Calculated Q value (MeV) \\
\hline${ }^{70} \mathrm{Ge}(n, 3 n)^{68} \mathrm{Ge}$ & -20.01 \\
${ }^{72} \mathrm{Ge}(n, 5 n)^{68} \mathrm{Ge}$ & -38.42 \\
${ }^{73} \mathrm{Ge}(n, 6 n)^{68} \mathrm{Ge}$ & -45.29 \\
${ }^{74} \mathrm{Ge}(n, 7 n)^{68} \mathrm{Ge}$ & -55.62 \\
${ }^{76} \mathrm{Ge}(n, 9 n)^{68} \mathrm{Ge}$ & -71.74 \\
\hline
\end{tabular}

Table 2: Calculated Energy Q-values for the Neutronic ${ }^{60}$ Co Reactions

\begin{tabular}{cc}
\hline Nuclear Reaction & Unbound Q Value (MeV) \\
\hline${ }^{70} \mathrm{Ge}(n, 5 p 6 n){ }^{60} \mathrm{Co}$ & -83.2 \\
${ }^{72} \mathrm{Ge}(n, 5 p 8 n){ }^{60} \mathrm{Co}$ & -101.3 \\
${ }^{73} \mathrm{Ge}(n, 5 p 9 n){ }^{60} \mathrm{Co}$ & -108.1 \\
${ }^{74} \mathrm{Ge}(n, 5 p 10 n){ }^{60} \mathrm{Co}$ & -118.3 \\
${ }^{76} \mathrm{Ge}(n, 5 p 12 n){ }^{60} \mathrm{Co}$ & -124.8 \\
\hline
\end{tabular}

The background budget of such experiments must account for the potential sources of background due to cosmic activation in the detector material. Table 3 shows the projected backgrounds for the MAJORANA DEMONSTRATOR experiment (Detwiler 2011). As seen in Table 3, the cosmogenic ${ }^{68} \mathrm{Ge}$ is responsible for $10 \%$ of the background and cosmogenic ${ }^{60} \mathrm{Co}$ in the germanium detectors is responsible for $1 \%$ of the total background. This shows the importance of limiting the activation of the germanium material by high energy cosmic rays. 
Table 3: MAJORANA DEMONSTRATOR Background Budget (Detwiler 2011)

\begin{tabular}{|c|c|c|c|c|}
\hline Componont & Isotope & $\begin{array}{c}\text { Gross Rate, } \\
\text { I.9-3 MoV } \\
\text { [c/modulo/ } \\
\text { month] }\end{array}$ & $\begin{array}{c}\text { ROI Background } \\
\text { (DEMONSTRATOR) } \\
\text { [c/ROI/t/y] }\end{array}$ & $\begin{array}{c}\text { ROI Background } \\
\text { (tonno scalo) } \\
\text { [c/ROI/t/y] }\end{array}$ \\
\hline \multirow{3}{*}{$\begin{array}{l}\text { Germanium } \\
\text { Crystals } \\
\text { (enriched) }\end{array}$} & ${ }^{\mathrm{a}} \mathrm{Ge}$ & $47(7.6)$ & 0.38 & negligible \\
\hline & ${ }^{\infty} \mathrm{Co}$ & 4.2 & 0.03 & negligible \\
\hline & U/Th & - & $<0.3$ & $<0.3$ \\
\hline $\begin{array}{l}\text { Plastic, } \\
\text { Electronics, } \\
\text { Cables }\end{array}$ & 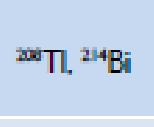 & 1.1 & 0.20 & 0.15 \\
\hline $\begin{array}{l}\text { Cryostat, Inner } \\
\text { Cu Shield } \\
\text { (EFCu) }\end{array}$ & ${ }^{200} \mathrm{Th},{ }^{214} \mathrm{Bi}$ & 2.1 & 0.91 & 0.48 \\
\hline \multirow{2}{*}{$\begin{array}{l}\text { Outer Cu } \\
\text { Shield }\end{array}$} & ${ }^{200} \mathrm{Tl},{ }^{214} \mathrm{Bi}$ & 0.8 & 0.40 & 0.02 \\
\hline & ${ }^{\infty} \mathrm{Co}$ & 20 & 0.02 & $1 \times 10^{-3}$ \\
\hline Pb Shield & ${ }^{200} \mathrm{Tl},{ }^{214} \mathrm{Bi}$ & 0.5 & 0.40 & negligible \\
\hline $\begin{array}{c}\text { Prompt } \\
\text { Cosmogenics }\end{array}$ & $\left(n,{ }^{*}\right)$ & - & $\sim 1$ & $\sim 0.06$ \\
\hline $\begin{array}{c}\text { Other } \\
(\alpha, \mathbf{R n}, \text { ext. } \gamma \ldots)\end{array}$ & & 0.1 & 0.18 & 0.12 \\
\hline \multicolumn{2}{|l|}{ Totalst } & $57.8(18.5)$ & 3.8 & 1.1 \\
\hline
\end{tabular}

To determine which material would be best for shielding the HPGe during shipping, Geant4, a free computer toolkit provided by CERN, was used to study the transport shielding problem. Geant4 uses Monte Carlo calculations to simulate the passage of particles through matter, providing information on the outbound particles created by cosmic rays traveling through certain materials. The primary components of cosmic rays (neutrons, protons, and muons) were simulated passing through $0 \mathrm{~cm}$ to $100 \mathrm{~cm}$ (at $10 \mathrm{~cm}$ intervals) of concrete, iron, lead, water, polyethylene, and borated polyethylene. Heavy concrete seems at first glance to be another material one might consider in shielding applications; however, its proprietary formulation is not available to the researchers, and so it could not be accurately simulated in this study. 


\subsection{Monte Carlo Tool Description}

In order to have a complete Monte Carlo simulation tool, several pieces of software must be used, including, at a minimum, one for the physics simulation, one for the radiation source model and one for the data analysis. This document refers to a hadronic simulation tool developed by our group that was used to analyze the shielding materials considered herein (Aguayo-Navarrete et al. 2010). This tool is intended to simulate hadronic interaction of cosmic rays impinging on a radiation shield and has three components:

- Geant4 Toolkit

- CRY library

- ROOT data analysis tool

Table 4: Software Versions Used in This Work (Aguayo-Navarrete et al. 2010)

\begin{tabular}{|c|c|c|}
\hline Code & Version & Source \\
\hline Geant4 & 9.3 .4 & Geant4.cern.ch \\
\hline CRY & 1.6 & www.Ilnl.gov \\
\hline ROOT & $3.10 / 02$ & $\begin{array}{l}\text { www-glast.slac. } \\
\text { stanford.edu/software/root } \\
\text { /walkthrough/install.htm }\end{array}$ \\
\hline Cygwin & 1.7.9-1 & www.cygwin.com \\
\hline Microsoft Visual Studio & 2010 Express & $\frac{\text { http://www.microsoft.com/visualstudio/en- }}{\frac{\text { us/products/2010-editions/visual-cpp- }}{\underline{\text { express }}}}$ \\
\hline
\end{tabular}

In Table 4, the tool set for a Monte Carlo application, based on Geant4, is presented as run in a Windows computing environment.

\subsection{Geant4}

Geant4 is a tool kit that uses Monte Carlo methodology to simulate the passage of particles through matter. It has useful applications in particle physics, nuclear physics, accelerator design, space engineering, and medical physics. Geant4 was specifically designed, using the $\mathrm{C}++$ programming language, "to expose the physics models utilized, to handle complex geometries, and to enable easy adaption for optimal use in different sets of applications” (Agostinelli et al. 2003).

In contrast to codes like Fluka, MCNP, ISABEL and SHIELD, Geant4 is capable of simulating the whole energy spectrum of interest in these calculations. The identified drawbacks of using this code are the questionable reliability of neutronic physics, which still has to be verified, and the high configurability of the code. This work uses the recommended configuration for high-energy physics as well as calorimetry and shielding applications (all energies) (The Geant4 Collaboration). The studies of test- 
beam data currently show that a cascade model is needed for a good description of hadronic showers. The QGSP_BERT physics list improves agreement with LHC test beam data for the longitudinal and lateral shower shape and energy resolution. This list is currently chosen by the LHC experiments ATLAS and CMS as their default physics list, which are two of the largest contributors to the development of Geant4. This configuration has the most up to date hadronic physics models, and they are being thoroughly validated.

\subsection{CRY}

Cosmic-Ray Shower Library (CRY) is free software produced by the Lawrence Livermore National Laboratory that is used to generate correlated cosmic-ray particle showers as either a transport or detector simulation code. It generates shower information for muons, neutrons, protons, electrons, and photons at one of three elevations (sea level, $2100 \mathrm{~m}$ and $11300 \mathrm{~m}$ ) within a specified area (up to $300 \mathrm{~m}$ by $300 \mathrm{~m}$ ). CRY also generates the time of arrival and the zenith angle of the secondary particles (Hagmann et al. 2008).

\subsection{ROOT}

ROOT (Kama 2011) is a data analysis toolkit. In conjunction with Geant4, ROOT is used to create spectra of the data that is simulated with the toolkit. The large amount of data generated by this type of application makes the use of a data analysis tool imperative. ROOT was developed at CERN to address the data analysis challenges of large data sets. 
PNNL-20693

\subsection{Material characterization}

This section provides details about the simulation results for various materials. The data are presented for neutron energies of $0-20 \mathrm{MeV}$, which are below the activation threshold energies of interest for germanium, $>20 \mathrm{MeV}$ and $>100 \mathrm{MeV}$. The data are provided in a similar fashion for protons and muons. This focus in this section is on attenuation of the incident particle flux, thus the data presented are principally outgoing flux of the same particle species. The detailed plots in this section also provide flux of secondary hadrons (neutrons and protons) produced by the primary neutrons, protons and muons. Section 4 presents direct comparisons of materials and summarizes the implications of these detailed studies for the design of shielding against cosmogenic activation.

\subsection{Iron}

\subsubsection{Sea Level Neutrons}

Iron has an atomic number of 26. The shielding properties of this material against the cosmic neutron flux are presented in three different energy regions in Figure 1. The same data is presented in Table 5. For low-energy neutrons, the secondary particle generation increases the outbound flux, breaking this trend at about $30 \mathrm{~cm}$, where the maximum amount of secondary particle flux is observed. For higher energy neutrons this effect is not observed, leading to the conclusion that if the end user of the shield is not concerned with neutrons below $20 \mathrm{MeV}$, then one can make this assertion: the thicker the shield the better. The exact simulated spectra for the 11 geometries simulated are presented in Figure 2. 


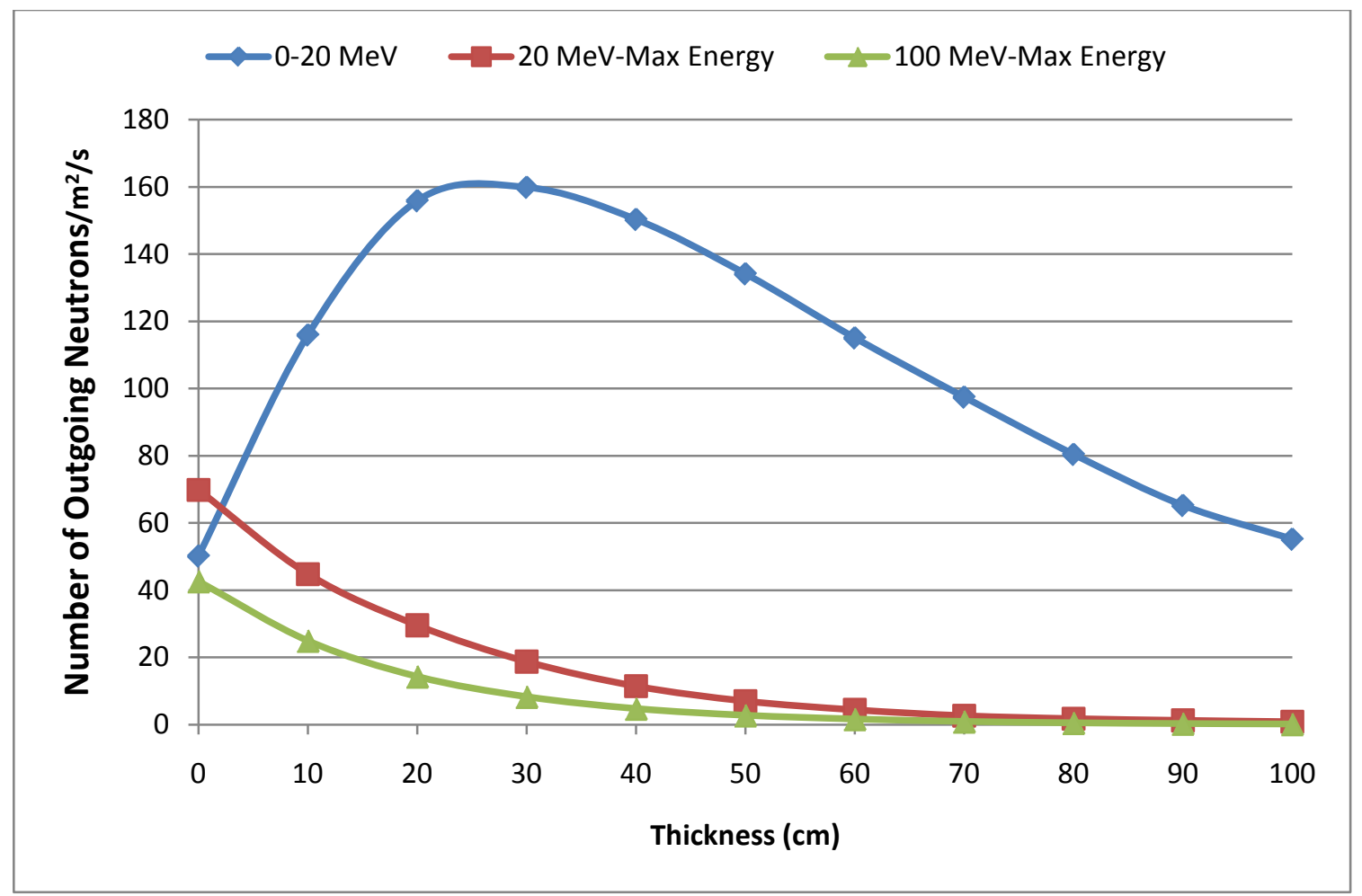

Figure 1: Cosmic Neutron Flux through Iron

Table 5: Cosmic Neutron Flux through Iron

\begin{tabular}{|cccc|}
\hline Thickness $(\mathbf{c m})$ & $\begin{array}{c}\text { Outbound } \\
\text { Neutrons } / \mathbf{m}^{2} / \mathrm{s} \\
\mathbf{0 - 2 0 ~ M e V}\end{array}$ & $\begin{array}{c}\text { Outbound } \\
\text { Neutrons } / \mathbf{m}^{2} / \mathbf{s} \\
\mathbf{2 0 ~ M e V - 1 0 ~ G e V}\end{array}$ & $\begin{array}{c}\text { Outbound } \\
\text { Neutrons } / \mathbf{m}^{2} / \mathbf{s} \\
100 \mathrm{MeV}-10 \mathrm{GeV}\end{array}$ \\
\hline 0 & $5.02 \mathrm{E}+01$ & $6.98 \mathrm{E}+01$ & $4.26 \mathrm{E}+01$ \\
10 & $1.16 \mathrm{E}+02$ & $4.48 \mathrm{E}+01$ & $2.50 \mathrm{E}+01$ \\
20 & $1.56 \mathrm{E}+02$ & $2.96 \mathrm{E}+01$ & $1.43 \mathrm{E}+01$ \\
30 & $1.60 \mathrm{E}+02$ & $1.87 \mathrm{E}+01$ & $8.29 \mathrm{E}+00$ \\
40 & $1.50 \mathrm{E}+02$ & $1.15 \mathrm{E}+01$ & $4.76 \mathrm{E}+00$ \\
50 & $1.34 \mathrm{E}+02$ & $7.01 \mathrm{E}+00$ & $2.77 \mathrm{E}+00$ \\
60 & $1.15 \mathrm{E}+02$ & $4.41 \mathrm{E}+00$ & $1.66 \mathrm{E}+00$ \\
70 & $9.74 \mathrm{E}+01$ & $2.65 \mathrm{E}+00$ & $9.35 \mathrm{E}-01$ \\
80 & $8.04 \mathrm{E}+01$ & $1.78 \mathrm{E}+00$ & $5.19 \mathrm{E}-01$ \\
90 & $6.52 \mathrm{E}+01$ & $1.26 \mathrm{E}+00$ & $3.01 \mathrm{E}-01$ \\
100 & $5.52 \mathrm{E}+01$ & $8.70 \mathrm{E}-01$ & $1.70 \mathrm{E}-01$ \\
\hline
\end{tabular}



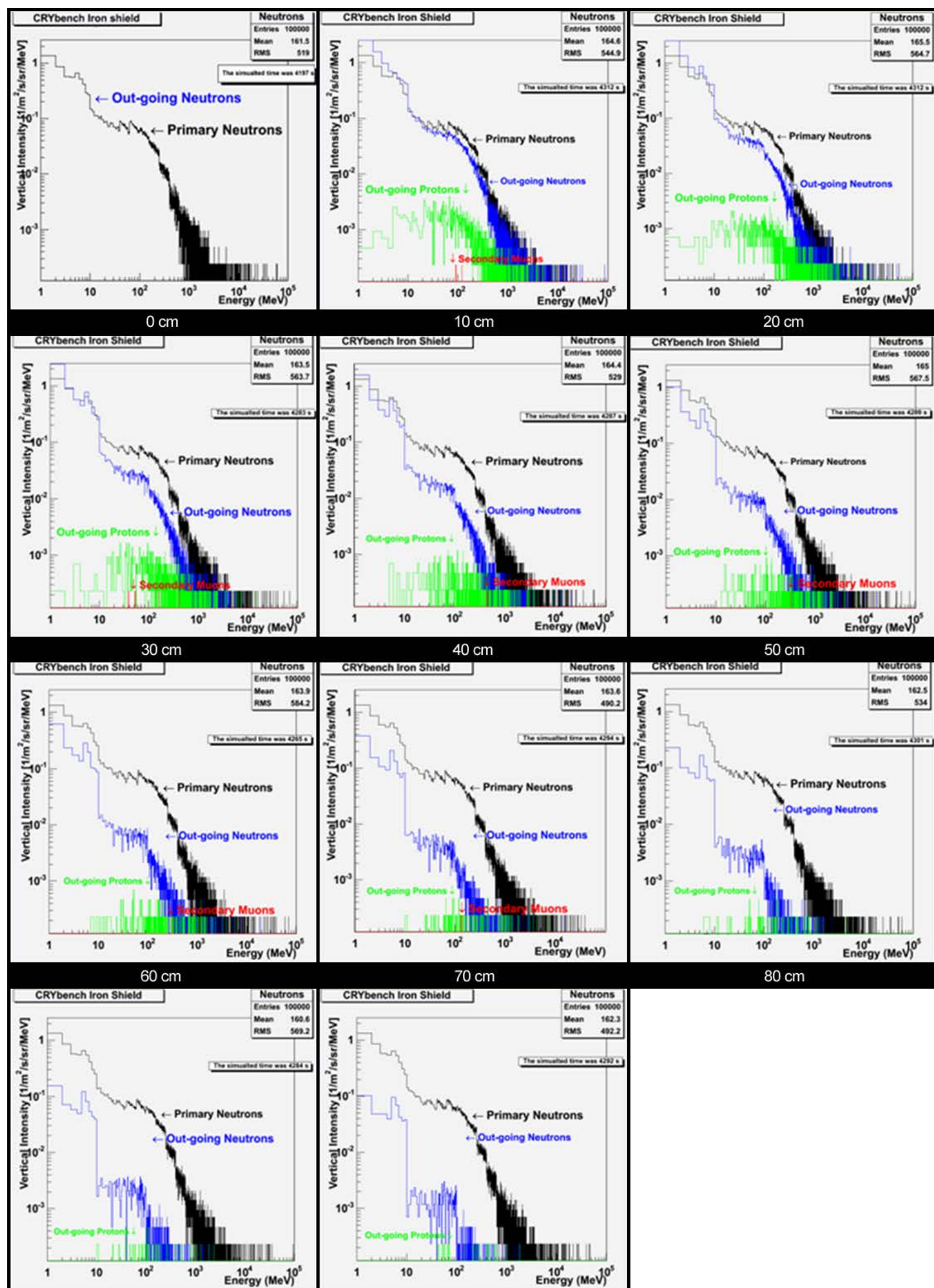

$90 \mathrm{~cm}$

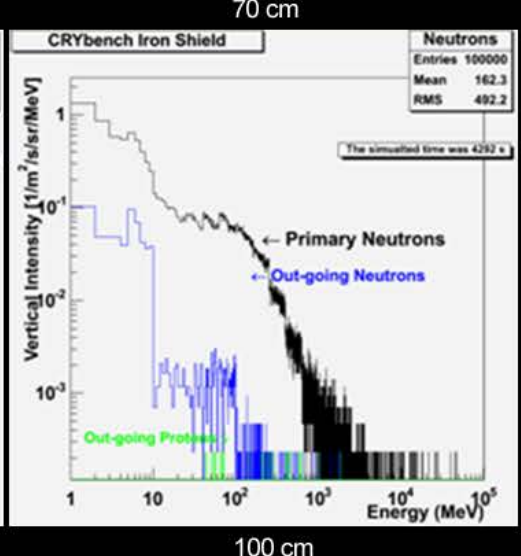

Figure 2: Simulated Spectra for Cosmic Neutrons through $0 \mathrm{~cm}$ to $100 \mathrm{~cm}$ of Iron 


\subsubsection{Sea level Protons}

The shielding properties of iron against the cosmic proton flux are presented in Figure 3, comparing the flux of outbound protons in three different energy regions. The same data is presented in Table 3 . To obtain the data for Figure 3 and Table 6, the simulation data was normalized to reflect the actual composition of proton flux in cosmic rays. For low-energy protons below $20 \mathrm{MeV}$, the secondary generation of protons in 10-cm thick iron increases the outbound flux. However, at $20 \mathrm{~cm}$, the iron starts to shield more effectively and decreases the number of outbound protons, showing a self shielding effect. For higher-energy protons this effect is not observed; the iron starts to shield the number of outbound protons immediately. The combination of these two effects suggests that the thicker the material is, the more effective the shield will be. The exact simulated spectra for the ten geometries of iron are presented in Figure 4. The secondary neutron generation for each geometry can be found in Table 22.

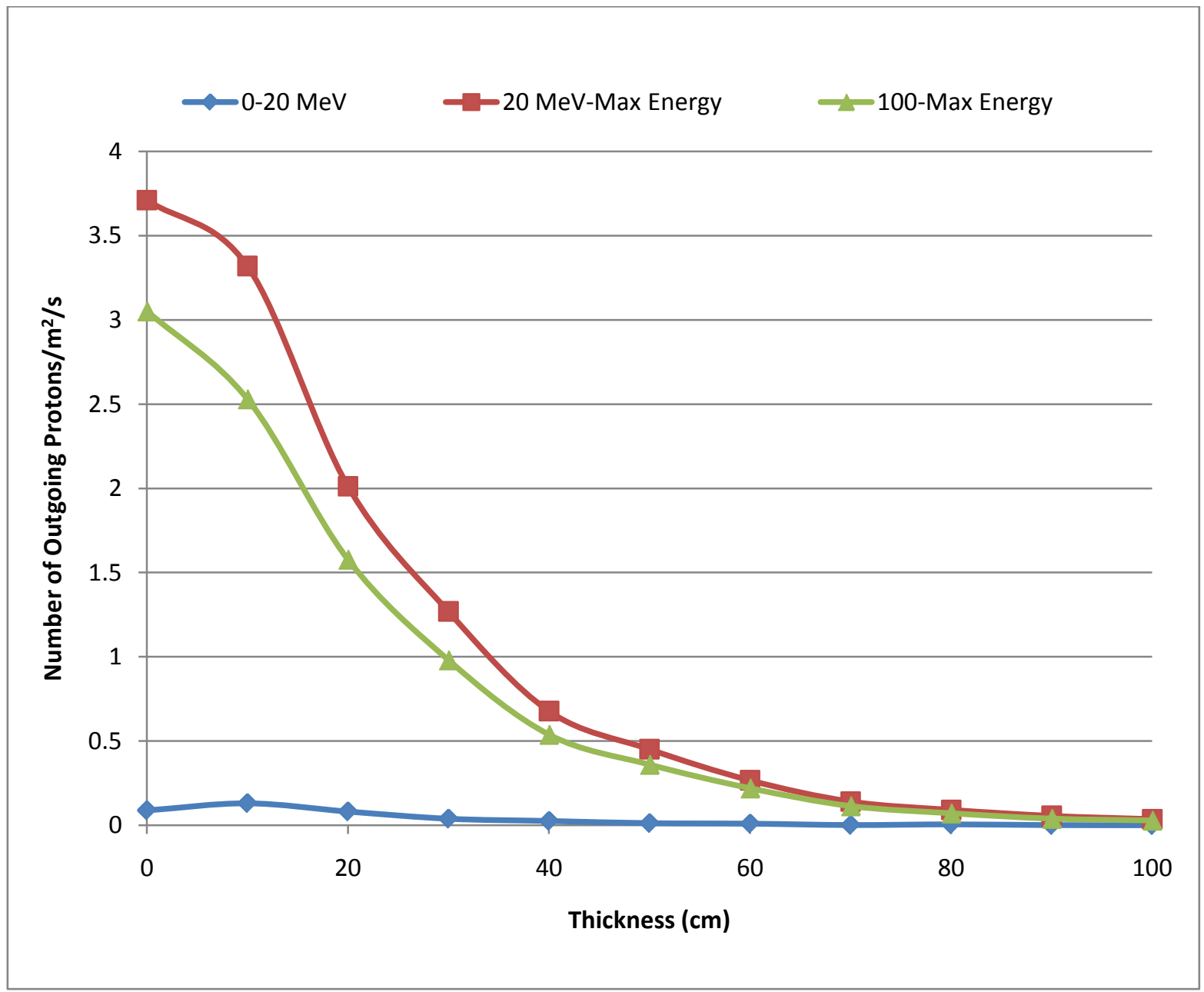

Figure 3: Cosmic Proton Flux through Iron 
PNNL-20693

Table 6: Cosmic Proton Flux through Iron

\begin{tabular}{|c|c|c|c|}
\hline Thickness (cm) & $\begin{array}{c}\text { Outbound } \\
\text { Protons } / \mathrm{m}^{2} / \mathrm{s} \\
0 \mathrm{MeV}-20 \mathrm{MeV}\end{array}$ & $\begin{array}{c}\text { Outbound } \\
\text { Protons } / \mathrm{m}^{2} / \mathrm{s} \\
20 \mathrm{MeV}-10 \mathrm{GeV}\end{array}$ & $\begin{array}{c}\text { Outbound } \\
\text { Protons } / \mathrm{m}^{2} / \mathrm{s} \\
100 \mathrm{MeV}-10 \mathrm{GeV}\end{array}$ \\
\hline 0 & $8.92 \mathrm{E}-02$ & $3.71 E+00$ & $3.05 E+00$ \\
\hline 10 & $1.32 \mathrm{E}-01$ & $3.32 \mathrm{E}+00$ & $2.53 \mathrm{E}+00$ \\
\hline 20 & 8.23E-02 & $2.01 E+00$ & $1.58 \mathrm{E}+00$ \\
\hline 30 & $3.93 \mathrm{E}-02$ & $1.27 \mathrm{E}+00$ & $9.81 \mathrm{E}-01$ \\
\hline 40 & $2.58 \mathrm{E}-02$ & $6.78 \mathrm{E}-01$ & 5.39E-01 \\
\hline 50 & $1.27 \mathrm{E}-02$ & $4.52 \mathrm{E}-01$ & 3.61E-01 \\
\hline 60 & $9.75 \mathrm{E}-03$ & $2.68 \mathrm{E}-01$ & $2.21 \mathrm{E}-01$ \\
\hline 70 & $1.50 \mathrm{E}-03$ & $1.42 \mathrm{E}-01$ & $1.15 \mathrm{E}-01$ \\
\hline 80 & $5.61 \mathrm{E}-03$ & $9.27 \mathrm{E}-02$ & $7.20 \mathrm{E}-02$ \\
\hline 90 & $1.12 \mathrm{E}-03$ & $5.70 \mathrm{E}-02$ & $4.01 E-02$ \\
\hline 100 & 3.79E-04 & $3.76 \mathrm{E}-02$ & 2.93E-02 \\
\hline
\end{tabular}




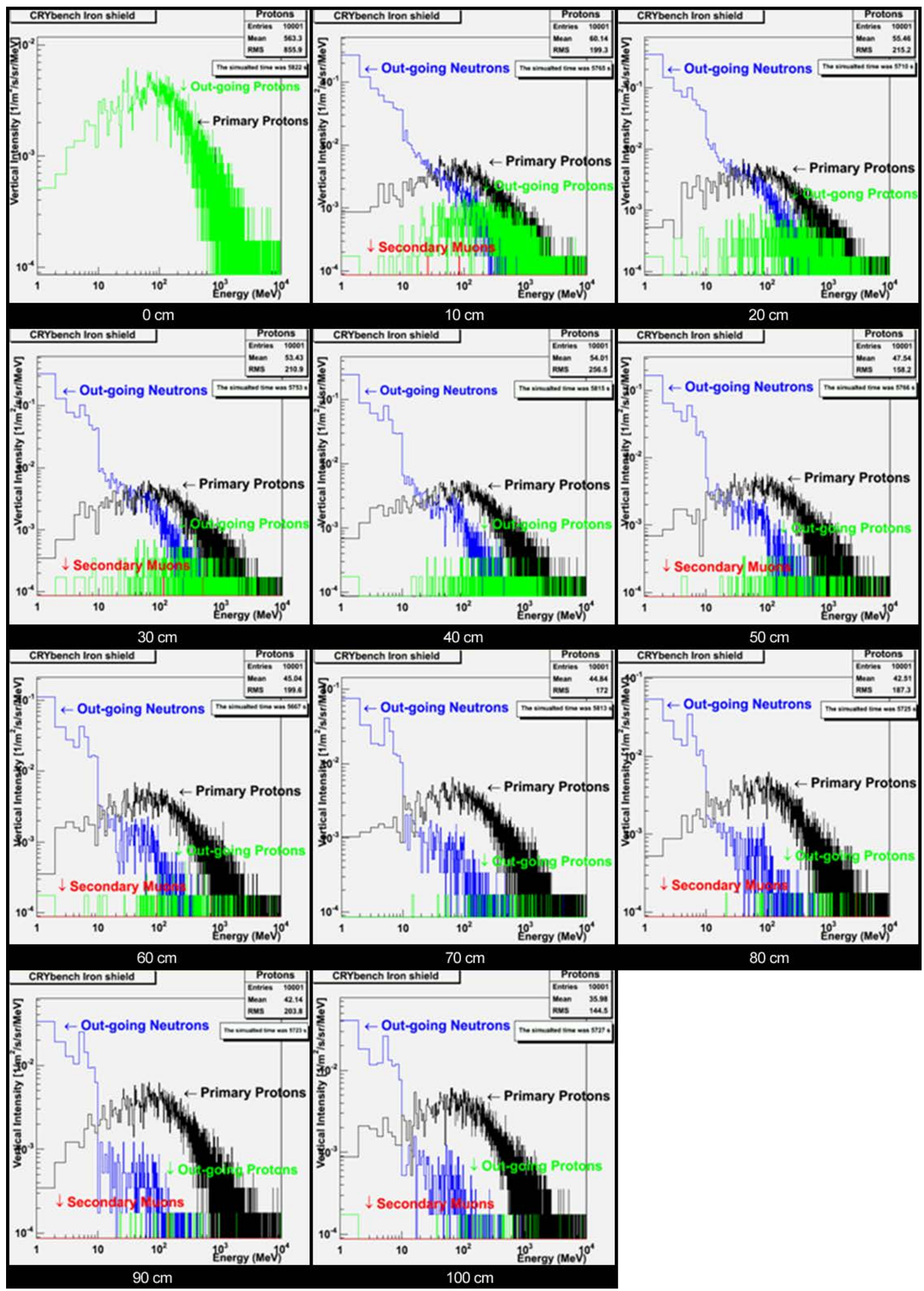

Figure 4: Simulated Spectra for Cosmic Protons through $0 \mathrm{~cm}$ to $100 \mathrm{~cm}$ of Iron 
PNNL-20693

\subsubsection{Sea Level Muons}

Iron, being a high-Z material, shields muons with relative efficiency. Outbound muon flux was categorized into the three energy regions seen in Figure 5.

Table 7 shows that there are very few muons under $100 \mathrm{MeV}$. Iron effectively shielded high-energy muons (100 MeV to $10 \mathrm{GeV}$ ). Iron of a thickness of approximately $97 \mathrm{~cm}$ shielded $50 \%$ of outbound muons. No muons were produced at any thickness by cosmogenic flux. Iron would be a highly recommended shielding material for cosmic ray muons. The exact simulated spectra for the ten geometries of iron are presented in Figure 6. In the spectra shown in Figure 4 a spike appears in the outgoing neutron flux $\sim 10 \mathrm{MeV}$ and increases with material thickness. This feature is attributed to the Giant Dipole Resonance (GDR) and the so called ‘Quasi-Deuteron’ region (Araujo et al. 2005).

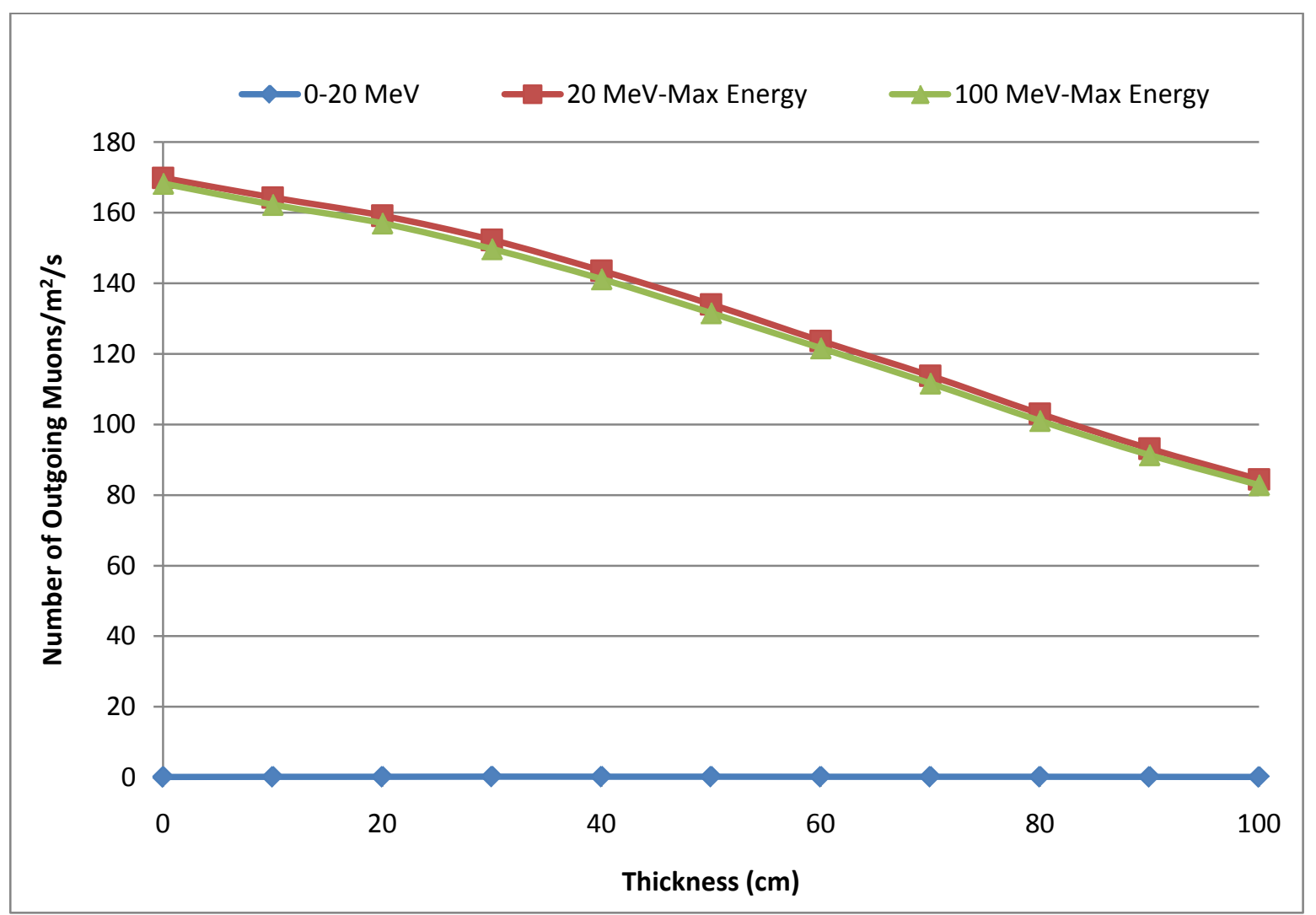

Figure 5: Cosmic Muon Flux through Iron 
PNNL-20693

Table 7: Cosmic Muon Flux through Iron

\begin{tabular}{|c|c|c|c|}
\hline Thickness (cm) & $\begin{array}{c}\text { Outbound } \\
\text { Muons } / \mathrm{m}^{2} / \mathrm{s} \\
0 \mathrm{MeV}-20 \mathrm{MeV}\end{array}$ & $\begin{array}{c}\text { Outbound } \\
\text { Muons } / \mathrm{m}^{2} / \mathrm{s} \\
20 \mathrm{MeV}-10 \mathrm{GeV}\end{array}$ & $\begin{array}{c}\text { Outbound } \\
\text { Muons } / \mathrm{m}^{2} / \mathrm{s}\end{array}$ \\
\hline 0 & $1.18 \mathrm{E}-01$ & $1.70 \mathrm{E}+02$ & $1.68 \mathrm{E}+02$ \\
\hline 10 & $1.74 \mathrm{E}-01$ & $1.64 \mathrm{E}+02$ & $1.62 \mathrm{E}+02$ \\
\hline 20 & $1.92 \mathrm{E}-01$ & $1.59 \mathrm{E}+02$ & $1.57 E+02$ \\
\hline 30 & $2.46 \mathrm{E}-01$ & $1.52 \mathrm{E}+02$ & $1.50 \mathrm{E}+02$ \\
\hline 40 & $2.26 \mathrm{E}-01$ & $1.44 \mathrm{E}+02$ & $1.41 \mathrm{E}+02$ \\
\hline 50 & $2.22 \mathrm{E}-01$ & $1.34 \mathrm{E}+02$ & $1.32 \mathrm{E}+02$ \\
\hline 60 & 1.97E-01 & $1.24 \mathrm{E}+02$ & $1.22 \mathrm{E}+02$ \\
\hline 70 & 1.97E-01 & $1.14 \mathrm{E}+02$ & $1.12 \mathrm{E}+02$ \\
\hline 80 & 1.97E-01 & $1.03 \mathrm{E}+02$ & $1.01 \mathrm{E}+02$ \\
\hline 90 & $1.62 \mathrm{E}-01$ & $9.32 \mathrm{E}+01$ & $9.14 \mathrm{E}+01$ \\
\hline 100 & $1.35 \mathrm{E}-01$ & $8.45 \mathrm{E}+01$ & $8.29 E+01$ \\
\hline
\end{tabular}




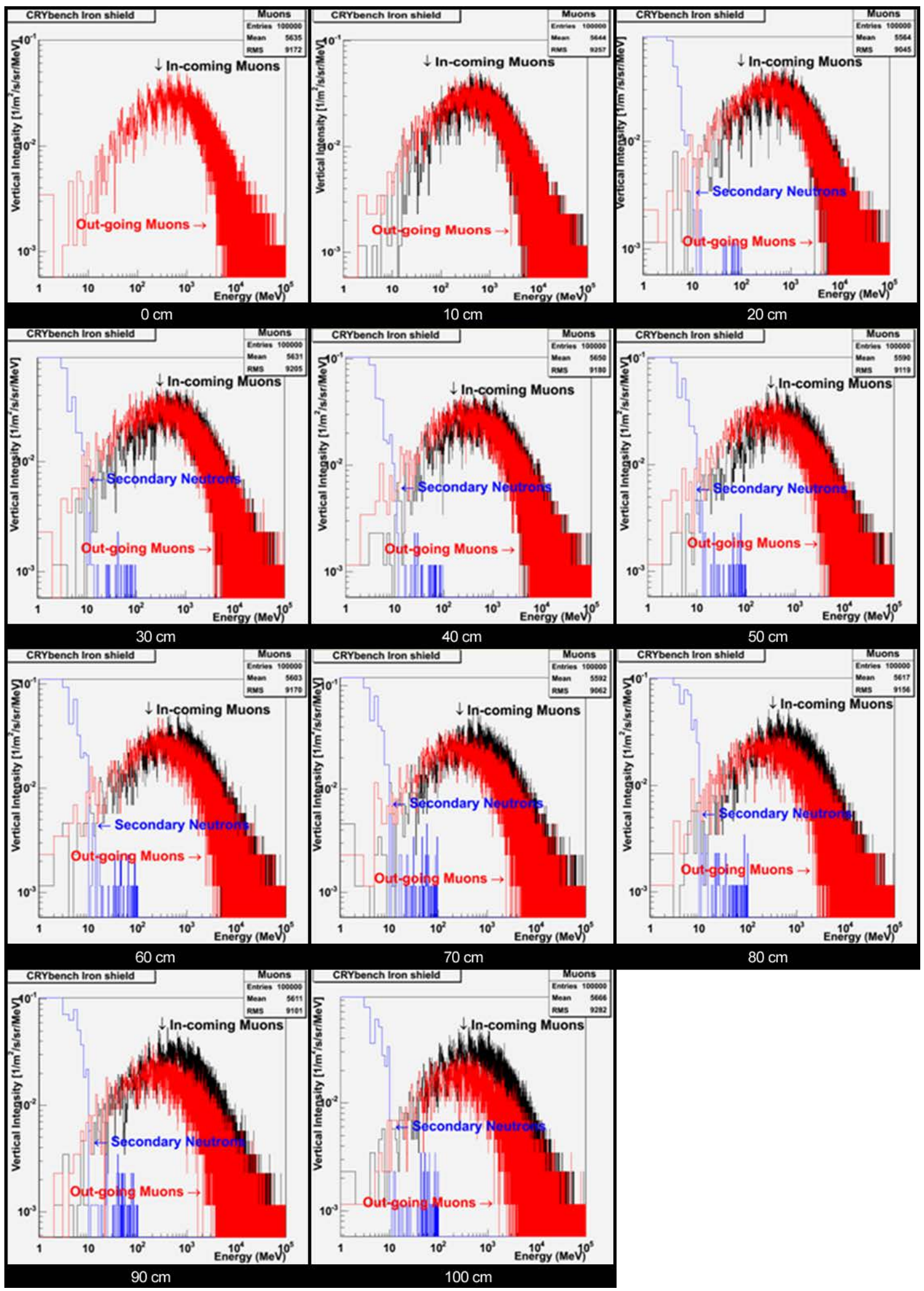

Figure 6: Simulated Spectra for Cosmic Muons through $0 \mathrm{~cm}$ to $100 \mathrm{~cm}$ of Iron 
PNNL-20693

\subsection{Lead}

\subsubsection{Sea Level Neutrons}

Lead shows shielding properties comparable to those of iron, as one can observe by comparing Figure 7 below to Figure 1. The trend of each energy range is similar, although there is a larger spike in generated low energy neutrons for small thicknesses through lead. Note that for lead, even after $100 \mathrm{~cm}$ the secondary generation shows still more low-energy neutrons. However, there is an exponential decay of outbound high energy neutrons, except for a slight uptick at $100 \mathrm{~cm}$ for neutrons in the $20 \mathrm{MeV}$ $10 \mathrm{GeV}$ energy range. The data for this graph is located in Table 8, divided into three energy regions, and each of the 11 spectra is in Figure 8.

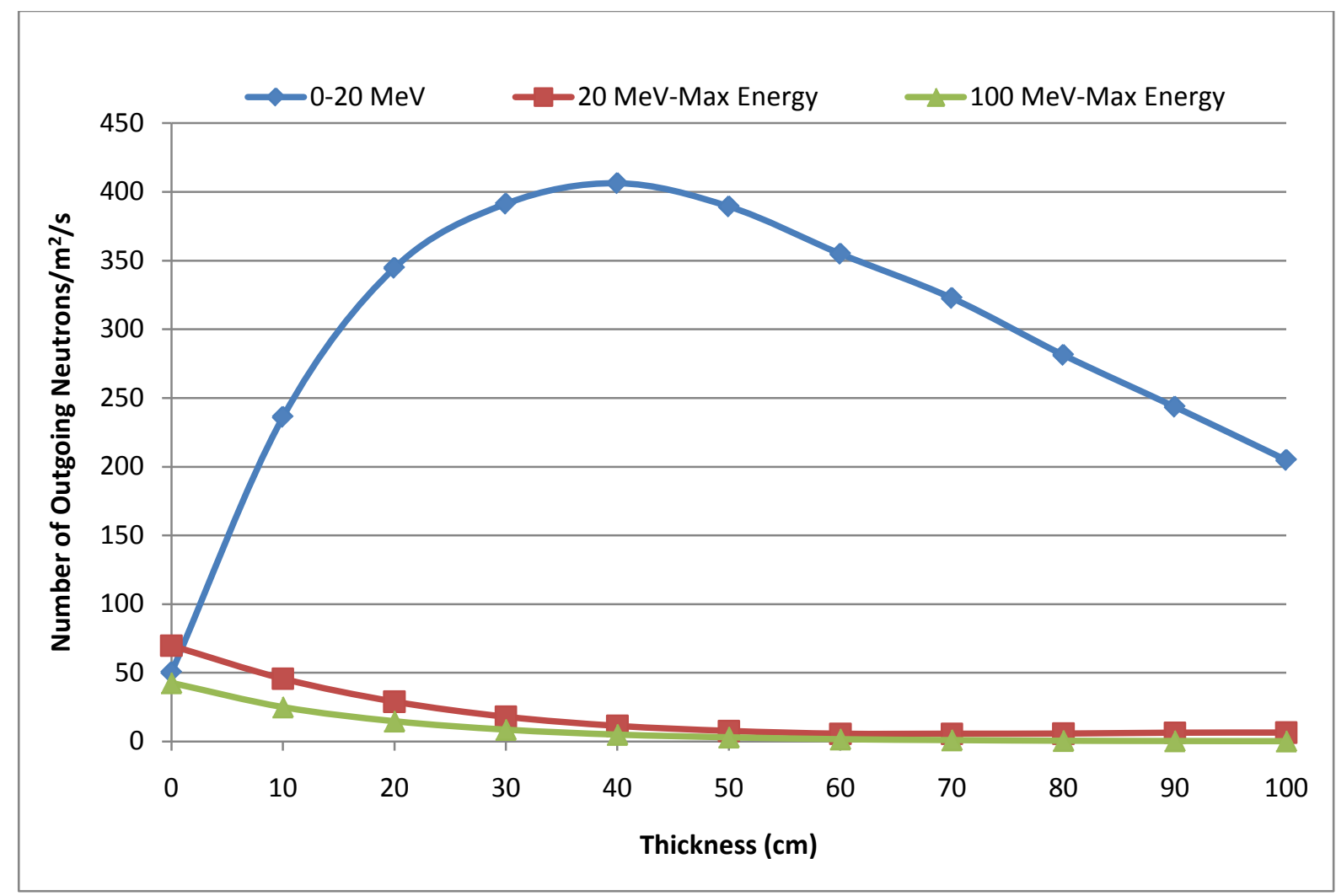

Figure 7: Cosmic Neutron Flux through Lead 
PNNL-20693

Table 8: Cosmic Neutron Flux through Lead

\begin{tabular}{|c|c|c|c|}
\hline Thickness $(\mathrm{cm})$ & $\begin{array}{c}\text { Outbound } \\
\text { Neutrons/m2/s } \\
0 \mathrm{MeV}-20 \mathrm{MeV}\end{array}$ & $\begin{array}{c}\text { Outbound } \\
\text { Neutrons } / \mathrm{m} 2 / \mathrm{s} \\
20 \mathrm{MeV}-10 \mathrm{GeV}\end{array}$ & $\begin{array}{c}\text { Outbound } \\
\text { Neutrons/m2/s } \\
100 \mathrm{MeV}-10 \mathrm{GeV}\end{array}$ \\
\hline 0 & $5.03 E+01$ & $6.97 E+01$ & $4.26 \mathrm{E}+01$ \\
\hline 10 & $2.36 \mathrm{E}+02$ & 4.57E+01 & $2.50 \mathrm{E}+01$ \\
\hline 20 & $3.45 \mathrm{E}+02$ & $2.90 \mathrm{E}+01$ & $1.47 \mathrm{E}+01$ \\
\hline 30 & $3.91 \mathrm{E}+02$ & $1.80 \mathrm{E}+01$ & $8.64 \mathrm{E}+00$ \\
\hline 40 & $4.06 \mathrm{E}+02$ & $1.14 \mathrm{E}+01$ & $5.03 \mathrm{E}+00$ \\
\hline 50 & $3.89 \mathrm{E}+02$ & $7.72 \mathrm{E}+00$ & $3.10 E+00$ \\
\hline 60 & $3.55 \mathrm{E}+02$ & $5.68 \mathrm{E}+00$ & $1.69 \mathrm{E}+00$ \\
\hline 70 & $3.23 E+02$ & $5.68 \mathrm{E}+00$ & $1.06 \mathrm{E}+00$ \\
\hline 80 & $2.81 \mathrm{E}+02$ & $5.78 \mathrm{E}+00$ & $5.92 \mathrm{E}-01$ \\
\hline 90 & $2.44 \mathrm{E}+02$ & $6.42 \mathrm{E}+00$ & $3.91 \mathrm{E}-01$ \\
\hline 100 & $2.05 \mathrm{E}+02$ & $6.50 \mathrm{E}+00$ & 2.60E-01 \\
\hline
\end{tabular}



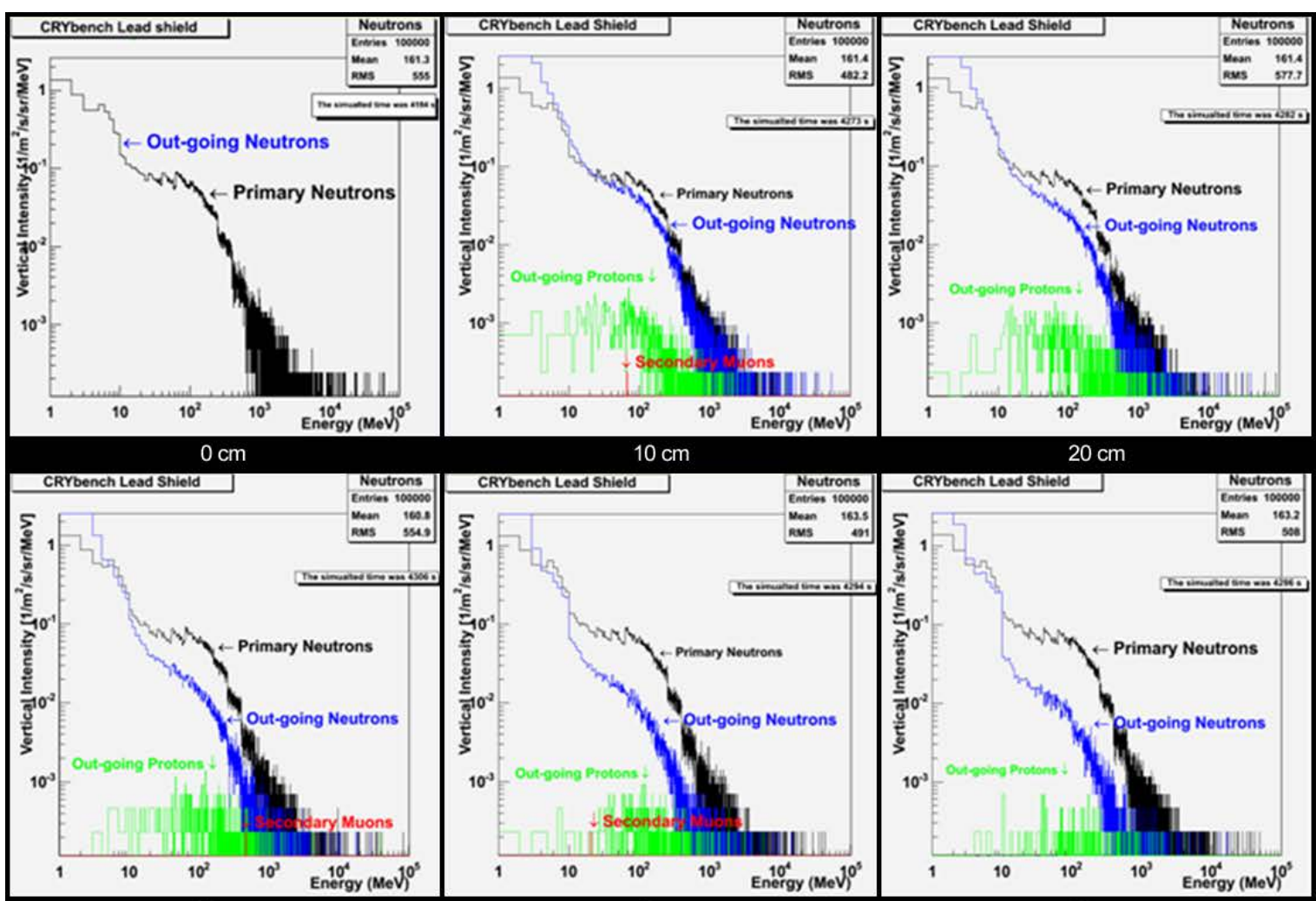

$20 \mathrm{~cm}$
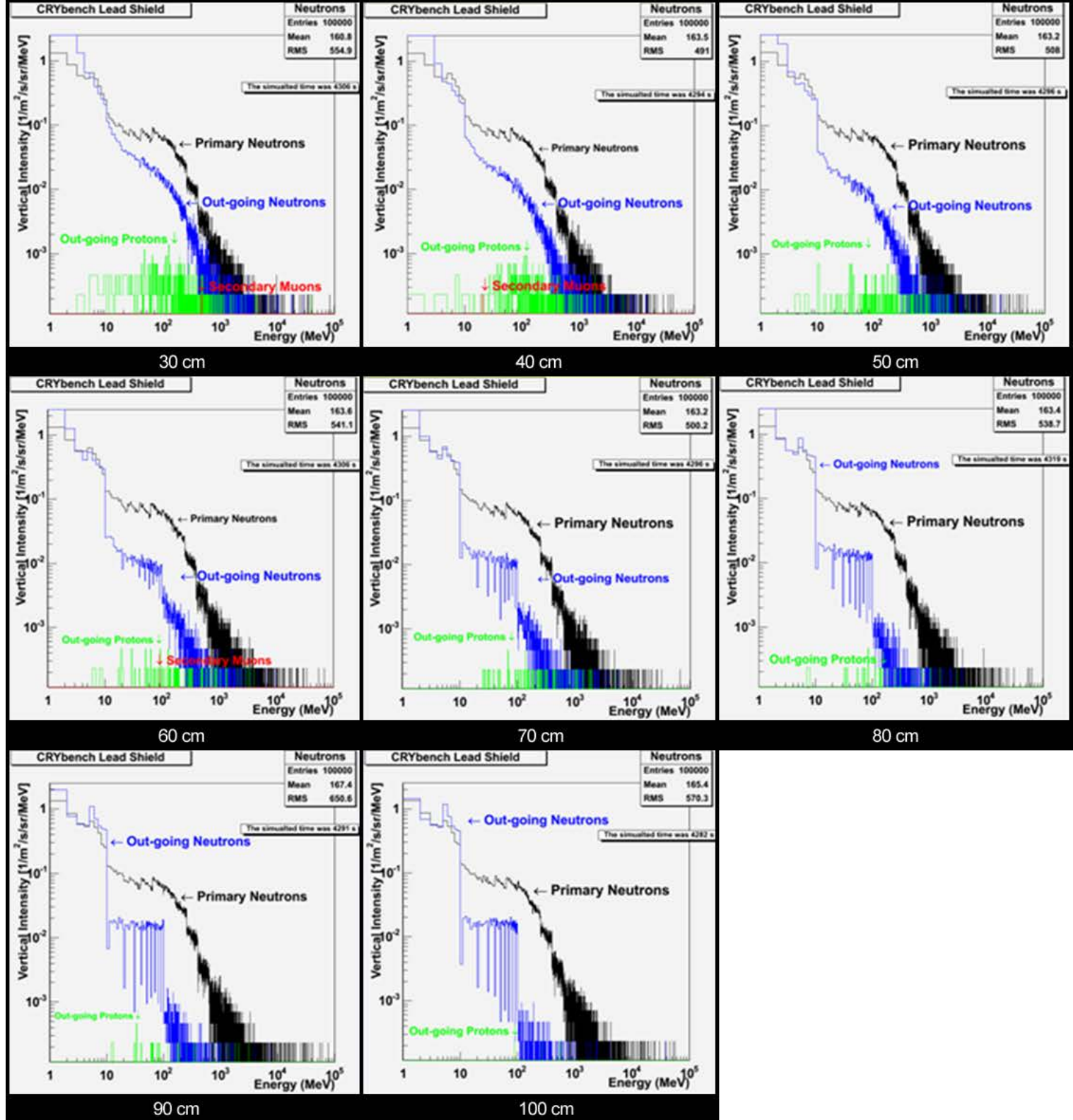

Figure 8: Simulated Spectra for Cosmic Neutrons through $0 \mathrm{~cm}$ to $100 \mathrm{~cm}$ of Lead 
PNNL-20693

\subsubsection{Sea level Protons}

Lead has an atomic number of 82. The shielding properties of this material against the cosmic proton flux are presented in Figure 9, which compares the flux of outbound protons in three different energy regions. The same data in table form is presented in Table 9. To obtain the data for Figure 9 and Table 7, the simulation data was normalized to reflect the actual composition of proton flux in cosmic rays. For low-energy protons below $20 \mathrm{MeV}$, the interactions of the cosmic proton flux with the lead at $10 \mathrm{~cm}$ produce more secondary protons than the lead shields. However, at $20 \mathrm{~cm}$, the lead starts to shield more effectively and decreases the flux of outbound protons. For higher energy protons this effect is not observed; the lead starts to shield the number of outbound protons immediately. The combination of these two effects implies that the thicker the material is the more effective the shield will be. The exact simulated spectra for the 10 geometries of lead plus no material are presented in Figure 10.

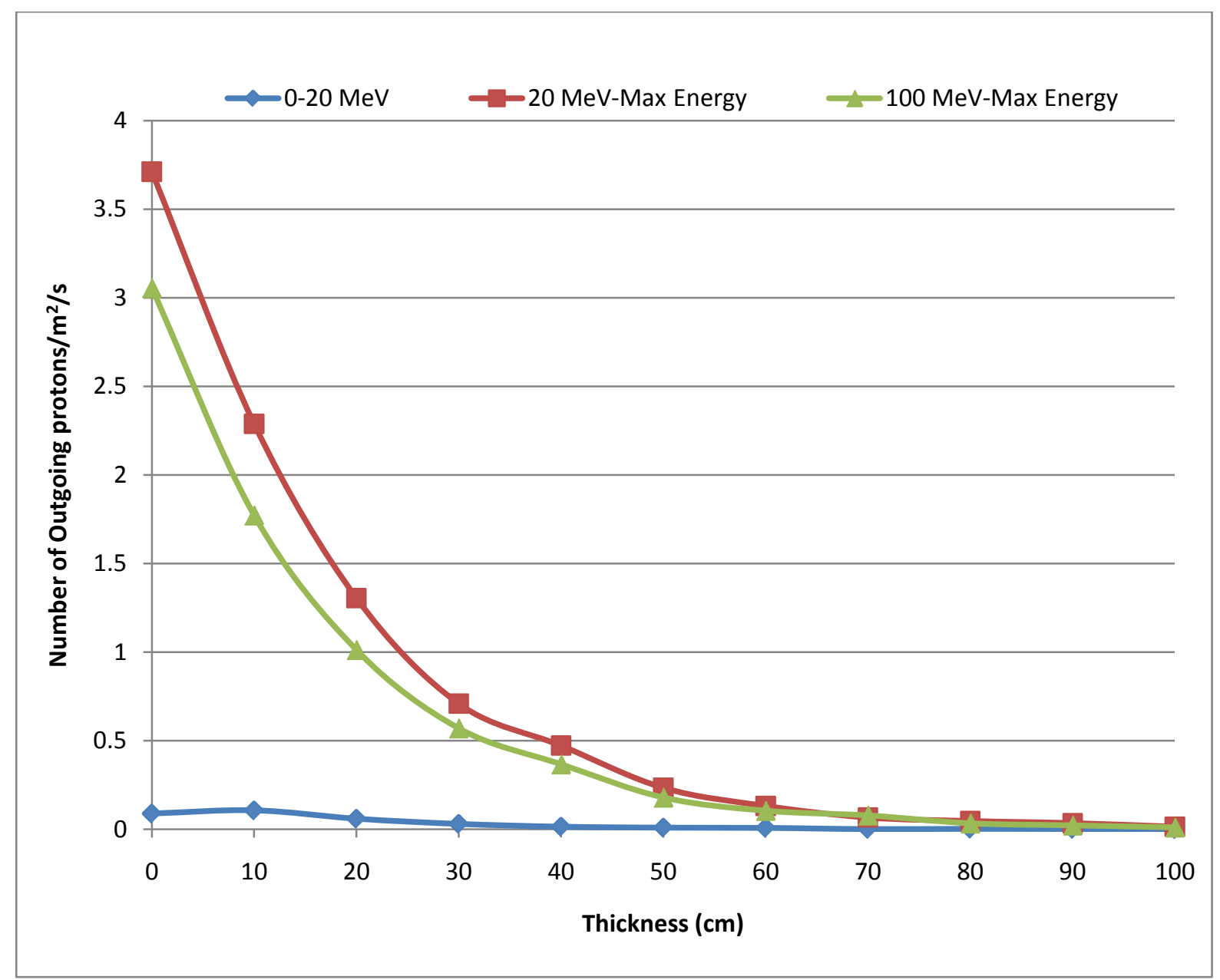

Figure 9: Cosmic Proton Flux through Lead 
PNNL-20693

Table 9: Cosmic Proton Flux through Lead

\begin{tabular}{|c|c|c|c|}
\hline Thickness (cm) & $\begin{array}{c}\text { Outbound } \\
\text { Protons } / \mathrm{m}^{2} / \mathrm{s} \\
0 \mathrm{MeV}-20 \mathrm{MeV}\end{array}$ & $\begin{array}{c}\text { Outbound } \\
\text { Protons } / \mathrm{m}^{2} / \mathrm{s} \\
20 \mathrm{MeV}-10 \mathrm{GeV}\end{array}$ & $\begin{array}{c}\text { Outbound } \\
\text { Protons } / \mathrm{m}^{2} / \mathrm{s} \\
100 \mathrm{MeV}-10 \mathrm{GeV}\end{array}$ \\
\hline 0 & $8.84 \mathrm{E}-02$ & $3.71 E+00$ & $3.05 E+00$ \\
\hline 10 & $1.06 \mathrm{E}-01$ & $2.29 E+00$ & $1.77 \mathrm{E}+00$ \\
\hline 20 & $5.92 \mathrm{E}-02$ & $1.31 \mathrm{E}+00$ & $1.01 \mathrm{E}+00$ \\
\hline 30 & $3.00 \mathrm{E}-02$ & 7.09E-01 & $5.70 \mathrm{E}-01$ \\
\hline 40 & $1.43 \mathrm{E}-02$ & 4.72E-01 & 3.67E-01 \\
\hline 50 & 8.99E-03 & $2.34 \mathrm{E}-01$ & 1.79E-01 \\
\hline 60 & 7.49E-03 & $1.32 \mathrm{E}-01$ & $1.04 \mathrm{E}-01$ \\
\hline 70 & 7.59E-04 & $6.60 \mathrm{E}-02$ & 7.80E-02 \\
\hline 80 & $2.26 \mathrm{E}-03$ & 4.66E-02 & $3.35 \mathrm{E}-02$ \\
\hline 90 & $1.12 \mathrm{E}-03$ & $3.46 \mathrm{E}-02$ & $2.18 \mathrm{E}-02$ \\
\hline 100 & $0.00 E+00$ & $1.44 \mathrm{E}-02$ & $1.06 \mathrm{E}-02$ \\
\hline
\end{tabular}




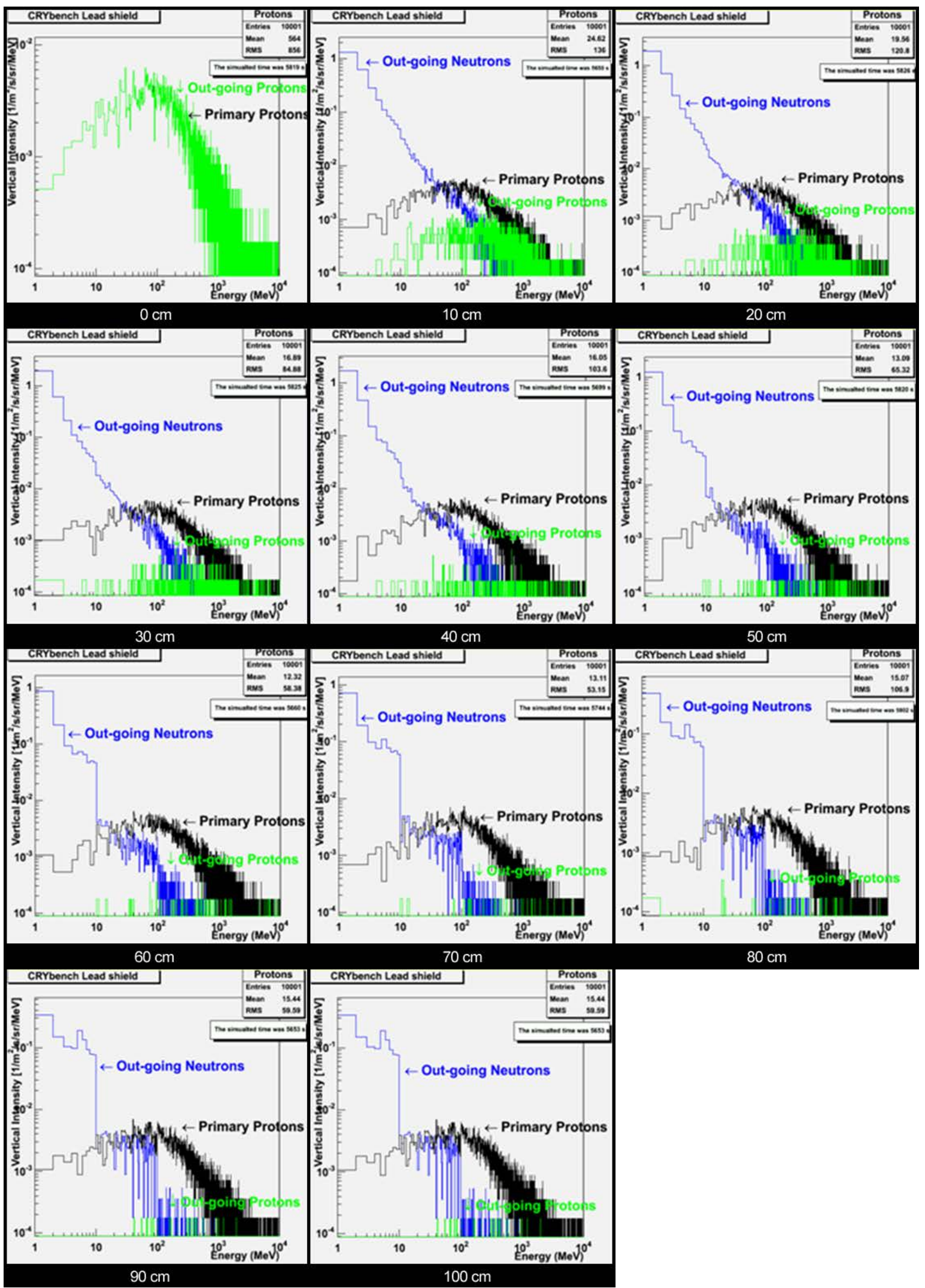

Figure 10: Simulated Spectra for Cosmic Protons through $0 \mathrm{~cm}$ to $100 \mathrm{~cm}$ of Lead 
PNNL-20693

\subsubsection{Sea Level Muons}

Lead, like iron, is also a high-Z material. Many of the same conclusions that were made for iron can be made for lead. Outbound muon flux was categorized into the three energy regions seen in Figure 11. Table 10 shows that there are very few muons under energies of $100 \mathrm{MeV}$. High-energy muons (100 MeV to $10 \mathrm{GeV}$ ) were shielded effectively. Lead with a thickness of approximately $98 \mathrm{~cm}$ shields $50 \%$ of incoming muons. No muons were produced at any thickness by cosmogenic flux. Lead would be a highly recommended shielding material for cosmic-ray muons. The exact simulated spectra for the 10 geometries of iron are presented in Figure 12.

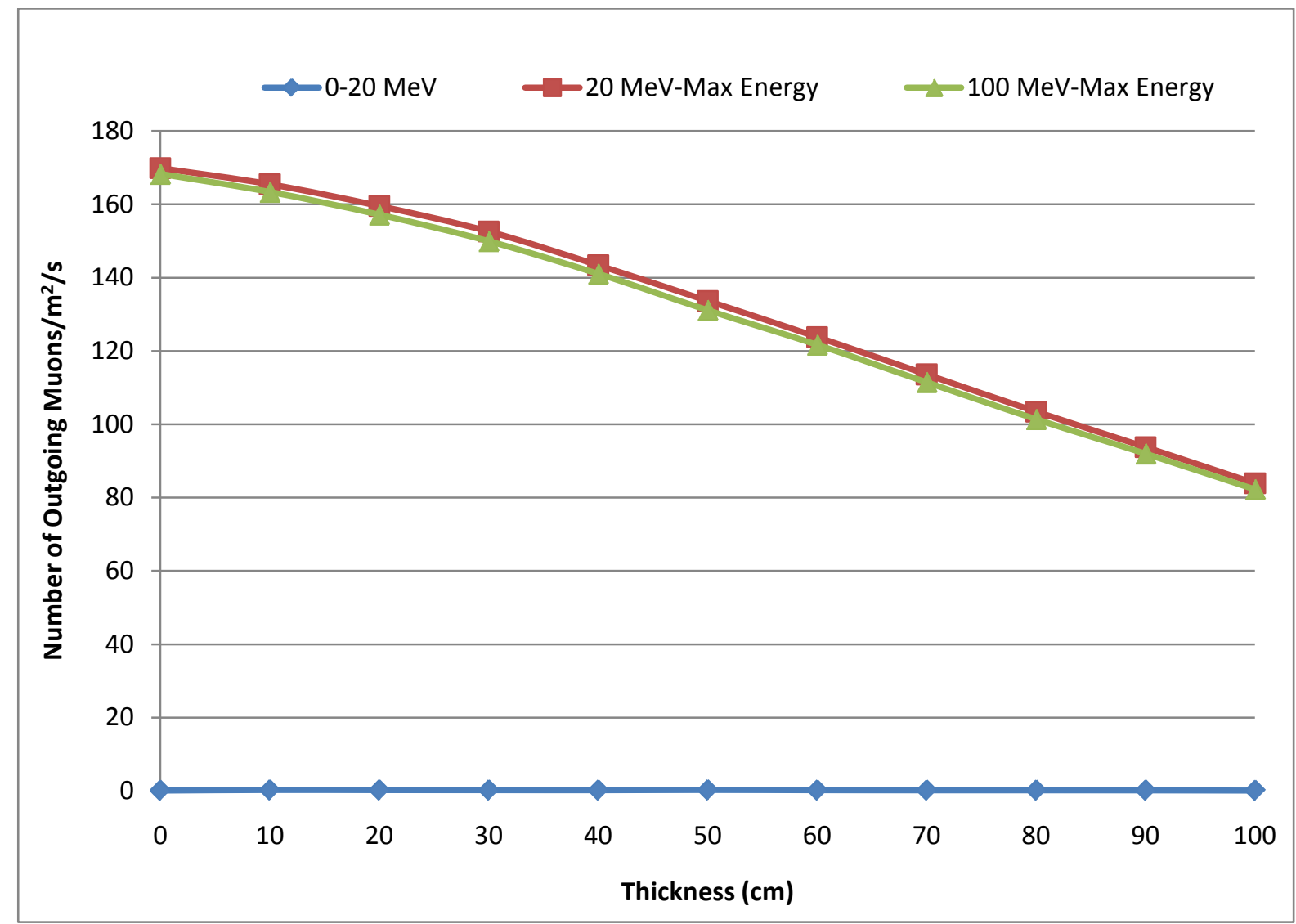

Figure 11: Cosmic Muon Flux through Lead

The secondary neutron flux is mainly below $20 \mathrm{MeV}$; thus they do not contribute to activation (see Appendix A). 
Table 10: Cosmic Muon Flux through Lead

\begin{tabular}{|cccc|}
\hline Thickness $(\mathbf{c m})$ & $\begin{array}{c}\text { Outbound } \\
\text { Muons } / \mathbf{m}^{2} / \mathbf{s} \\
\mathbf{0 ~ M e V - 2 0 ~ M e V}\end{array}$ & $\begin{array}{c}\text { Outbound Muons } / \mathbf{m}^{2} / \mathrm{s} \\
\mathbf{2 0 ~ M e V - 1 0 ~ G e V}\end{array}$ & $\begin{array}{c}\text { Outbound Muons } / \mathbf{m}^{2} / \mathbf{s} \\
100 \mathrm{MeV}-10 \mathrm{GeV}\end{array}$ \\
\hline $\mathbf{0}$ & $1.18 \mathrm{E}-01$ & $1.70 \mathrm{E}+02$ & $1.68 \mathrm{E}+02$ \\
$\mathbf{1 0}$ & $2.33 \mathrm{E}-01$ & $1.65 \mathrm{E}+02$ & $1.63 \mathrm{E}+02$ \\
$\mathbf{2 0}$ & $2.12 \mathrm{E}-01$ & $1.60 \mathrm{E}+02$ & $1.57 \mathrm{E}+02$ \\
$\mathbf{3 0}$ & $1.99 \mathrm{E}-01$ & $1.53 \mathrm{E}+02$ & $1.50 \mathrm{E}+02$ \\
$\mathbf{4 0}$ & $1.88 \mathrm{E}-01$ & $1.43 \mathrm{E}+02$ & $1.41 \mathrm{E}+02$ \\
$\mathbf{5 0}$ & $2.39 \mathrm{E}-01$ & $1.34 \mathrm{E}+02$ & $1.31 \mathrm{E}+02$ \\
$\mathbf{6 0}$ & $1.94 \mathrm{E}-01$ & $1.24 \mathrm{E}+02$ & $1.22 \mathrm{E}+02$ \\
$\mathbf{7 0}$ & $1.69 \mathrm{E}-01$ & $1.14 \mathrm{E}+02$ & $1.12 \mathrm{E}+02$ \\
$\mathbf{8 0}$ & $1.69 \mathrm{E}-01$ & $1.03 \mathrm{E}+02$ & $1.01 \mathrm{E}+02$ \\
$\mathbf{9 0}$ & $1.57 \mathrm{E}-01$ & $9.38 \mathrm{E}+01$ & $9.20 \mathrm{E}+01$ \\
$\mathbf{1 0 0}$ & $1.18 \mathrm{E}-01$ & $8.39 \mathrm{E}+01$ & $8.23 \mathrm{E}+01$ \\
\hline
\end{tabular}



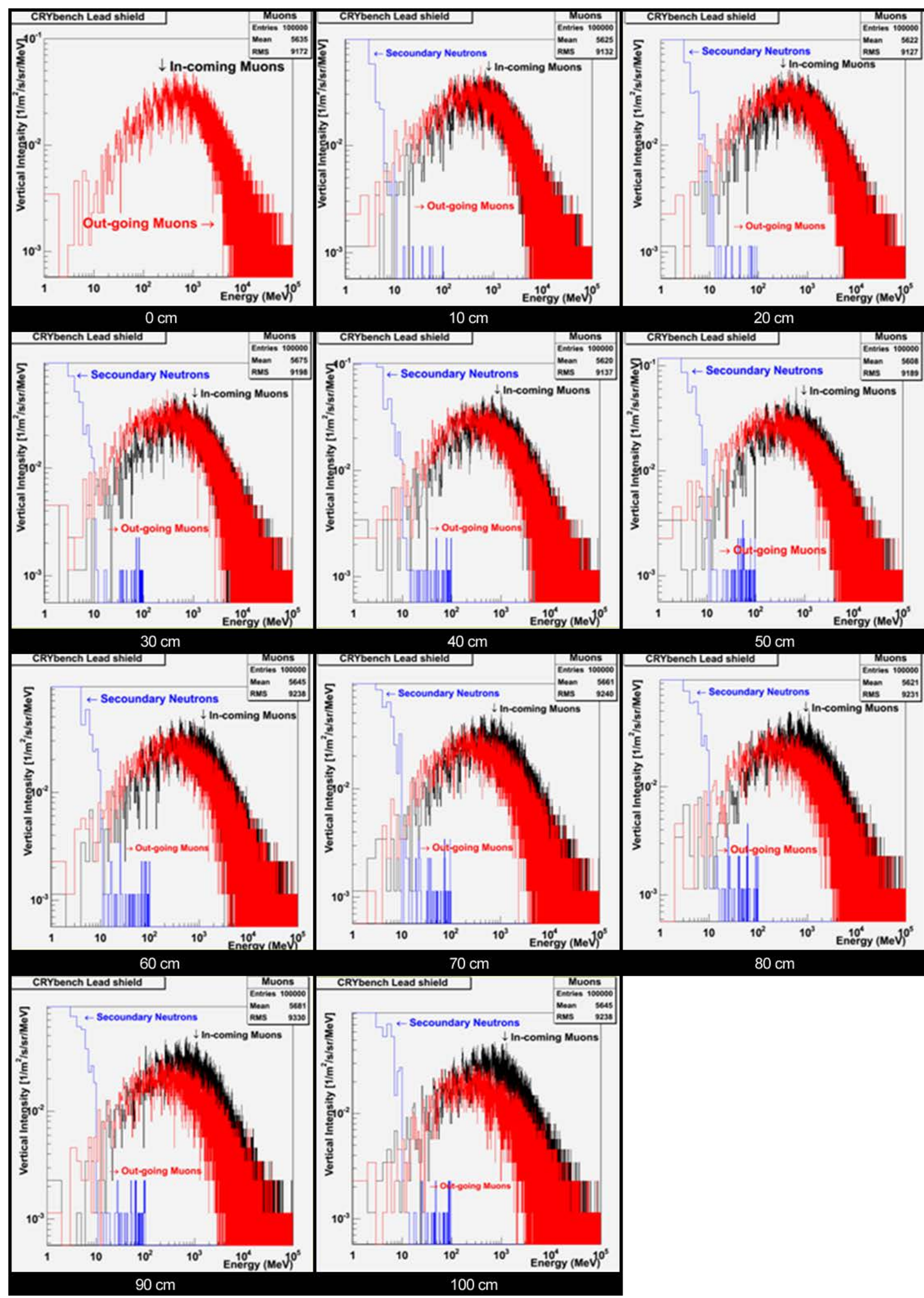

Figure 12: Simulated Spectra for Cosmic Muons through $0 \mathrm{~cm}$ to $100 \mathrm{~cm}$ of Lead 
PNNL-20693

\subsection{Polyethylene}

\subsubsection{Sea Level Neutrons}

Neutron flux in polyethylene (PE) decreases proportionately with increase in thickness, compared with iron and lead, which demonstrate a maximal neutron flux around $30 \mathrm{~cm}$. Figure 13 demonstrates that there is a constant decrease in neutron flux for an increase in thickness. It does not, however, provide better shielding for high-energy neutrons. Table 11 provides the data for this graph. One can observe that $100 \mathrm{~cm}$ of polyethylene provides less shielding against high-energy neutrons than $30 \mathrm{~cm}$ of iron or lead (Table 5 and Table 9). The spectra for each of the 11 simulations are in Figure 14.

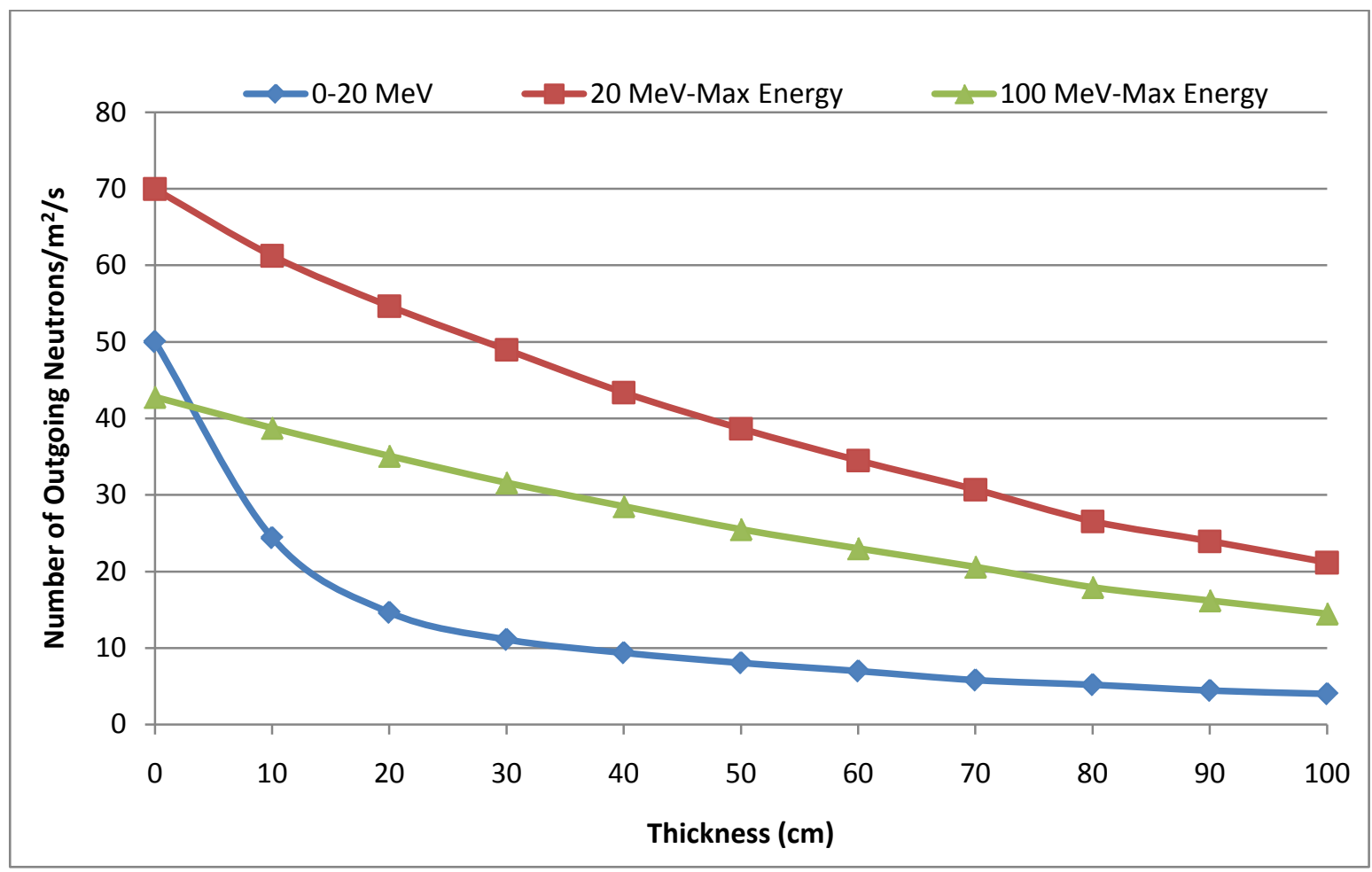

Figure 13: Cosmic Neutron Flux through Polyethylene 
Table 11: Cosmic Neutron Flux through Polyethylene

\begin{tabular}{|c|c|c|c|}
\hline Thickness $(\mathrm{cm})$ & $\begin{array}{c}\text { Outbound } \\
\text { Neutrons } / \mathrm{m}^{2} / \mathrm{s} \\
0 \mathrm{MeV}-20 \mathrm{MeV}\end{array}$ & $\begin{array}{c}\text { Outbound } \\
\text { Neutrons } / \mathrm{m}^{2} / \mathrm{s} \\
20 \mathrm{MeV}-10 \mathrm{GeV}\end{array}$ & $\begin{array}{c}\text { Outbound } \\
\text { Neutrons } / \mathrm{m}^{2} / \mathrm{s} \\
100 \mathrm{MeV}-10 \mathrm{GeV}\end{array}$ \\
\hline 0 & $5.00 E+01$ & $7.00 \mathrm{E}+01$ & $4.28 \mathrm{E}+01$ \\
\hline 10 & $2.44 \mathrm{E}+01$ & $6.13 E+01$ & $3.87 E+01$ \\
\hline 20 & $1.47 \mathrm{E}+01$ & $5.47 \mathrm{E}+01$ & $3.51 \mathrm{E}+01$ \\
\hline 30 & $1.11 \mathrm{E}+01$ & $4.90 \mathrm{E}+01$ & $3.16 \mathrm{E}+01$ \\
\hline 40 & $9.38 \mathrm{E}+00$ & $4.34 \mathrm{E}+01$ & $2.85 \mathrm{E}+01$ \\
\hline 50 & $8.06 \mathrm{E}+00$ & $3.87 E+01$ & $2.55 \mathrm{E}+01$ \\
\hline 60 & $7.00 \mathrm{E}+00$ & $3.45 E+01$ & $2.30 E+01$ \\
\hline 70 & $5.81 E+00$ & $3.07 E+01$ & $2.06 \mathrm{E}+01$ \\
\hline 80 & $5.21 E+00$ & $2.66 \mathrm{E}+01$ & $1.80 \mathrm{E}+01$ \\
\hline 90 & $4.45 E+00$ & $2.40 \mathrm{E}+01$ & $1.62 \mathrm{E}+01$ \\
\hline 100 & $4.02 \mathrm{E}+00$ & $2.12 \mathrm{E}+01$ & $1.45 \mathrm{E}+01$ \\
\hline
\end{tabular}



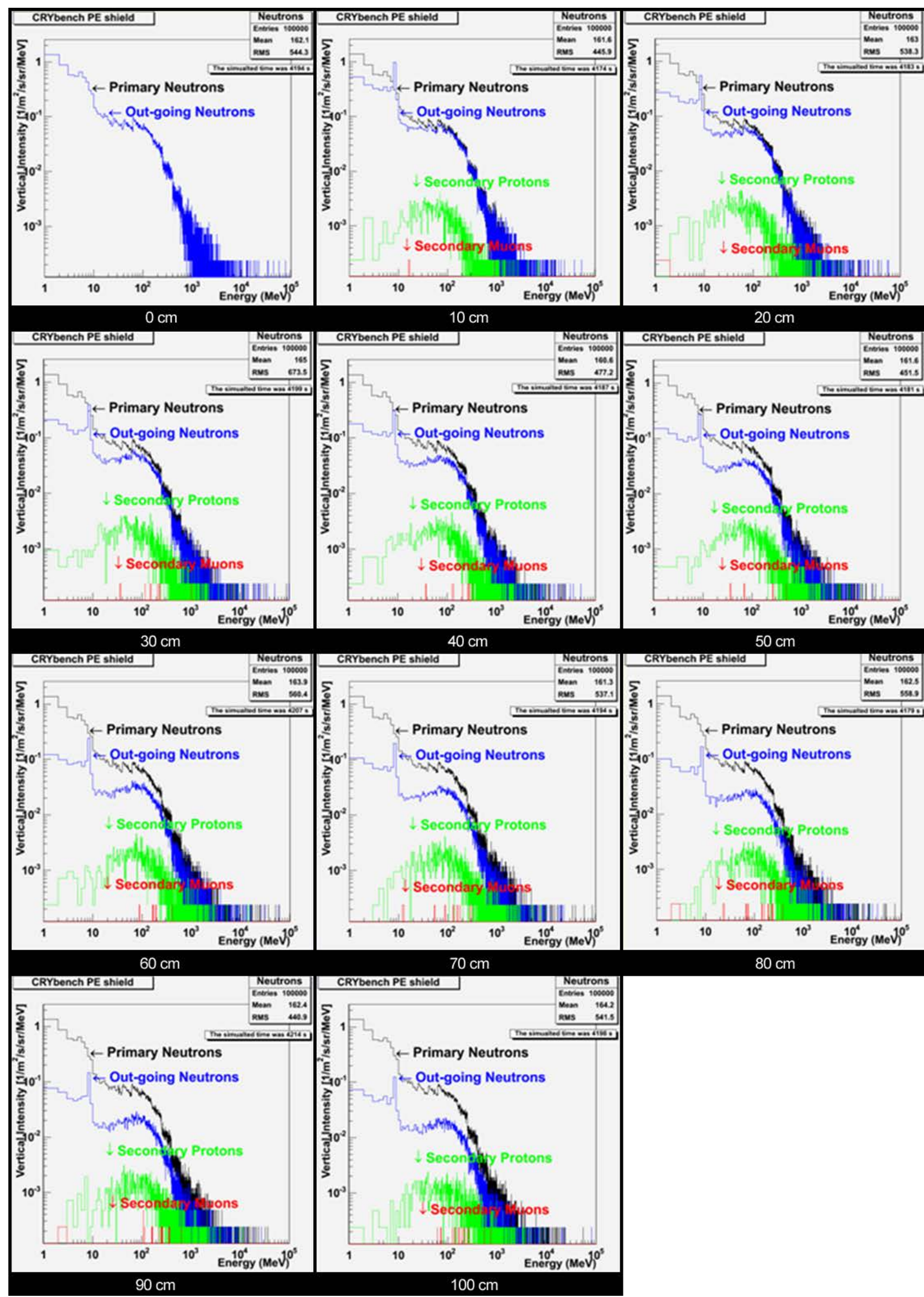

Figure 14: Simulated Spectra for Cosmic Neutrons through $0 \mathrm{~cm}$ to $100 \mathrm{~cm}$ of Polyethylene 


\subsubsection{Sea level Protons}

The shielding properties of PE against the cosmic proton flux are presented in Figure 15, comparing the flux of outbound protons in three different energy regions. The same data is presented in Table 12. For low-energy protons (below $20 \mathrm{MeV}$ ), the PE appears to provide very little to no shielding effect against protons. For higher-energy protons, the interactions of the protons with the PE create more secondary protons that are self shielded at about $60 \mathrm{~cm}$. After $60 \mathrm{~cm}$, the PE works to shield higherenergy protons. The combination of these two effects implies that if the shield is to block protons with energy greater than $20 \mathrm{MeV}$ it must be thicker than $60 \mathrm{~cm}$. Therefore, PE does not make an effective shield against low-energy protons. The exact simulated spectra for the 10 geometries of PE are presented in Figure 16. This figure features a spike in the outgoing neutron flux slightly below $10 \mathrm{MeV}$ that increases with material thickness. This phenomenon warrants further investigation.

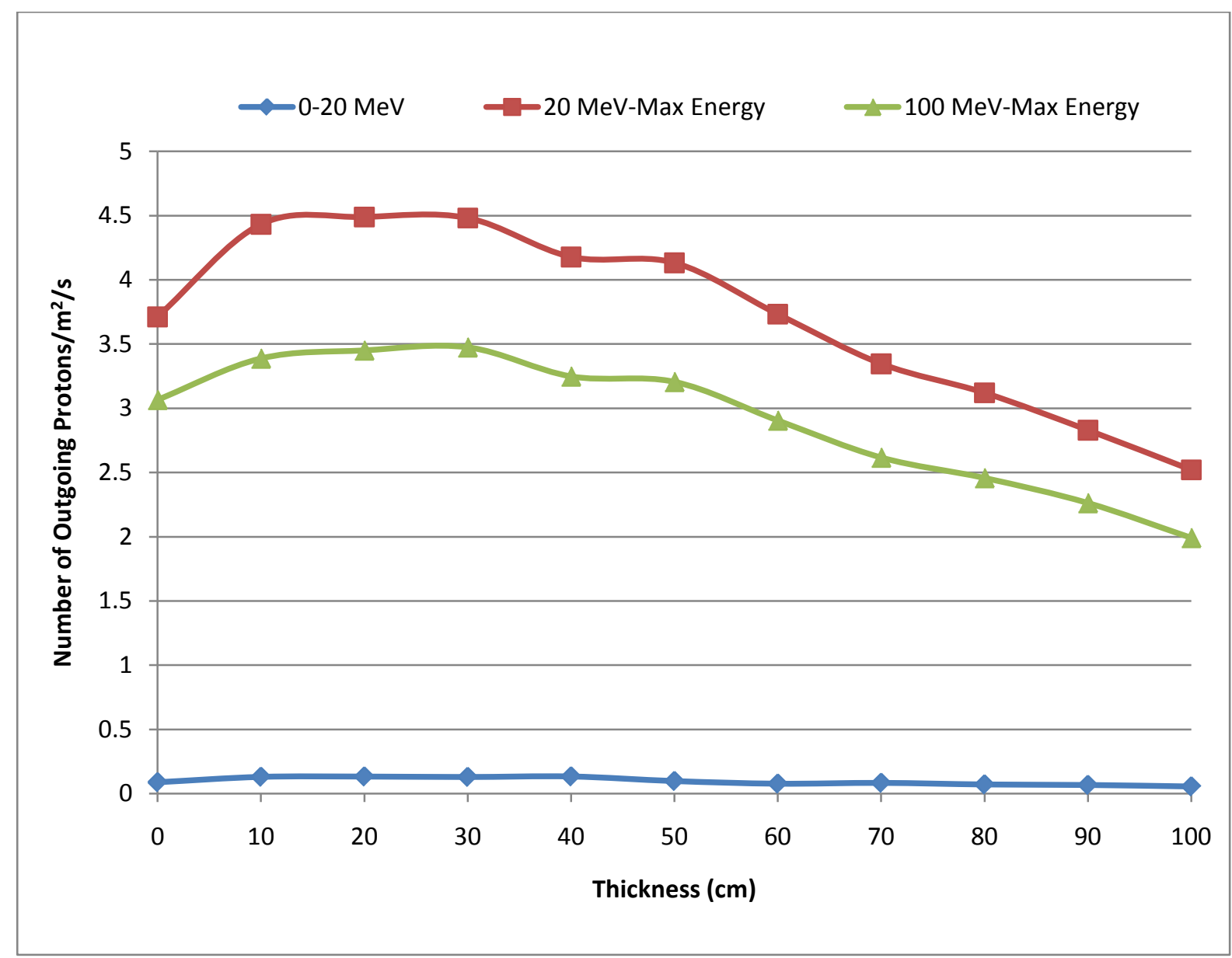

Figure 15: Cosmic Proton Flux through Polyethylene 
Table 12: Cosmic Proton Flux through Polyethylene

\begin{tabular}{|c|c|c|c|}
\hline Thickness (cm) & $\begin{array}{c}\text { Outbound } \\
\text { Protons } / \mathrm{m}^{2} / \mathrm{s} \\
0 \mathrm{MeV}-20 \mathrm{MeV}\end{array}$ & $\begin{array}{c}\text { Outbound } \\
\text { Protons } / \mathrm{m}^{2} / \mathrm{s} \\
20 \mathrm{MeV}-10 \mathrm{GeV}\end{array}$ & $\begin{array}{c}\text { Outbound } \\
\text { Protons } / \mathrm{m}^{2} / \mathrm{s} \\
100 \mathrm{MeV}-10 \mathrm{GeV}\end{array}$ \\
\hline 0 & 8.81E-02 & $3.71 \mathrm{E}+00$ & $3.07 E+00$ \\
\hline 10 & $1.30 \mathrm{E}-01$ & $4.43 \mathrm{E}+00$ & $3.39 \mathrm{E}+00$ \\
\hline 20 & $1.33 \mathrm{E}-01$ & $4.49 E+00$ & $3.45 E+00$ \\
\hline 30 & $1.29 \mathrm{E}-01$ & $4.48 \mathrm{E}+00$ & $3.48 \mathrm{E}+00$ \\
\hline 40 & 1.33E-01 & $4.18 \mathrm{E}+00$ & $3.25 E+00$ \\
\hline 50 & $9.73 \mathrm{E}-02$ & $4.13 E+00$ & $3.21 \mathrm{E}+00$ \\
\hline 60 & 7.68E-02 & $3.73 E+00$ & $2.91 \mathrm{E}+00$ \\
\hline 70 & 8.31E-02 & $3.35 E+00$ & $2.62 \mathrm{E}+00$ \\
\hline 80 & 7.08E-02 & $3.12 \mathrm{E}+00$ & $2.46 \mathrm{E}+00$ \\
\hline 90 & $6.66 \mathrm{E}-02$ & $2.83 E+00$ & $2.26 \mathrm{E}+00$ \\
\hline 100 & 5.50E-02 & $2.52 \mathrm{E}+00$ & $1.99 \mathrm{E}+00$ \\
\hline
\end{tabular}




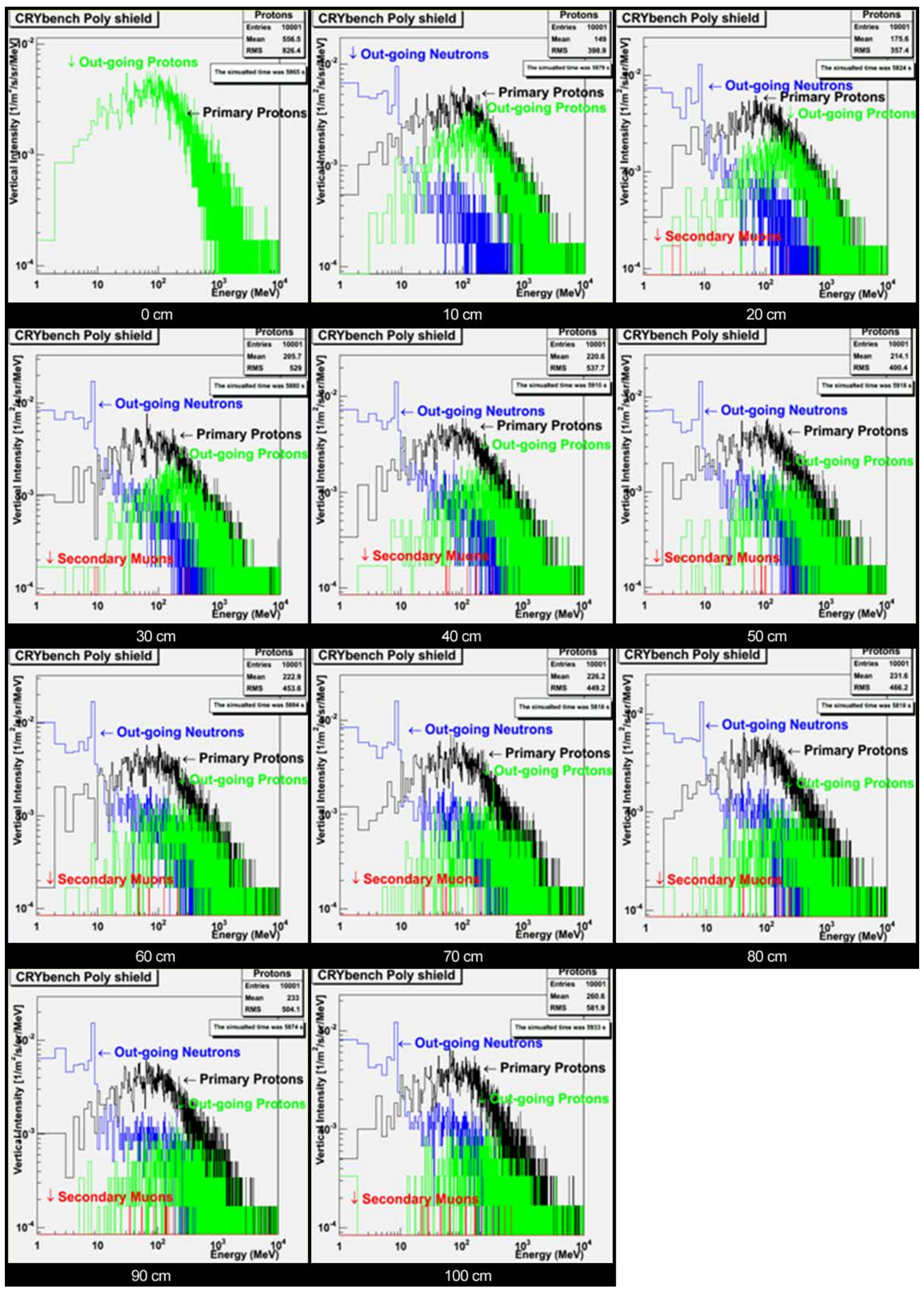

Figure 16: Simulated Spectra for Cosmic Protons through $0 \mathrm{~cm}$ to $100 \mathrm{~cm}$ of Polyethylene 
PNNL-20693

\subsubsection{Sea Level Muons}

Polyethylene is a low-Z material which shields cosmic rays poorly. Outbound muon flux was categorized into the three energy regions seen in Figure 17. PE with a thickness of $100 \mathrm{~cm}$ shielded 29\% of the incoming muons. Table 13 shows that up until a thickness of $40 \mathrm{~cm}$, almost no muons are attenuated. No secondary muons were produced at any thickness by cosmogenic flux. PE is the worst low-Z material for shielding muons and is therefore not recommended for muon shielding. The exact simulated spectra for the 10 geometries of iron are presented in Figure 18.

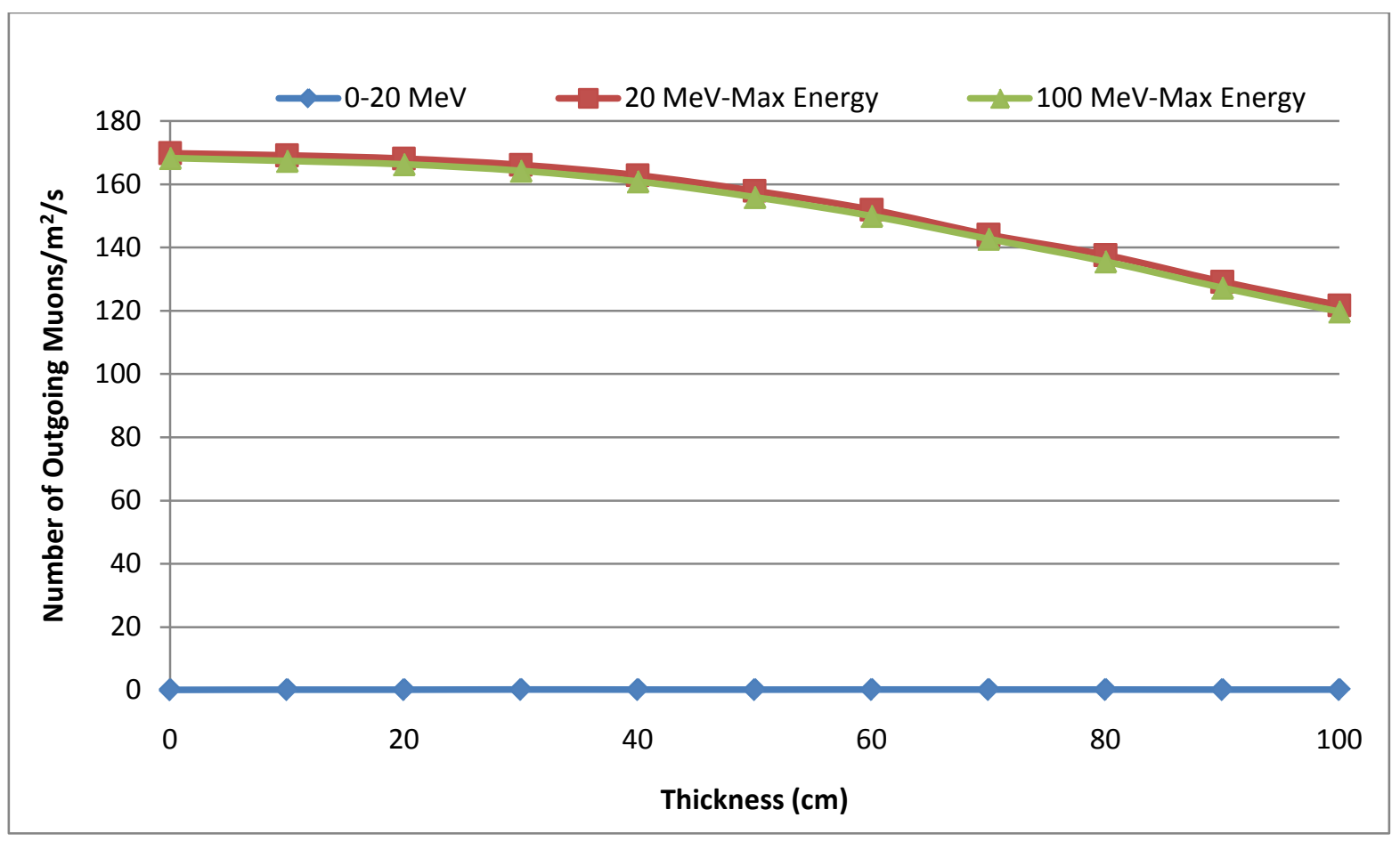

Figure 17: Cosmic Muon Flux through Polyethylene 
PNNL-20693

Table 13: Cosmic Muon Flux through Polyethylene

\begin{tabular}{|c|c|c|c|}
\hline Thickness (cm) & $\begin{array}{c}\text { Outbound } \\
\text { Muons } / \mathrm{m}^{2} / \mathrm{s} \\
0 \mathrm{MeV}-20 \mathrm{MeV}\end{array}$ & 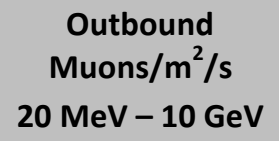 & $\begin{array}{c}\text { Outbound } \\
\text { Muons } / \mathrm{m}^{2} / \mathrm{s}\end{array}$ \\
\hline 0 & $1.03 \mathrm{E}-01$ & $1.70 \mathrm{E}+02$ & $1.68 \mathrm{E}+02$ \\
\hline 10 & $1.54 \mathrm{E}-01$ & $1.69 \mathrm{E}+02$ & $1.67 \mathrm{E}+02$ \\
\hline 20 & $1.52 \mathrm{E}-01$ & $1.68 \mathrm{E}+02$ & $1.66 \mathrm{E}+02$ \\
\hline 30 & $1.99 \mathrm{E}-01$ & $1.66 \mathrm{E}+02$ & $1.64 \mathrm{E}+02$ \\
\hline 40 & 1.77E-01 & $1.63 \mathrm{E}+02$ & $1.61 \mathrm{E}+02$ \\
\hline 50 & 1.63E-01 & $1.58 \mathrm{E}+02$ & $1.56 \mathrm{E}+02$ \\
\hline 60 & $1.90 \mathrm{E}-01$ & $1.52 E+02$ & $1.50 \mathrm{E}+02$ \\
\hline 70 & $1.86 \mathrm{E}-01$ & $1.44 \mathrm{E}+02$ & $1.43 \mathrm{E}+02$ \\
\hline 80 & $1.85 \mathrm{E}-01$ & $1.38 \mathrm{E}+02$ & $1.36 \mathrm{E}+02$ \\
\hline 90 & $1.63 \mathrm{E}-01$ & $1.29 E+02$ & $1.27 \mathrm{E}+02$ \\
\hline 100 & $1.79 \mathrm{E}-01$ & $1.22 \mathrm{E}+02$ & $1.20 \mathrm{E}+02$ \\
\hline
\end{tabular}




$$
\begin{aligned}
& \frac{111}{A 1 A} \\
& \frac{11 A}{1 A} \\
& \hline
\end{aligned}
$$


PNNL-20693

\subsection{Borated Polyethylene}

\subsubsection{Sea Level Neutrons}

There is little difference between the effect of borated polyethylene (BPE) on neutrons and that of PE. It is likely one would add boron to the polyethylene specifically for additional neutron shielding (because of boron's neutron capture effects), however, this boron doping does not affect attenuation properties of the material at the energies of interest, so there was little difference in the outbound neutron flux of the two materials. Figure 19 presents the shielding effects of BPE on neutrons, while the data is presented in Table 14. The separate spectra for each simulation are in Figure 20.

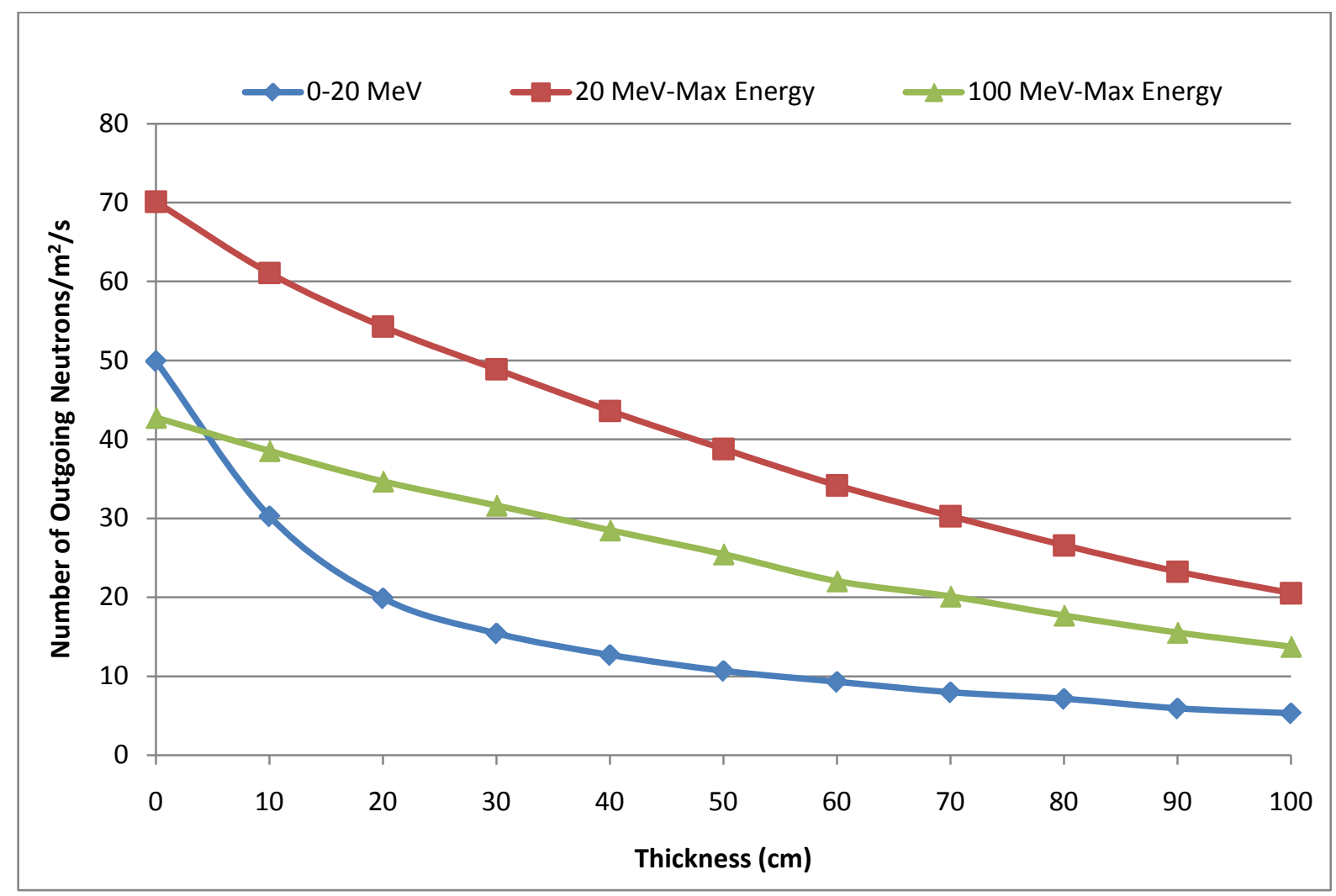

Figure 19: Cosmic Neutron Flux through Borated Polyethylene 
Table 14: Cosmic Neutron Flux through Borated Polyethylene

\begin{tabular}{|cccc|}
\hline Thickness $(\mathbf{c m})$ & $\begin{array}{c}\text { Outbound } \\
\text { Neutrons } / \mathrm{m}^{2} / \mathrm{s} \\
\mathbf{0} \mathrm{MeV}-20 \mathrm{MeV}\end{array}$ & $\begin{array}{c}\text { Outbound } \\
\text { Neutrons } / \mathrm{m}^{2} / \mathrm{s} \\
20 \mathrm{MeV}-10 \mathrm{GeV}\end{array}$ & $\begin{array}{c}\text { Outbound } \\
\text { Neutrons } / \mathbf{m}^{2} / \mathrm{s} \\
100 \mathrm{MeV}-10 \mathrm{GeV}\end{array}$ \\
\hline $\mathbf{0}$ & $4.99 \mathrm{E}+01$ & $7.01 \mathrm{E}+01$ & $4.28 \mathrm{E}+01$ \\
$\mathbf{1 0}$ & $3.03 \mathrm{E}+01$ & $6.11 \mathrm{E}+01$ & $3.86 \mathrm{E}+01$ \\
$\mathbf{2 0}$ & $1.99 \mathrm{E}+01$ & $5.43 \mathrm{E}+01$ & $3.47 \mathrm{E}+01$ \\
$\mathbf{3 0}$ & $1.54 \mathrm{E}+01$ & $4.89 \mathrm{E}+01$ & $3.16 \mathrm{E}+01$ \\
$\mathbf{4 0}$ & $1.27 \mathrm{E}+01$ & $4.36 \mathrm{E}+01$ & $2.85 \mathrm{E}+01$ \\
$\mathbf{5 0}$ & $1.07 \mathrm{E}+01$ & $3.88 \mathrm{E}+01$ & $2.55 \mathrm{E}+01$ \\
$\mathbf{6 0}$ & $9.29 \mathrm{E}+00$ & $3.42 \mathrm{E}+01$ & $2.21 \mathrm{E}+01$ \\
70 & $7.97 \mathrm{E}+00$ & $3.03 \mathrm{E}+01$ & $2.01 \mathrm{E}+01$ \\
$\mathbf{8 0}$ & $7.14 \mathrm{E}+00$ & $2.66 \mathrm{E}+01$ & $1.77 \mathrm{E}+01$ \\
$\mathbf{9 0}$ & $5.92 \mathrm{E}+00$ & $2.32 \mathrm{E}+01$ & $1.55 \mathrm{E}+01$ \\
$\mathbf{1 0 0}$ & $5.31 \mathrm{E}+00$ & $2.05 \mathrm{E}+01$ & $1.38 \mathrm{E}+01$ \\
\hline
\end{tabular}




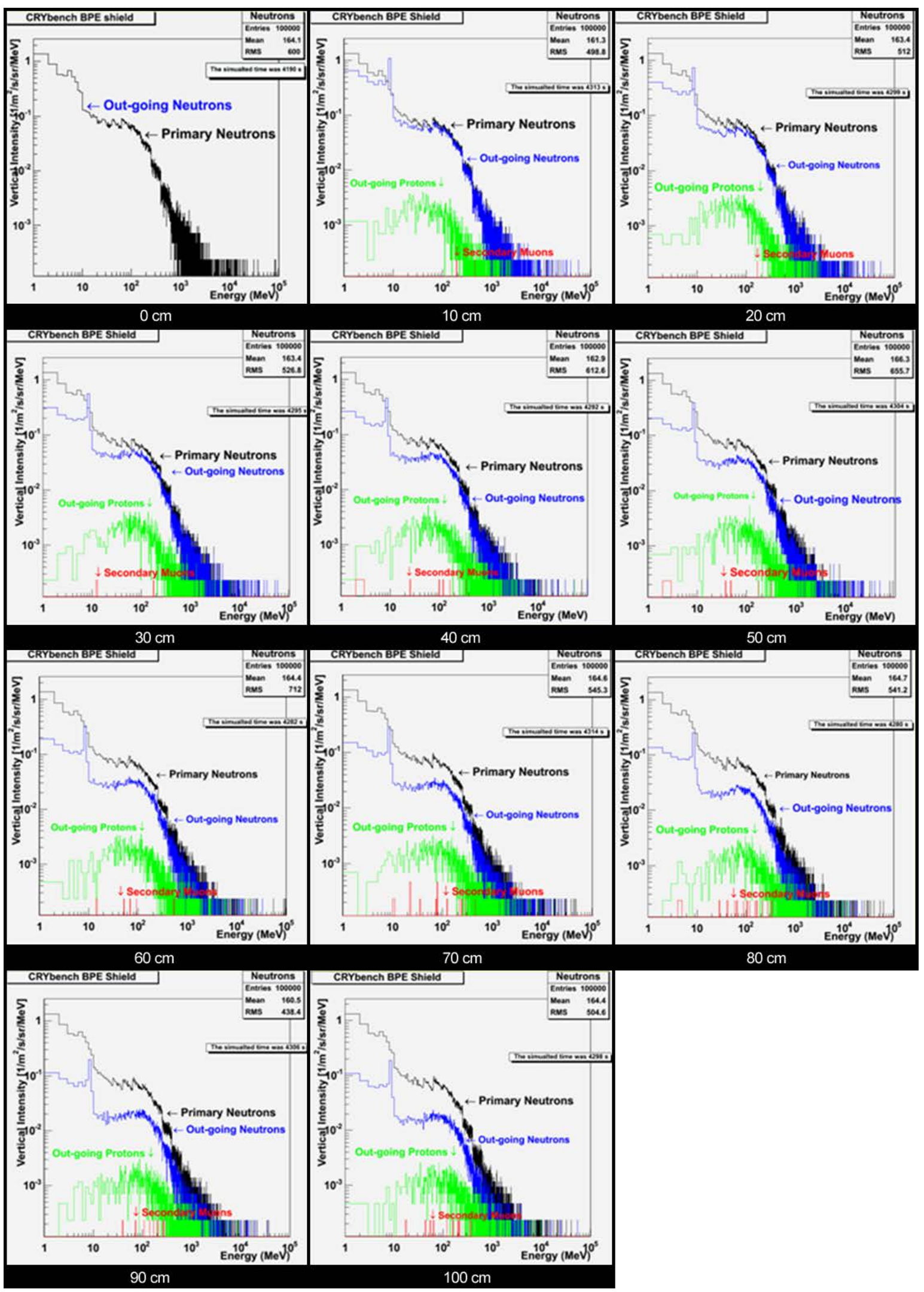

Figure 20: Simulated Spectra for Cosmic Neutrons through $0 \mathrm{~cm}$ to $100 \mathrm{~cm}$ of Borated Polyethylene 
PNNL-20693

\subsubsection{Sea level Protons}

The shielding properties of BPE against cosmic proton flux are presented in Figure 21, comparing the flux of outbound protons in three different energy regions. The same data is presented in Table 15. To obtain the data for Figure 21 and Table 13, the simulation data was normalized to reflect the actual composition of proton flux in cosmic rays at sea level. For low-energy protons (below $20 \mathrm{MeV}$ ) the BPE appears to have very little or no shielding effect against protons. For higher-energy protons, the interactions of the protons with the BPE create more protons than are shielded up to a thickness of about $40 \mathrm{~cm}$. After $40 \mathrm{~cm}$, the BPE works to shield against higher-energy protons. The combination of these two effects implies that if the shield is to block protons with energy greater than $20 \mathrm{MeV}$ it must be thicker than $40 \mathrm{~cm}$; therefore BPE is considered a poor shield against low-energy protons. The exact simulated spectra for the 10 geometries of BPE are presented in Figure 22.

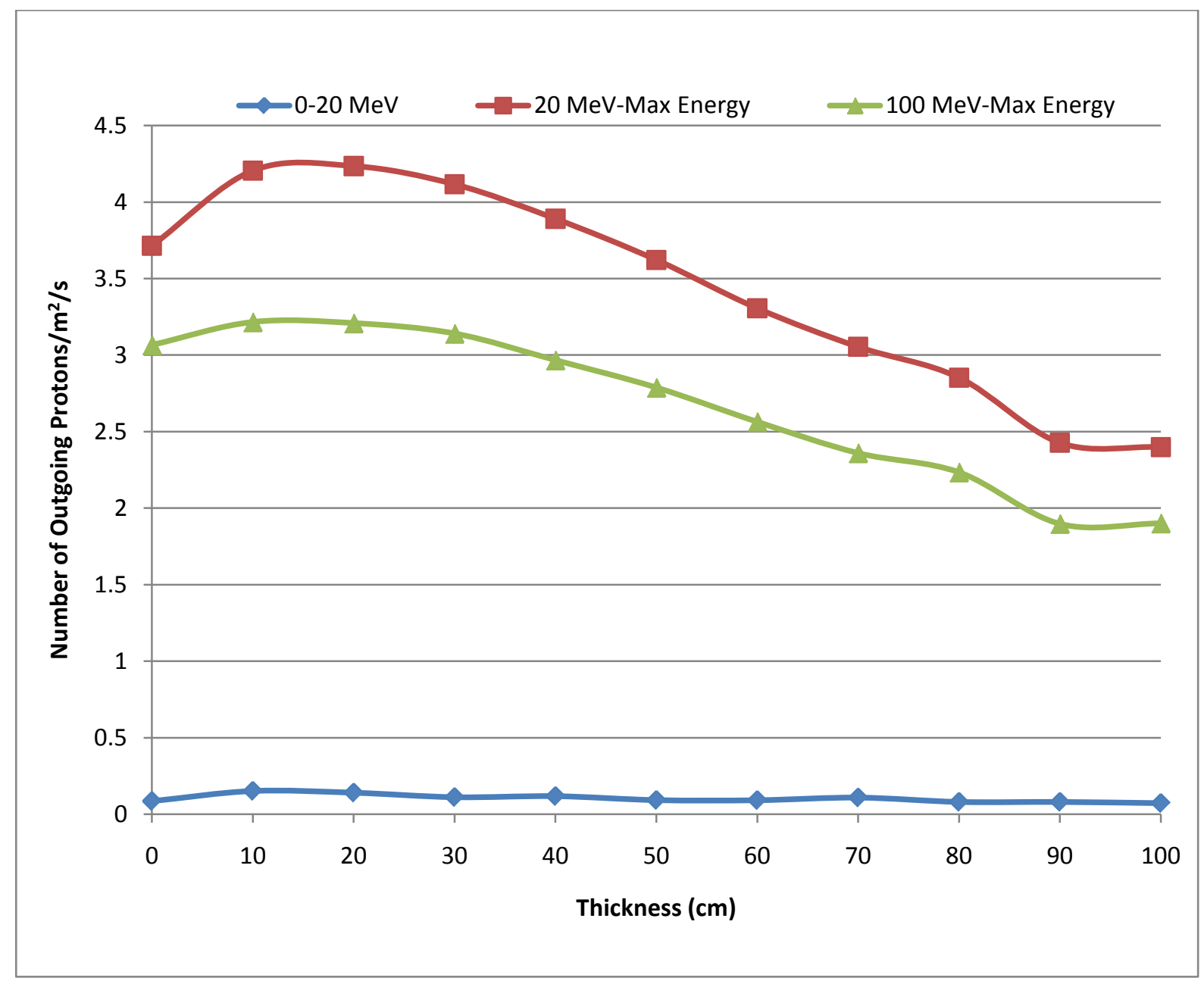

Figure 21: Cosmic Proton Flux through Borated Polyethylene 
PNNL-20693

Table 15: Cosmic Proton Flux through Borated Polyethylene

\begin{tabular}{|cccc|}
\hline Thickness $(\mathbf{c m})$ & $\begin{array}{c}\text { Outbound } \\
\text { Protons } / \mathrm{m}^{2} / \mathrm{s} \\
\mathbf{0} \mathrm{MeV}-20 \mathrm{MeV}\end{array}$ & $\begin{array}{c}\text { Outbound } \\
\text { Protons } / \mathrm{m}^{2} / \mathrm{s} \\
20 \mathrm{MeV}-10 \mathrm{GeV}\end{array}$ & $\begin{array}{c}\text { Outbound } \\
\text { Protons } / \mathrm{m}^{2} / \mathrm{s} \\
100 \mathrm{MeV}-10 \mathrm{GeV}\end{array}$ \\
\hline $\mathbf{0}$ & $8.62 \mathrm{E}-02$ & $3.71 \mathrm{E}+00$ & $3.07 \mathrm{E}+00$ \\
$\mathbf{1 0}$ & $1.52 \mathrm{E}-01$ & $4.21 \mathrm{E}+00$ & $3.22 \mathrm{E}+00$ \\
$\mathbf{2 0}$ & $1.41 \mathrm{E}-01$ & $4.24 \mathrm{E}+00$ & $3.21 \mathrm{E}+00$ \\
$\mathbf{3 0}$ & $1.12 \mathrm{E}-01$ & $4.12 \mathrm{E}+00$ & $3.14 \mathrm{E}+00$ \\
$\mathbf{4 0}$ & $1.19 \mathrm{E}-01$ & $3.89 \mathrm{E}+00$ & $2.97 \mathrm{E}+00$ \\
$\mathbf{5 0}$ & $9.28 \mathrm{E}-02$ & $3.62 \mathrm{E}+00$ & $2.79 \mathrm{E}+00$ \\
$\mathbf{6 0}$ & $9.21 \mathrm{E}-02$ & $3.31 \mathrm{E}+00$ & $2.56 \mathrm{E}+00$ \\
70 & $1.09 \mathrm{E}-01$ & $3.05 \mathrm{E}+00$ & $2.36 \mathrm{E}+00$ \\
$\mathbf{8 0}$ & $8.09 \mathrm{E}-02$ & $2.85 \mathrm{E}+00$ & $2.23 \mathrm{E}+00$ \\
90 & $8.08 \mathrm{E}-02$ & $2.43 \mathrm{E}+00$ & $1.90 \mathrm{E}+00$ \\
$\mathbf{1 0 0}$ & $7.30 \mathrm{E}-02$ & $2.40 \mathrm{E}+00$ & $1.90 \mathrm{E}+00$ \\
\hline
\end{tabular}



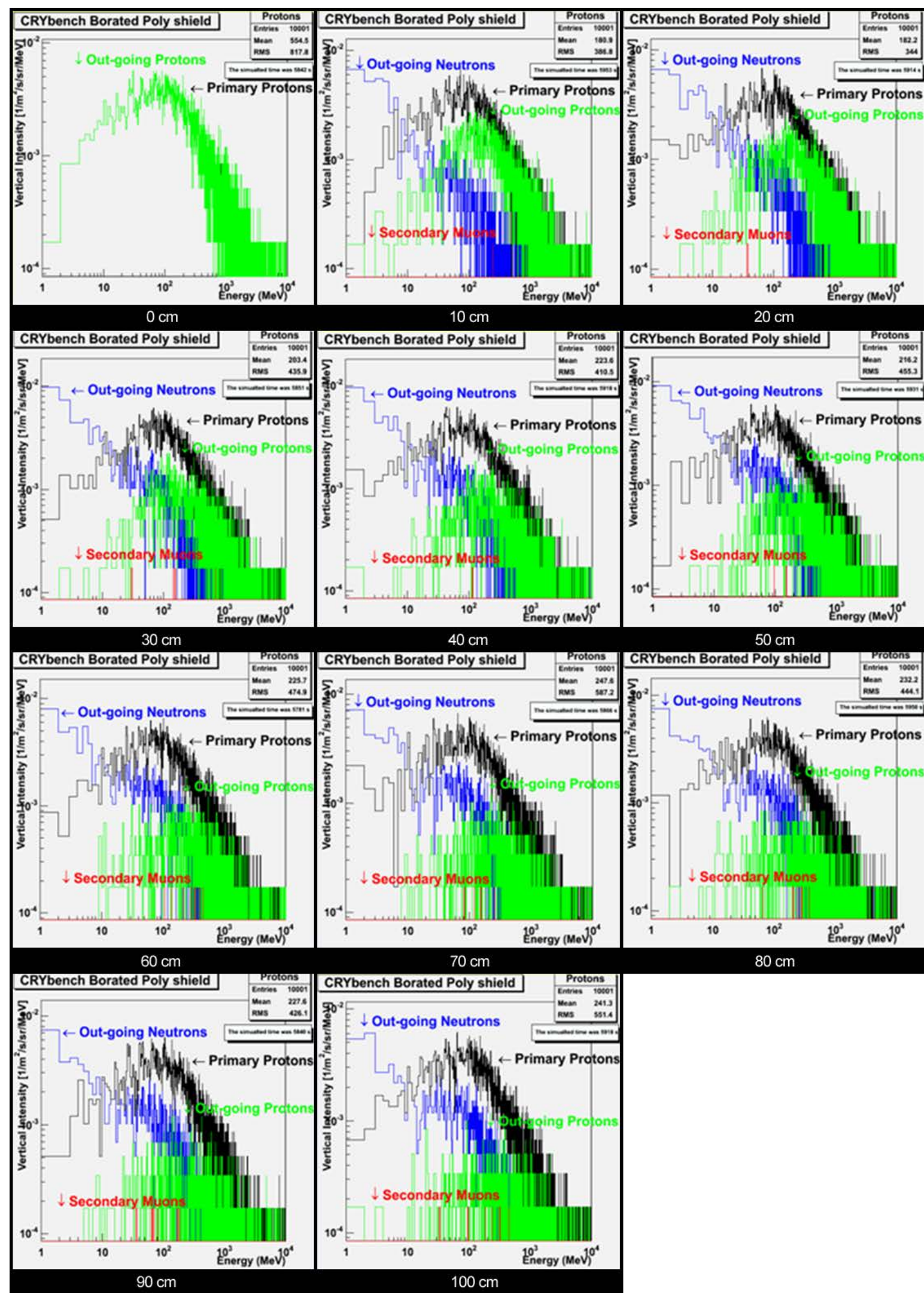

Figure 22: Simulated Spectra for Cosmic Protons through $0 \mathrm{~cm}$ to $100 \mathrm{~cm}$ of Borated Polyethylene 
PNNL-20693

\subsubsection{Sea Level Muons}

Borated polyethylene is a low-Z material, which shields cosmic ray muons poorly. Outbound muon flux was categorized into the three energy regions seen in Figure 23. At a thickness of $100 \mathrm{~cm}$, the BPE shielded 31\% of all incoming muons. Table 16 shows that up to a thickness of $20 \mathrm{~cm}$, almost no muons were shielded. No muons were produced at any thickness by cosmogenic flux. BPE would not be recommended as a shielding material against cosmic ray muons. The exact simulated spectra for the 10 geometries considered impinging on iron are presented in Figure 24.

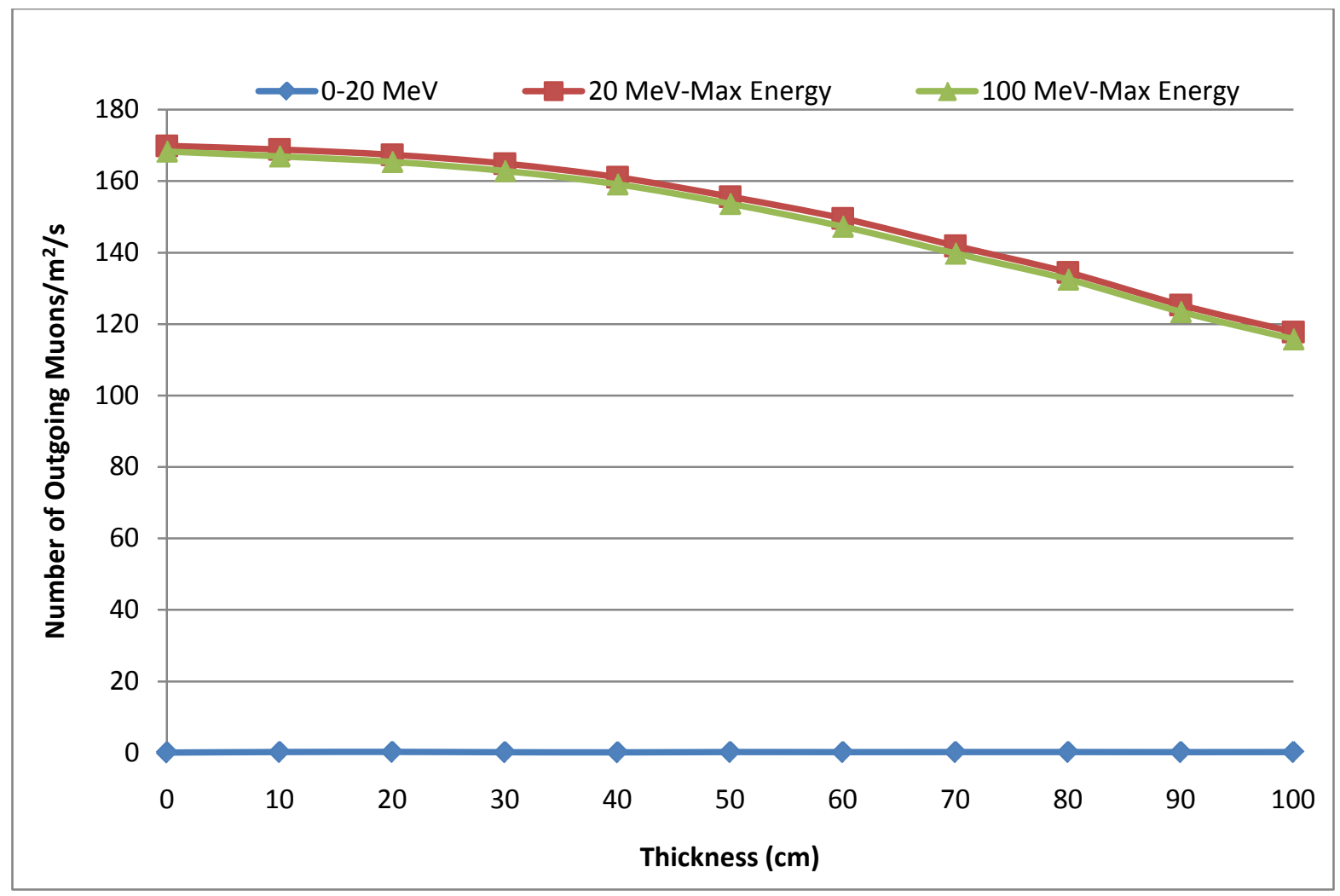

Figure 23: Cosmic Muon Flux through Borated Polyethylene 
PNNL-20693

Table 16: Cosmic Muon Flux through Borated Polyethylene

\begin{tabular}{|c|c|c|c|}
\hline Thickness (cm) & $\begin{array}{c}\text { Outbound } \\
\text { Muons } / \mathrm{m}^{2} / \mathrm{s} \\
0 \mathrm{MeV}-20 \mathrm{MeV}\end{array}$ & 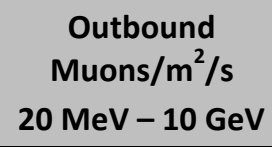 & 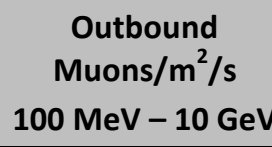 \\
\hline 0 & $1.03 \mathrm{E}-01$ & $1.70 \mathrm{E}+02$ & $1.68 \mathrm{E}+02$ \\
\hline 10 & $2.12 \mathrm{E}-01$ & $1.69 \mathrm{E}+02$ & $1.67 \mathrm{E}+02$ \\
\hline 20 & $2.41 \mathrm{E}-01$ & $1.67 \mathrm{E}+02$ & $1.65 \mathrm{E}+02$ \\
\hline 30 & $1.71 \mathrm{E}-01$ & $1.65 \mathrm{E}+02$ & $1.63 \mathrm{E}+02$ \\
\hline 40 & 1.44E-01 & $1.61 \mathrm{E}+02$ & $1.59 \mathrm{E}+02$ \\
\hline 50 & 2.10E-01 & $1.56 \mathrm{E}+02$ & $1.54 \mathrm{E}+02$ \\
\hline 60 & $1.93 \mathrm{E}-01$ & $1.50 \mathrm{E}+02$ & $1.47 \mathrm{E}+02$ \\
\hline 70 & $2.05 \mathrm{E}-01$ & $1.42 \mathrm{E}+02$ & $1.40 \mathrm{E}+02$ \\
\hline 80 & $2.12 \mathrm{E}-01$ & $1.34 \mathrm{E}+02$ & $1.32 \mathrm{E}+02$ \\
\hline 90 & $1.90 \mathrm{E}-01$ & $1.25 \mathrm{E}+02$ & $1.23 \mathrm{E}+02$ \\
\hline 100 & $2.05 E-01$ & $1.18 \mathrm{E}+02$ & $1.16 \mathrm{E}+02$ \\
\hline
\end{tabular}



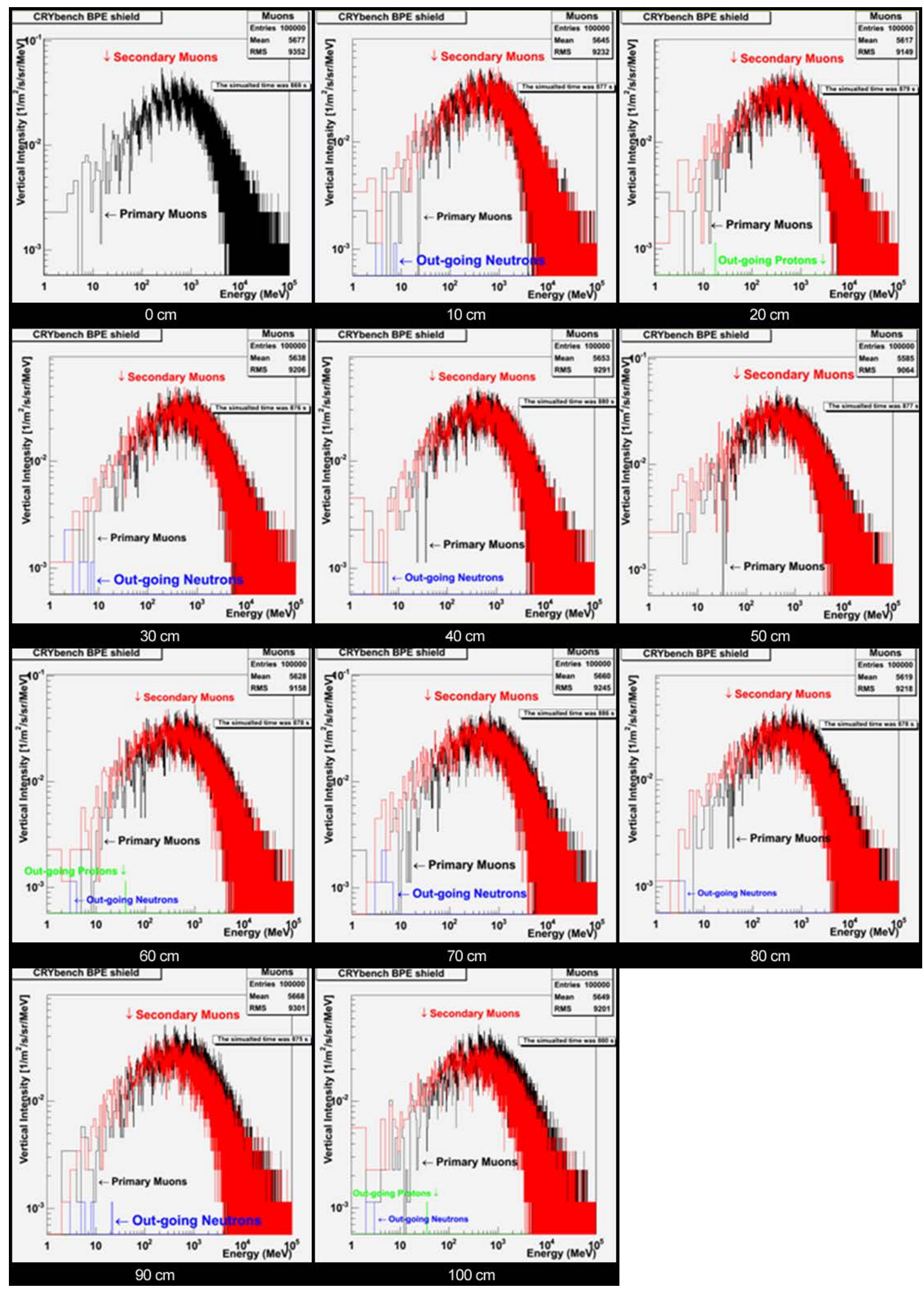

Figure 24: Simulated Spectra for Cosmic Muons through $0 \mathrm{~cm}$ to $100 \mathrm{~cm}$ of Borated Polyethylene 
PNNL-20693

\subsection{Water}

\subsubsection{Sea Level Neutrons}

Water is often used as a moderator for neutrons. The effects of water on neutron flux are displayed in Figure 25, with the data in Table 17. Despite water's low density, its ability to shield neutrons is comparable to the other materials tested in this investigation with the exception of iron and lead. Figure 26 presents the individual spectra for each simulation.

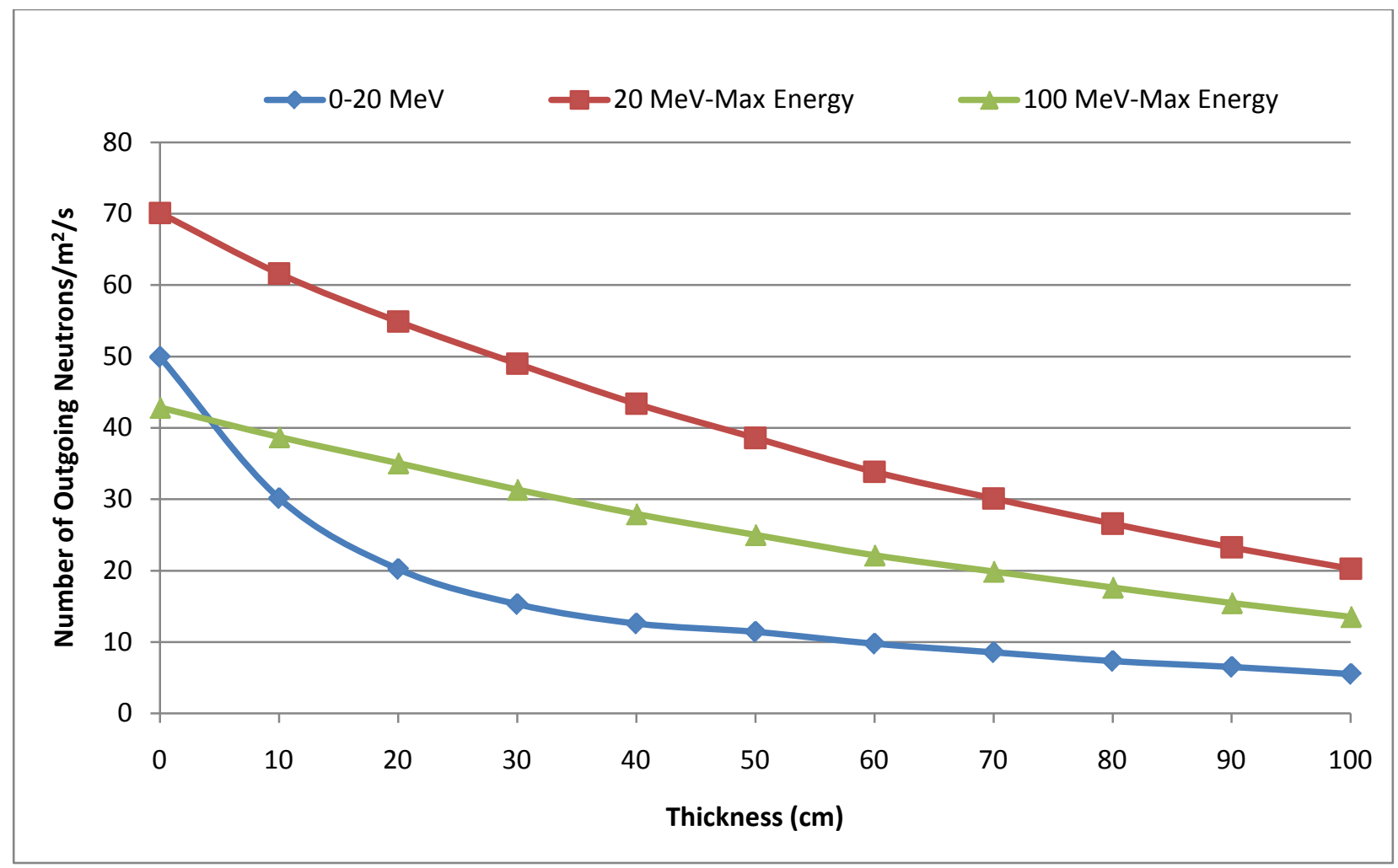

Figure 25: Cosmic Neutron Flux through Water 
PNNL-20693

Table 17: Cosmic Neutron Flux through Water

\begin{tabular}{|cccc|}
\hline Thickness $(\mathbf{c m})$ & $\begin{array}{c}\text { Outbound } \\
\text { Neutrons } / \mathrm{m}^{2} / \mathrm{s} \\
\mathbf{0 ~ M e V - 2 0 ~ M e V}\end{array}$ & $\begin{array}{c}\text { Outbound } \\
\text { Neutrons } / \mathbf{m}^{2} / \mathrm{s} \\
20 \mathrm{MeV}-10 \mathrm{GeV}\end{array}$ & $\begin{array}{c}\text { Outbound } \\
\text { Neutrons } / \mathbf{m}^{2} / \mathrm{s} \\
100 \mathrm{MeV}-10 \mathrm{GeV}\end{array}$ \\
\hline $\mathbf{0}$ & $4.99 \mathrm{E}+01$ & $7.01 \mathrm{E}+01$ & $4.28 \mathrm{E}+01$ \\
$\mathbf{1 0}$ & $3.01 \mathrm{E}+01$ & $6.16 \mathrm{E}+01$ & $3.87 \mathrm{E}+01$ \\
$\mathbf{2 0}$ & $2.02 \mathrm{E}+01$ & $5.49 \mathrm{E}+01$ & $3.50 \mathrm{E}+01$ \\
$\mathbf{3 0}$ & $1.53 \mathrm{E}+01$ & $4.90 \mathrm{E}+01$ & $3.13 \mathrm{E}+01$ \\
$\mathbf{4 0}$ & $1.26 \mathrm{E}+01$ & $4.34 \mathrm{E}+01$ & $2.79 \mathrm{E}+01$ \\
$\mathbf{5 0}$ & $1.14 \mathrm{E}+01$ & $3.86 \mathrm{E}+01$ & $2.50 \mathrm{E}+01$ \\
$\mathbf{6 0}$ & $9.75 \mathrm{E}+00$ & $3.39 \mathrm{E}+01$ & $2.22 \mathrm{E}+01$ \\
70 & $8.54 \mathrm{E}+00$ & $3.01 \mathrm{E}+01$ & $1.99 \mathrm{E}+01$ \\
$\mathbf{8 0}$ & $7.32 \mathrm{E}+00$ & $2.66 \mathrm{E}+01$ & $1.76 \mathrm{E}+01$ \\
$\mathbf{9 0}$ & $6.49 \mathrm{E}+00$ & $2.33 \mathrm{E}+01$ & $1.55 \mathrm{E}+01$ \\
$\mathbf{1 0 0}$ & $5.50 \mathrm{E}+00$ & $2.03 \mathrm{E}+01$ & $1.35 \mathrm{E}+01$ \\
\hline
\end{tabular}




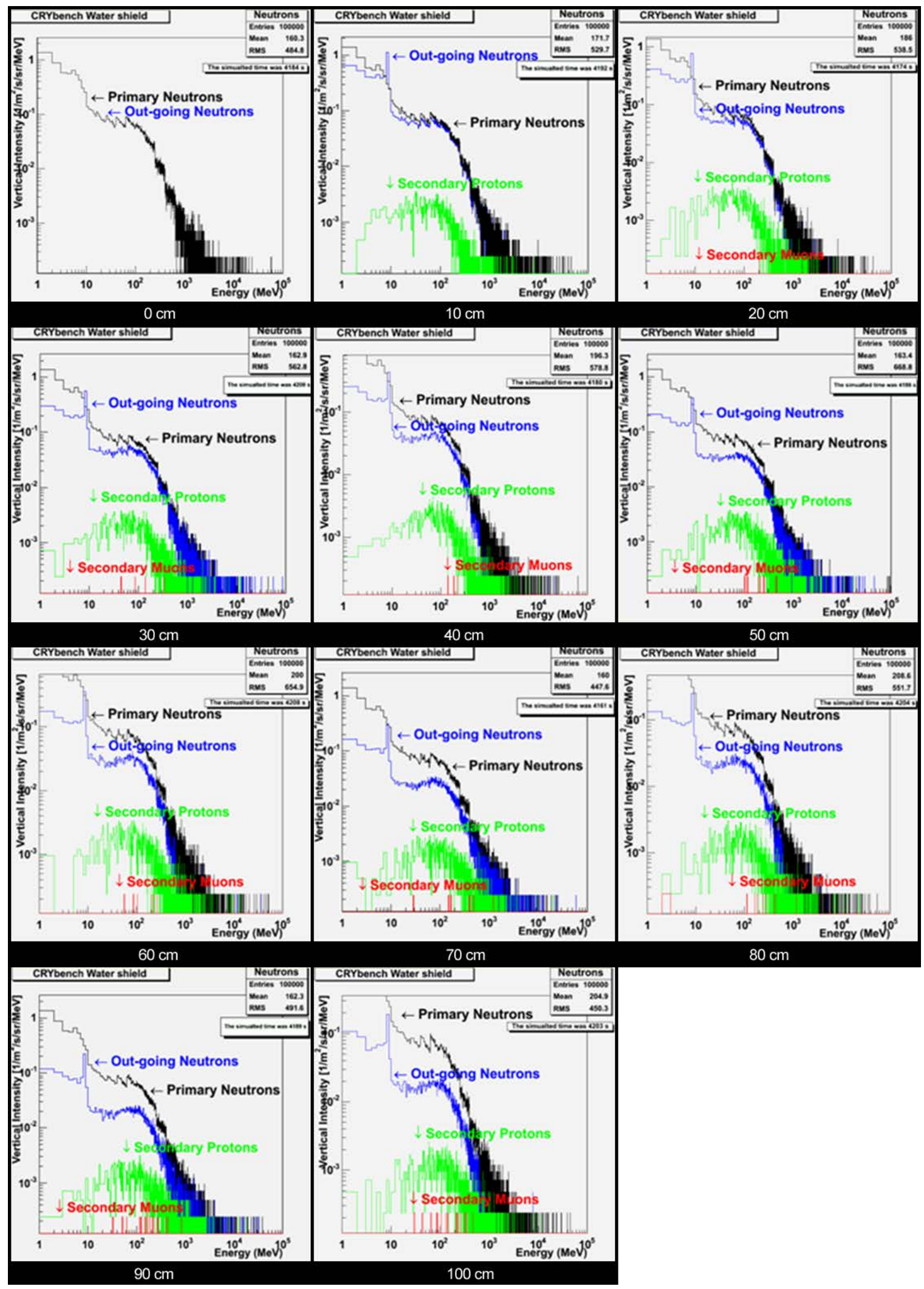

Figure 26: Simulated Spectra for Cosmic Neutrons through $0 \mathrm{~cm}$ to $100 \mathrm{~cm}$ of Water 
PNNL-20693

\subsubsection{Sea level Protons}

The shielding properties of water against the cosmic proton flux are presented in Figure 27 and Table 18, comparing the flux of outbound protons in three different energy regions. To obtain the data for Table 18 , the simulation data was normalized to reflect the actual composition of proton flux in cosmic rays at sea level. For low-energy protons (below $20 \mathrm{MeV}$ ), the water appears to have virtually no shielding effect against protons. For higher-energy protons, the interactions of the protons with the water create more protons than are shielded up to about $50 \mathrm{~cm}$. At thicknesses greater than $50 \mathrm{~cm}$, the water works to shield against higher-energy protons. The combination of these two effects implies that if the shield is to block protons with energy greater than $20 \mathrm{MeV}$ it must be thicker than $50 \mathrm{~cm}$, making water an ineffective shield against low-energy protons. The exact simulated spectra for the 10 geometries of water are presented in Figure 28.

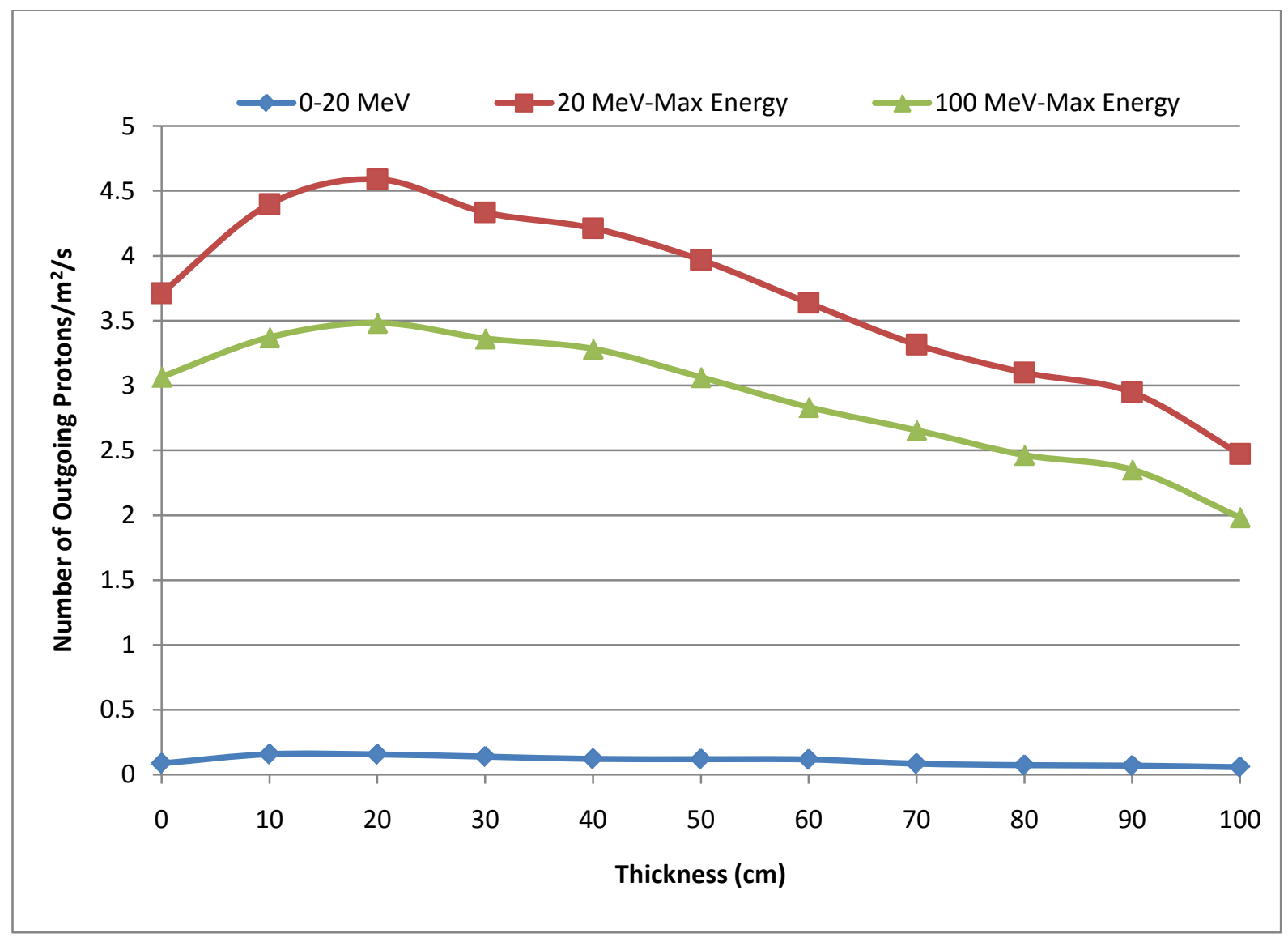

Figure 27: Cosmic Proton Flux through Water 
PNNL-20693

Table 18: Cosmic Proton Flux through Water

\begin{tabular}{|cccc|}
\hline Thickness $(\mathbf{c m})$ & $\begin{array}{c}\text { Outbound } \\
\text { Protons } / \mathbf{m}^{2} / \mathrm{s} \\
\mathbf{0} \mathbf{M e V}-20 \mathrm{MeV}\end{array}$ & $\begin{array}{c}\text { Outbound } \\
\text { Protons } / \mathbf{m}^{2} / \mathrm{s} \\
20 \mathrm{MeV}-10 \mathrm{GeV}\end{array}$ & $\begin{array}{c}\text { Outbound } \\
\text { Protons } / \mathbf{m}^{2} / \mathrm{s} \\
100 \mathrm{MeV}-10 \mathrm{GeV}\end{array}$ \\
\hline $\mathbf{0}$ & $8.81 \mathrm{E}-02$ & $3.71 \mathrm{E}+00$ & $3.07 \mathrm{E}+00$ \\
$\mathbf{1 0}$ & $1.59 \mathrm{E}-01$ & $4.40 \mathrm{E}+00$ & $3.37 \mathrm{E}+00$ \\
$\mathbf{2 0}$ & $1.57 \mathrm{E}-01$ & $4.59 \mathrm{E}+00$ & $3.48 \mathrm{E}+00$ \\
$\mathbf{3 0}$ & $1.40 \mathrm{E}-01$ & $4.33 \mathrm{E}+00$ & $3.36 \mathrm{E}+00$ \\
$\mathbf{4 0}$ & $1.22 \mathrm{E}-01$ & $4.21 \mathrm{E}+00$ & $3.28 \mathrm{E}+00$ \\
$\mathbf{5 0}$ & $1.20 \mathrm{E}-01$ & $3.97 \mathrm{E}+00$ & $3.06 \mathrm{E}+00$ \\
$\mathbf{6 0}$ & $1.18 \mathrm{E}-01$ & $3.64 \mathrm{E}+00$ & $2.83 \mathrm{E}+00$ \\
$\mathbf{8 0}$ & $8.55 \mathrm{E}-02$ & $3.32 \mathrm{E}+00$ & $2.65 \mathrm{E}+00$ \\
$\mathbf{9 0}$ & $7.42 \mathrm{E}-02$ & $3.10 \mathrm{E}+00$ & $2.46 \mathrm{E}+00$ \\
100 & $7.08 \mathrm{E}-02$ & $2.95 \mathrm{E}+00$ & $2.35 \mathrm{E}+00$ \\
& $5.88 \mathrm{E}-02$ & $2.47 \mathrm{E}+00$ & $1.98 \mathrm{E}+00$ \\
\hline
\end{tabular}




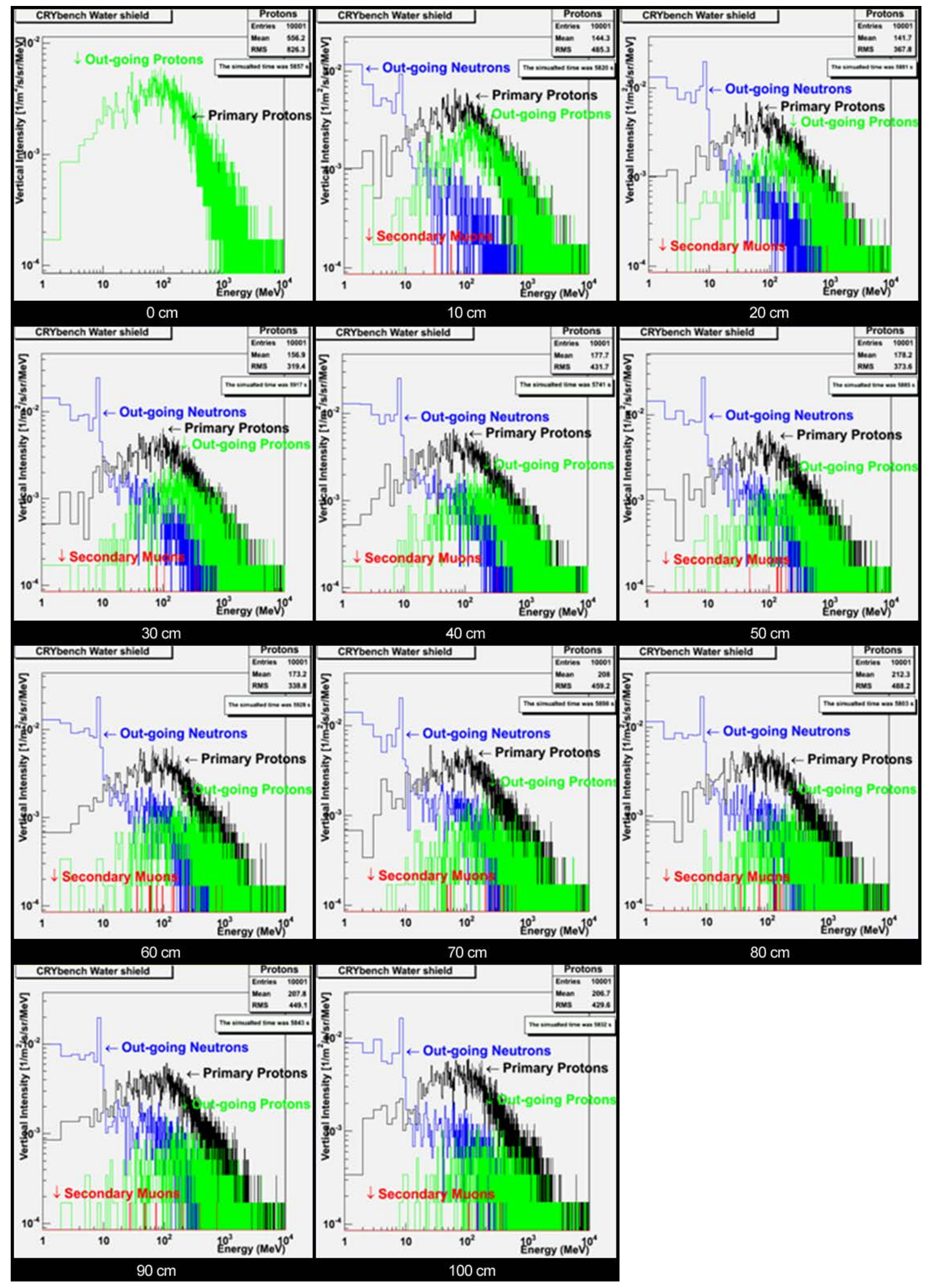

Figure 28: Simulated Spectra for Cosmic Protons through $0 \mathrm{~cm}$ to $100 \mathrm{~cm}$ of Water 
PNNL-20693

\subsubsection{Sea Level Muons}

Water is a low-Z material which shields cosmic ray muons poorly. Outbound muon flux was categorized into the three energy regions shown in Figure 29. At a thickness of $100 \mathrm{~cm}$, water shielded $29 \%$ of all incoming muons. No muons were produced at any thickness by cosmogenic flux. The Table 19 shows that up until $40 \mathrm{~cm}$ of thickness, almost no muons are shielded. Water would not be suggested as a shielding material against cosmic-ray muons. The exact simulated spectra for the 10 geometries considered impinging on iron are presented in Figure 30.

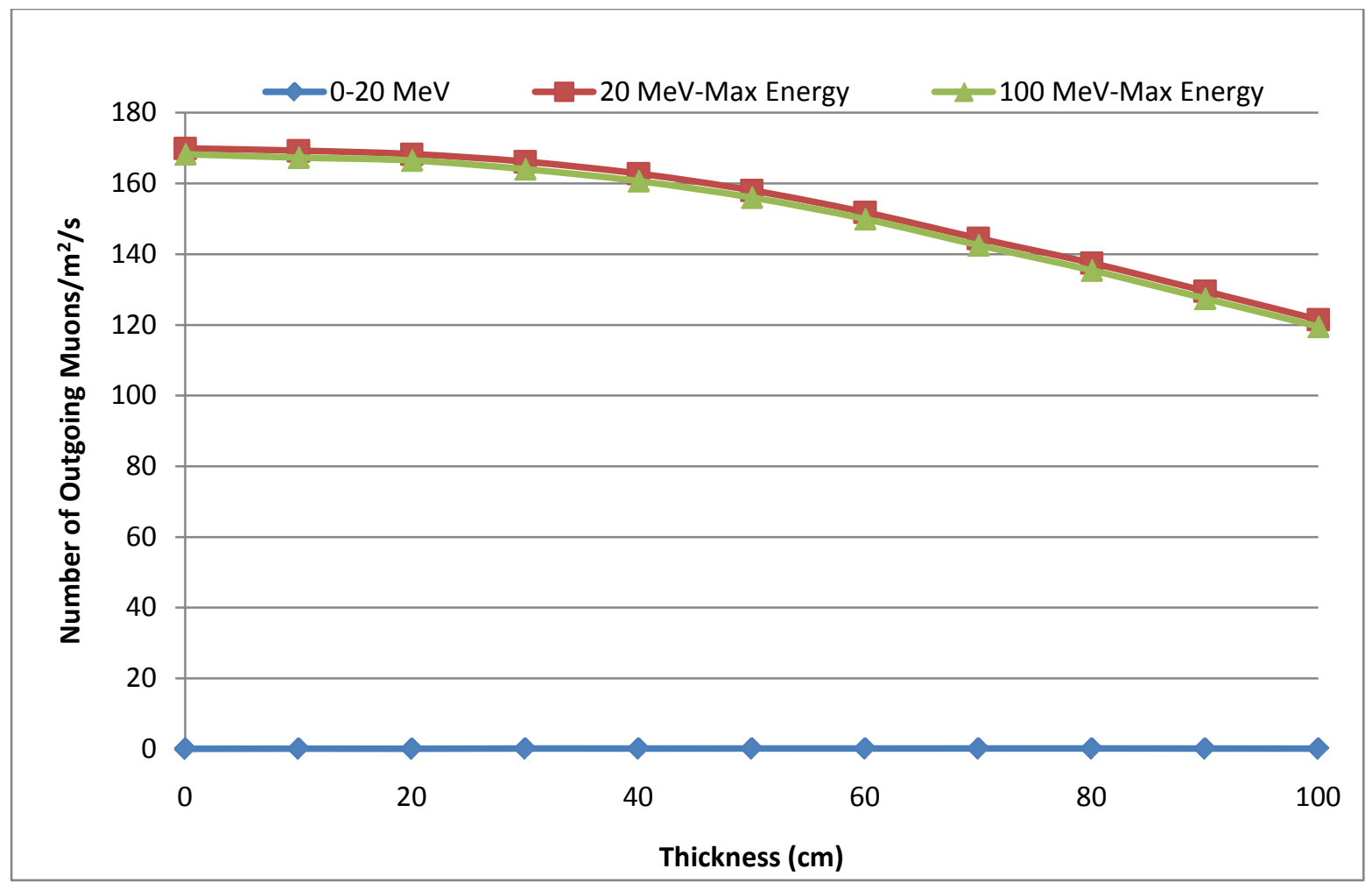

Figure 29: Cosmic Muon Flux through Water 
Table 19: Cosmic Muon Flux through Water

\begin{tabular}{|c|c|c|c|}
\hline Thickness (cm) & $\begin{array}{c}\text { Outbound } \\
\text { Muons } / \mathrm{m}^{2} / \mathrm{s} \\
0 \mathrm{MeV}-20 \mathrm{MeV}\end{array}$ & $\begin{array}{c}\text { Outbound } \\
\text { Muons } / \mathrm{m}^{2} / \mathrm{s} \\
20 \mathrm{MeV}-10 \mathrm{GeV}\end{array}$ & $\begin{array}{c}\text { Outbound } \\
\text { Muons } / \mathrm{m}^{2} / \mathrm{s} \\
100 \mathrm{MeV}-10 \mathrm{GeV}\end{array}$ \\
\hline 0 & $1.03 \mathrm{E}-01$ & $1.70 \mathrm{E}+02$ & $1.68 \mathrm{E}+02$ \\
\hline 10 & $1.38 \mathrm{E}-01$ & $1.69 \mathrm{E}+02$ & $1.67 \mathrm{E}+02$ \\
\hline 20 & $1.21 \mathrm{E}-01$ & $1.68 \mathrm{E}+02$ & $1.67 E+02$ \\
\hline 30 & $1.79 E-01$ & $1.66 \mathrm{E}+02$ & $1.64 \mathrm{E}+02$ \\
\hline 40 & $1.68 \mathrm{E}-01$ & $1.63 \mathrm{E}+02$ & $1.61 \mathrm{E}+02$ \\
\hline 50 & $1.82 \mathrm{E}-01$ & $1.58 \mathrm{E}+02$ & $1.56 \mathrm{E}+02$ \\
\hline 60 & $1.84 \mathrm{E}-01$ & $1.52 E+02$ & $1.50 \mathrm{E}+02$ \\
\hline 70 & $1.87 \mathrm{E}-01$ & $1.44 \mathrm{E}+02$ & $1.43 E+02$ \\
\hline 80 & $1.90 \mathrm{E}-01$ & $1.37 \mathrm{E}+02$ & $1.35 \mathrm{E}+02$ \\
\hline 90 & $1.72 \mathrm{E}-01$ & $1.30 \mathrm{E}+02$ & $1.27 \mathrm{E}+02$ \\
\hline 100 & $1.53 \mathrm{E}-01$ & $1.22 \mathrm{E}+02$ & $1.20 \mathrm{E}+02$ \\
\hline
\end{tabular}



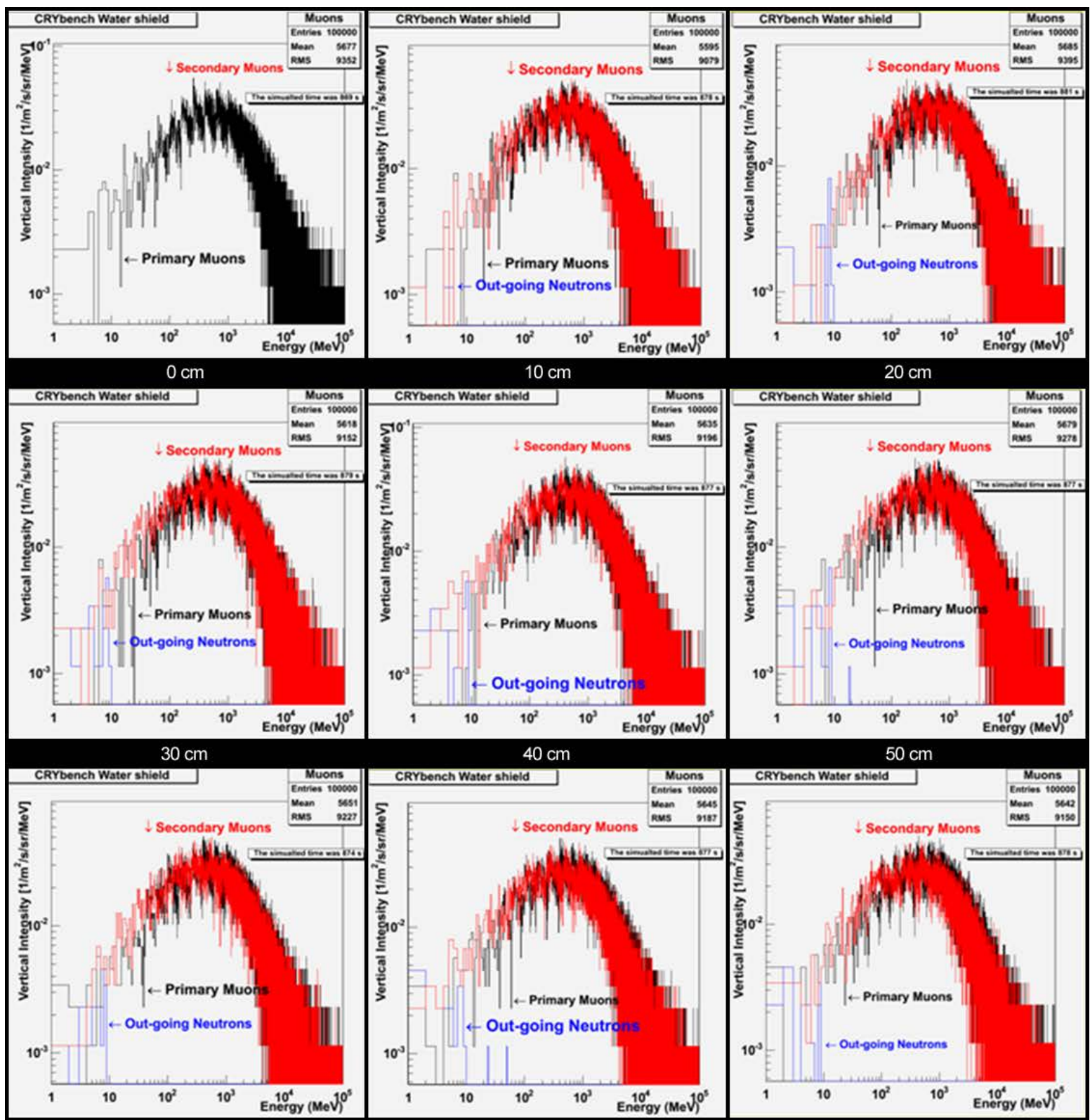

$50 \mathrm{~cm}$
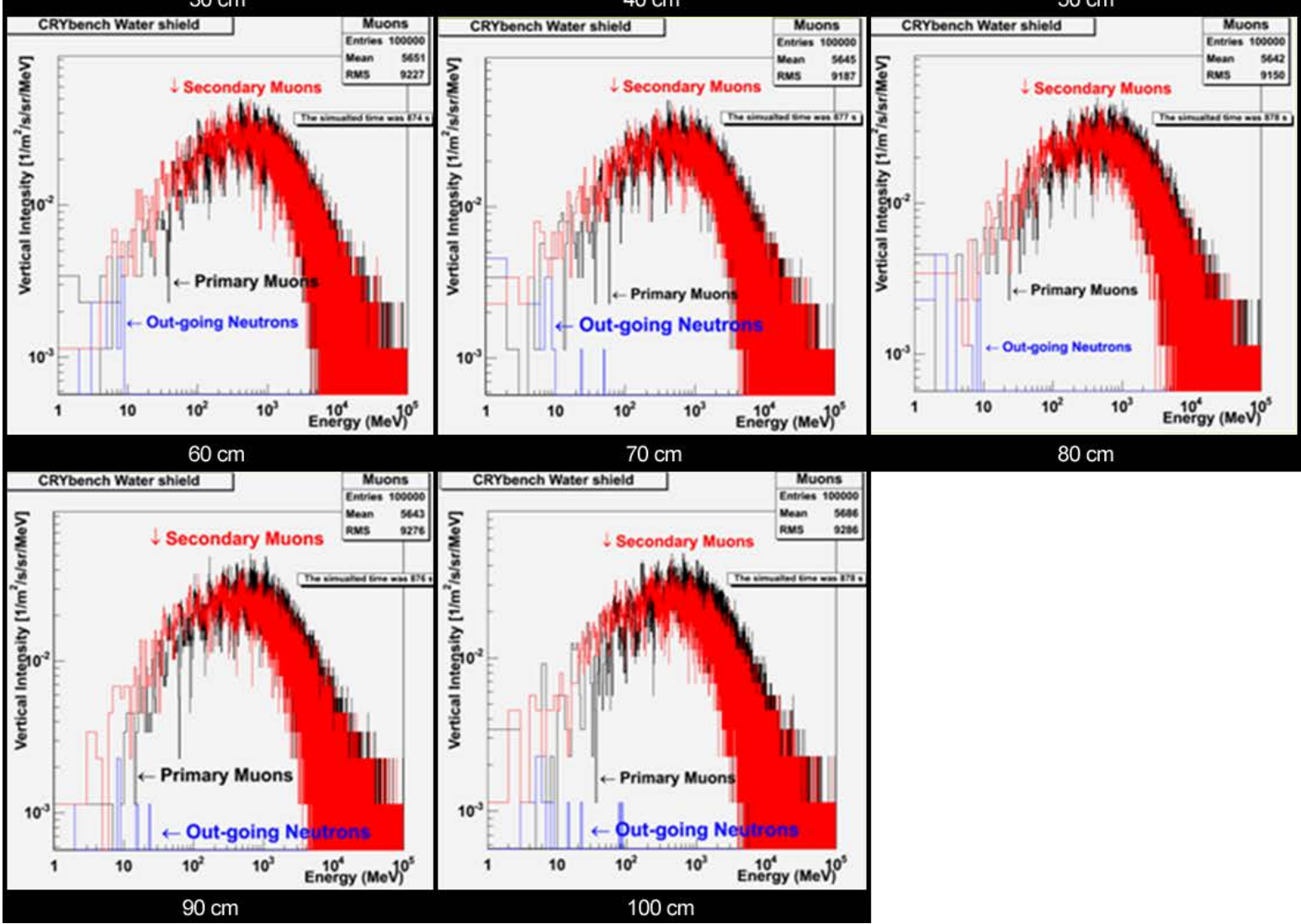

Figure 30: Simulated Spectra for Cosmic Muons through $0 \mathrm{~cm}$ to $100 \mathrm{~cm}$ of Water 
PNNL-20693

\subsection{Concrete}

\subsubsection{Sea Level Neutrons}

Concrete offers neutron shielding similar to PE, BPE, and water. Figure 31 suggests that the flux of neutrons through concrete steadily declines with material thickness, due to the low secondary generation in this material. However, the concrete's efficiency at shielding the neutrons decreases at greater thicknesses. Table 20 presents the data for Figure 31, while Figure 32 displays the spectra for each of the 11 simulations.

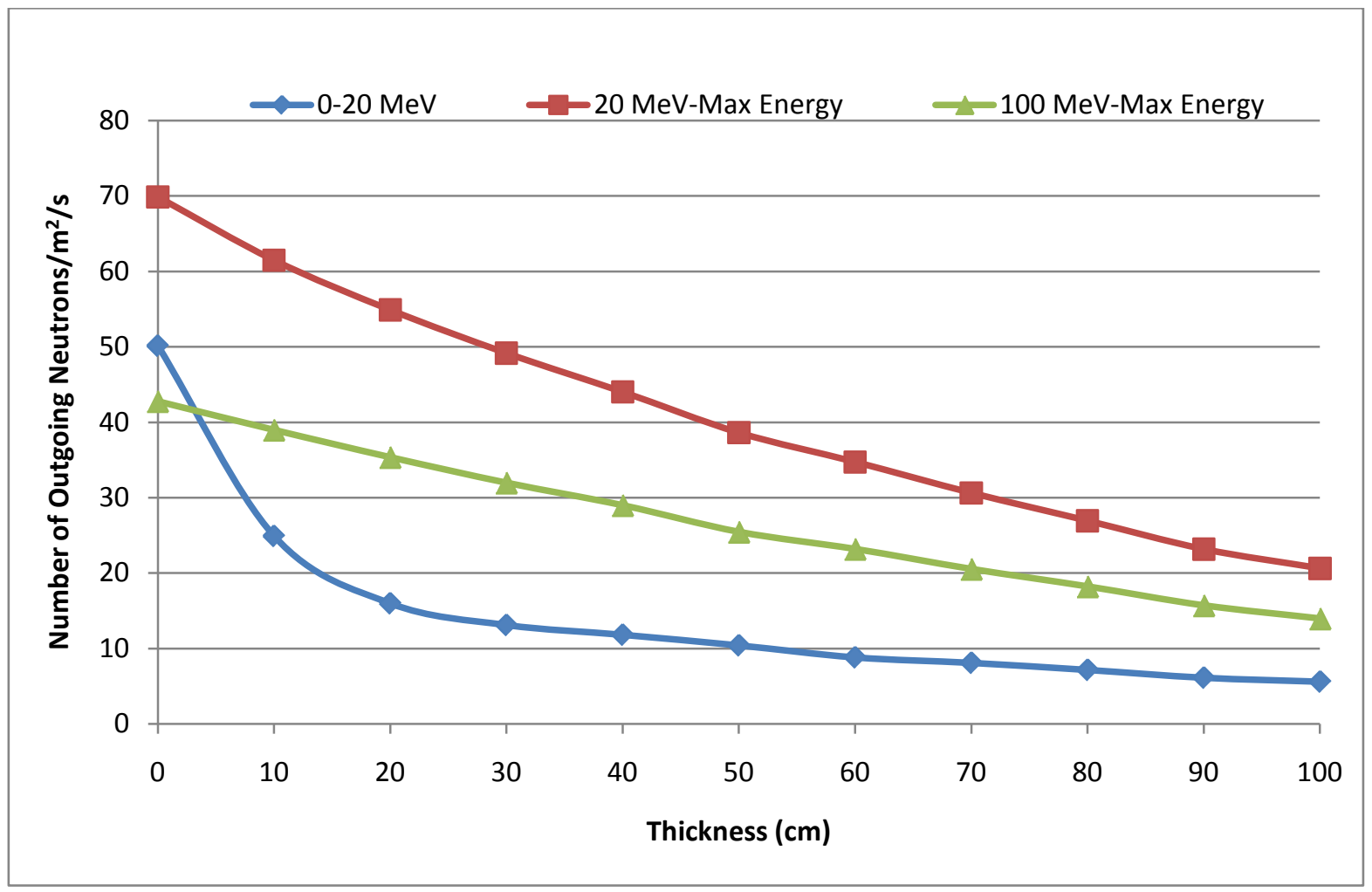

Figure 31: Cosmic Neutron Flux through Concrete 
Table 20: Cosmic Neutron Flux through Concrete

\begin{tabular}{|c|c|c|c|}
\hline Thickness (cm) & $\begin{array}{c}\text { Outbound } \\
\text { Neutrons } / \mathrm{m}^{2} / \mathrm{s} \\
0 \mathrm{MeV}-20 \mathrm{MeV}\end{array}$ & $\begin{array}{c}\text { Outbound } \\
\text { Neutrons } / \mathrm{m}^{2} / \mathrm{s} \\
20 \mathrm{MeV}-10 \mathrm{GeV}\end{array}$ & $\begin{array}{c}\text { Outbound } \\
\text { Neutrons } / \mathrm{m}^{2} / \mathrm{s} \\
100 \mathrm{MeV}-10 \mathrm{GeV}\end{array}$ \\
\hline 0 & $5.01 \mathrm{E}+01$ & $6.99 \mathrm{E}+01$ & $4.28 \mathrm{E}+01$ \\
\hline 10 & $2.49 \mathrm{E}+01$ & $6.15 E+01$ & $3.90 \mathrm{E}+01$ \\
\hline 20 & $1.60 \mathrm{E}+01$ & $5.49 \mathrm{E}+01$ & $3.54 \mathrm{E}+01$ \\
\hline 30 & $1.31 \mathrm{E}+01$ & $4.92 \mathrm{E}+01$ & $3.20 \mathrm{E}+01$ \\
\hline 40 & $1.18 \mathrm{E}+01$ & $4.40 \mathrm{E}+01$ & $2.90 \mathrm{E}+01$ \\
\hline 50 & $1.04 \mathrm{E}+01$ & $3.86 \mathrm{E}+01$ & $2.55 E+01$ \\
\hline 60 & $8.82 \mathrm{E}+00$ & $3.47 \mathrm{E}+01$ & $2.32 \mathrm{E}+01$ \\
\hline 70 & $8.10 \mathrm{E}+00$ & $3.06 \mathrm{E}+01$ & $2.05 E+01$ \\
\hline 80 & $7.16 \mathrm{E}+00$ & $2.69 \mathrm{E}+01$ & $1.82 \mathrm{E}+01$ \\
\hline 90 & $6.13 \mathrm{E}+00$ & $2.32 \mathrm{E}+01$ & $1.57 \mathrm{E}+01$ \\
\hline 100 & $5.61 \mathrm{E}+00$ & $2.06 \mathrm{E}+01$ & $1.40 \mathrm{E}+01$ \\
\hline
\end{tabular}




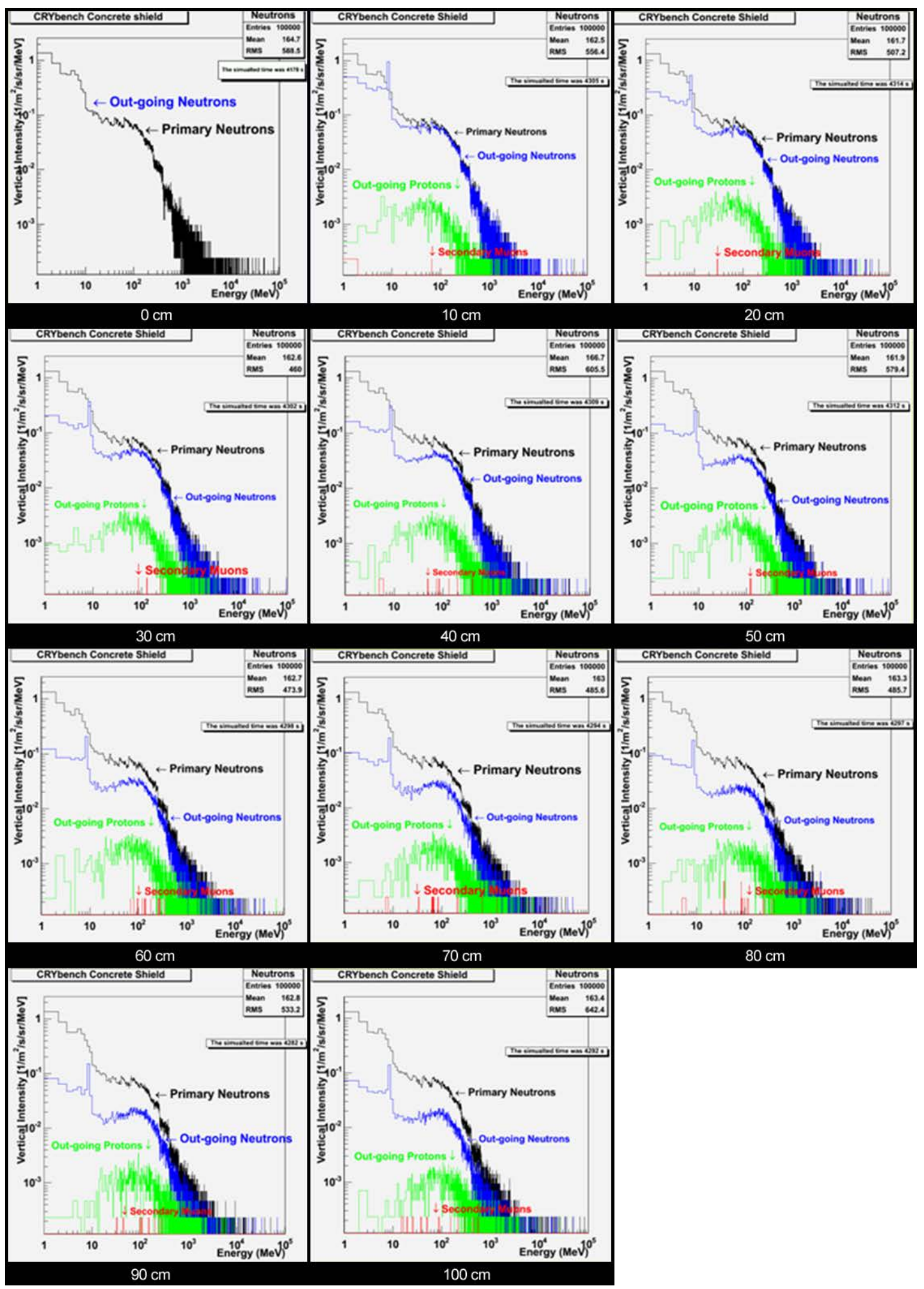

Figure 32: Simulated Spectra for Cosmic Neutrons through $0 \mathrm{~cm}$ to $100 \mathrm{~cm}$ of Concrete 
PNNL-20693

\subsubsection{Sea Level Protons}

The shielding properties of concrete against the cosmic proton flux are presented in Figure 33, comparing the flux of outbound protons in three different energy regions, with the same data presented in Table 21. To obtain the data for Figure 33 and Table 21, the simulation data results were normalized to reflect the actual composition of proton flux in cosmic rays. For low-energy protons (below $20 \mathrm{MeV}$ ), the concrete appears to have little to no shielding effect against the cosmic proton flux. For higher-energy protons, the thicker the concrete, the more effectively it shields against protons. Therefore the best concrete shield will be made as thick as possible to block the most protons. Concrete does not make an effective shield against low-energy protons. The exact simulated spectra for the 10 geometries of PE are presented in Figure 34.

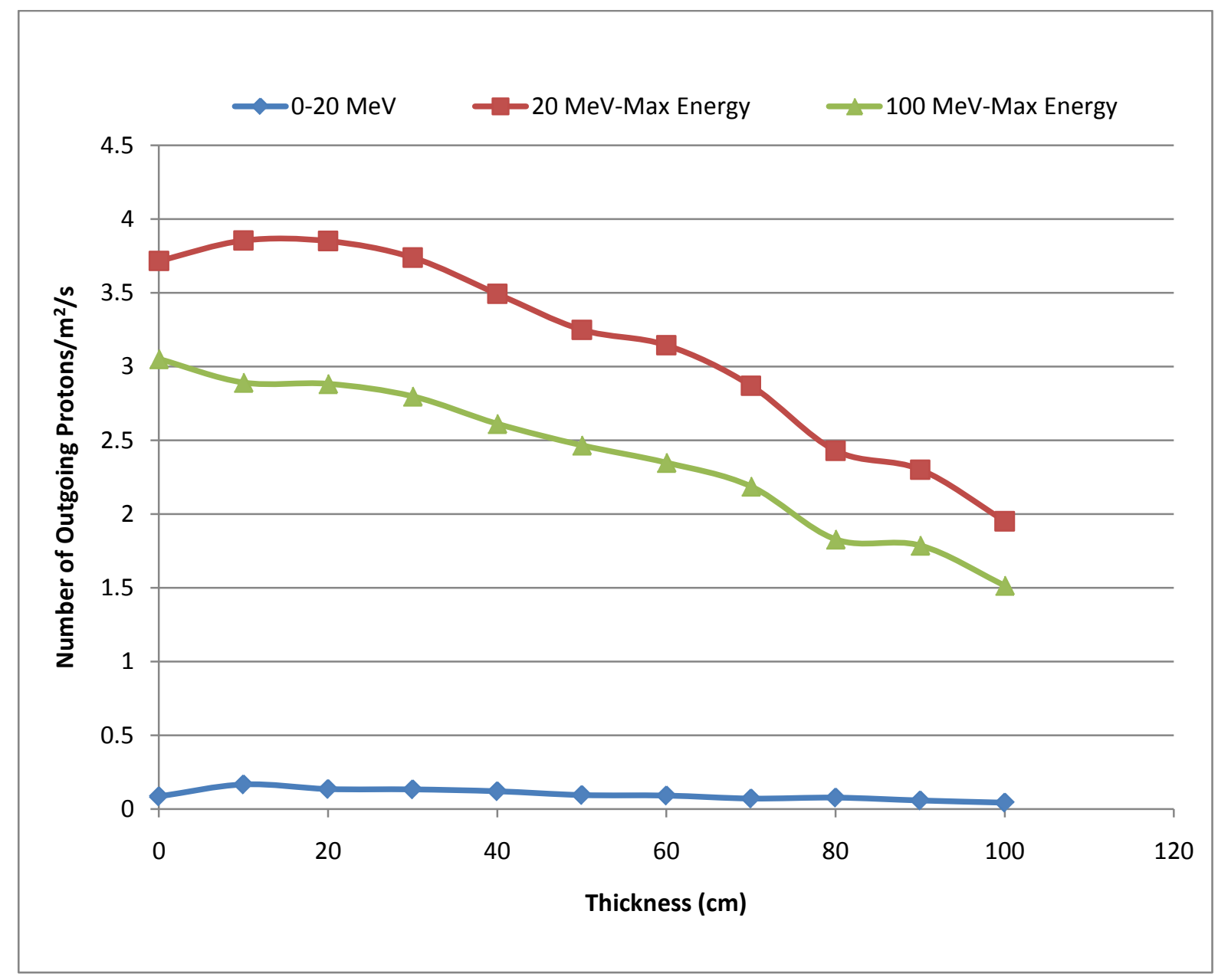

Figure 33: Cosmic Proton Flux through Concrete 
PNNL-20693

Table 21: Cosmic Proton Flux through Concrete

\begin{tabular}{|cccc|}
\hline Thickness $(\mathbf{c m})$ & $\begin{array}{c}\text { Outbound } \\
\text { Protons } / \mathbf{m}^{2} / \mathrm{s} \\
\mathbf{0 ~ M e V - 2 0 ~ M e V}\end{array}$ & $\begin{array}{c}\text { Outbound } \\
\text { Protons } / \mathbf{m}^{2} / \mathbf{s} \\
\mathbf{2 0 ~ M e V}-10 \mathrm{GeV}\end{array}$ & $\begin{array}{c}\text { Outbound } \\
\text { Protons } / \mathbf{m}^{2} / \mathbf{s} \\
100 \mathrm{MeV}-10 \mathrm{GeV}\end{array}$ \\
\hline $\mathbf{0}$ & $8.46 \mathrm{E}-02$ & $3.72 \mathrm{E}+00$ & $3.05 \mathrm{E}+00$ \\
$\mathbf{1 0}$ & $1.66 \mathrm{E}-01$ & $3.85 \mathrm{E}+00$ & $2.89 \mathrm{E}+00$ \\
$\mathbf{2 0}$ & $1.35 \mathrm{E}-01$ & $3.85 \mathrm{E}+00$ & $2.88 \mathrm{E}+00$ \\
$\mathbf{3 0}$ & $1.32 \mathrm{E}-01$ & $3.74 \mathrm{E}+00$ & $2.80 \mathrm{E}+00$ \\
$\mathbf{5 0}$ & $1.20 \mathrm{E}-01$ & $3.49 \mathrm{E}+00$ & $2.61 \mathrm{E}+00$ \\
$\mathbf{6 0}$ & $9.39 \mathrm{E}-02$ & $3.25 \mathrm{E}+00$ & $2.47 \mathrm{E}+00$ \\
$\mathbf{7 0}$ & $9.05 \mathrm{E}-02$ & $3.14 \mathrm{E}+00$ & $2.35 \mathrm{E}+00$ \\
$\mathbf{8 0}$ & $7.04 \mathrm{E}-02$ & $2.87 \mathrm{E}+00$ & $2.19 \mathrm{E}+00$ \\
$\mathbf{9 0}$ & $7.67 \mathrm{E}-02$ & $2.43 \mathrm{E}+00$ & $1.83 \mathrm{E}+00$ \\
$\mathbf{1 0 0}$ & $5.72 \mathrm{E}-02$ & $2.30 \mathrm{E}+00$ & $1.79 \mathrm{E}+00$ \\
\hline & $4.23 \mathrm{E}-02$ & $1.95 \mathrm{E}+00$ & $1.51 \mathrm{E}+00$ \\
\hline
\end{tabular}



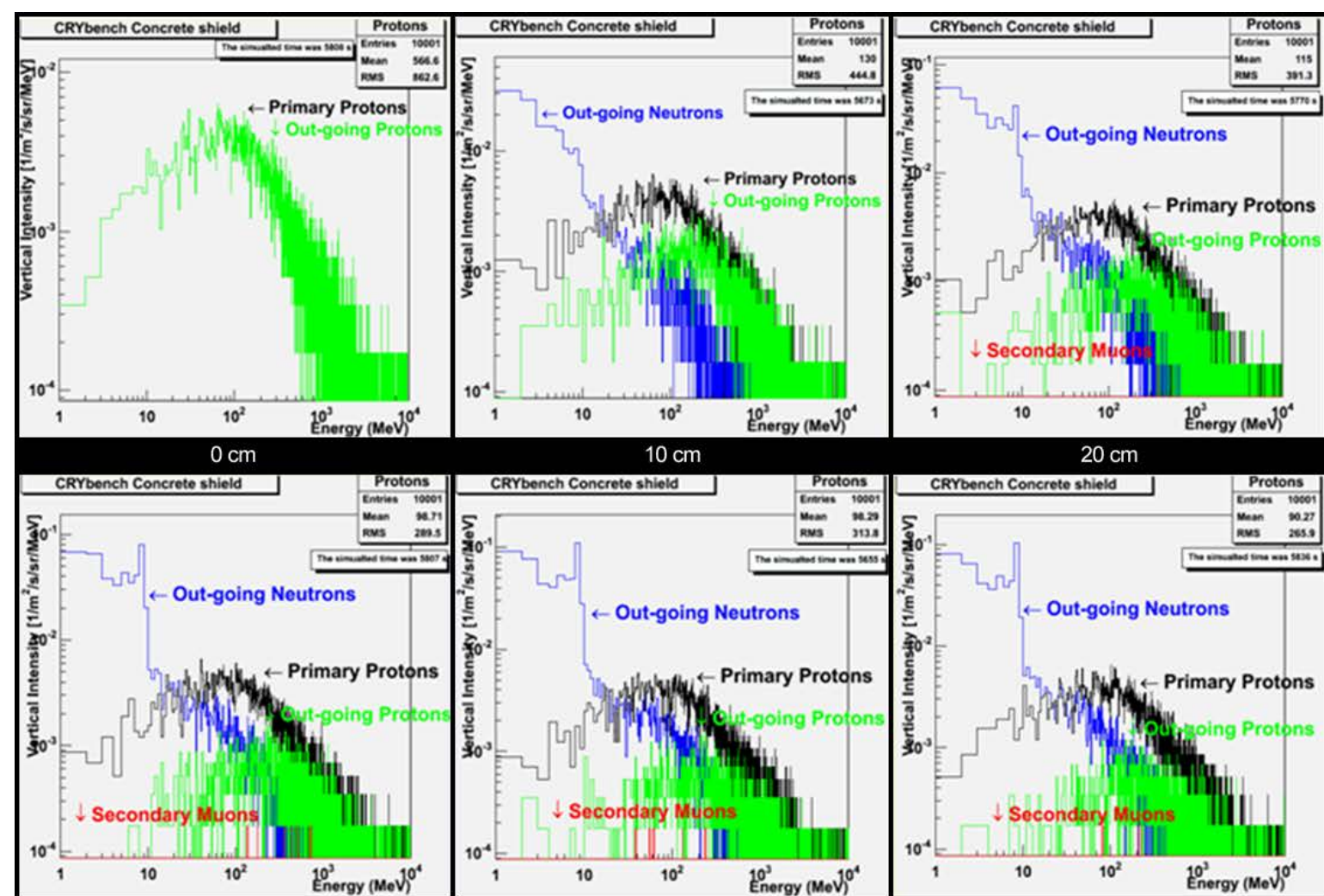

$10 \mathrm{~cm}$

$20 \mathrm{~cm}$
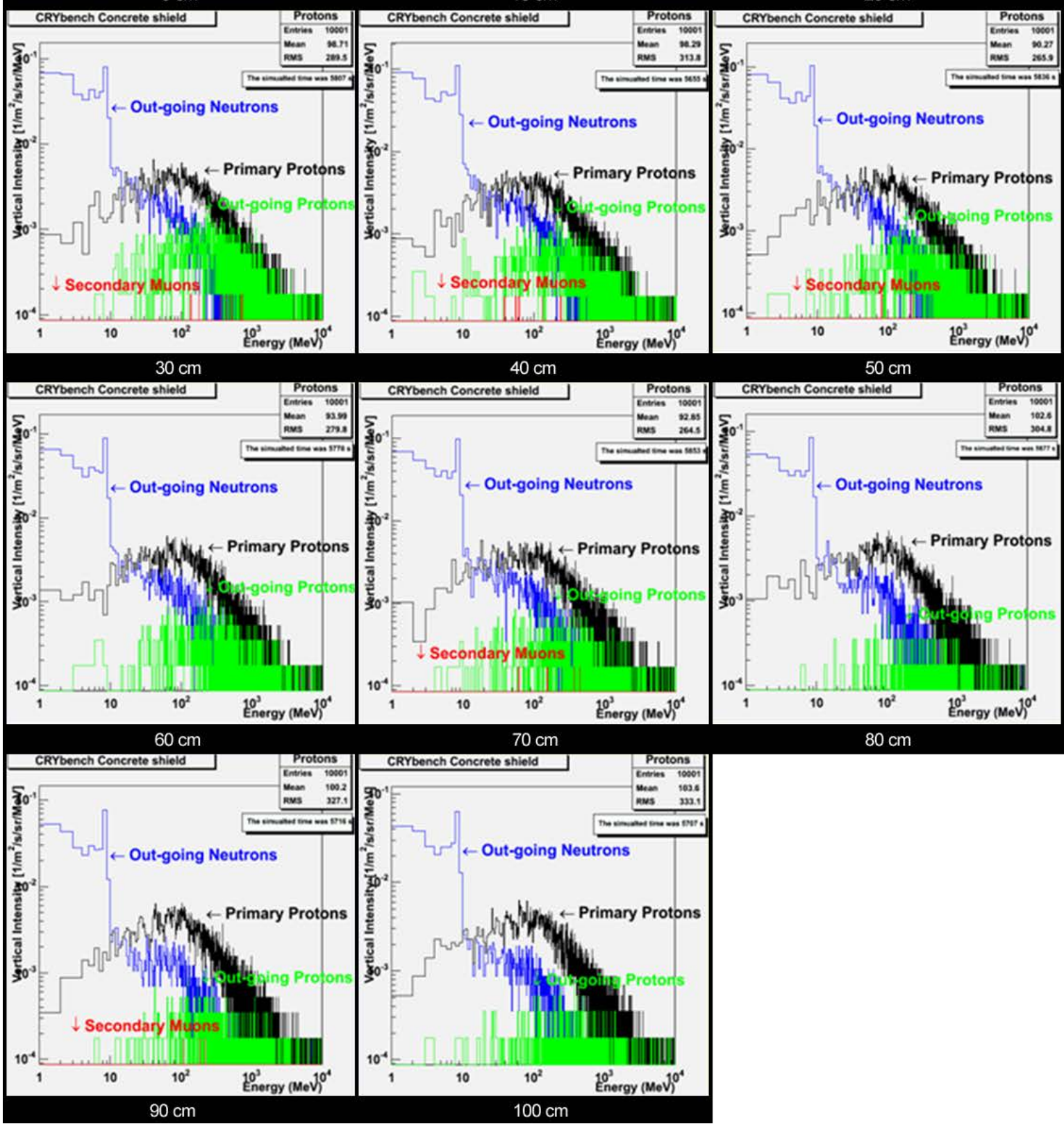

Figure 34: Simulated Spectra for Cosmic Protons through $0 \mathrm{~cm}$ to $100 \mathrm{~cm}$ of Concrete 
PNNL-20693

\subsubsection{Sea Level Muons}

Concrete, is a low-Z material which shields cosmic ray muons poorly. Outbound muon flux was categorized into the three energy regions seen in Figure 35. At a thickness of $100 \mathrm{~cm}, 33 \%$ of all incoming muons were shielded. No muons were produced at any thickness by cosmogenic flux. Table 22 shows that up to a $20 \mathrm{~cm}$ thickness, almost no muons are shielded. Although concrete would not be recommended as a shielding material against cosmic ray muons, it is the best of the low-Z shielding materials. The exact simulated spectra for the 10 geometries of iron are presented in Figure 36.

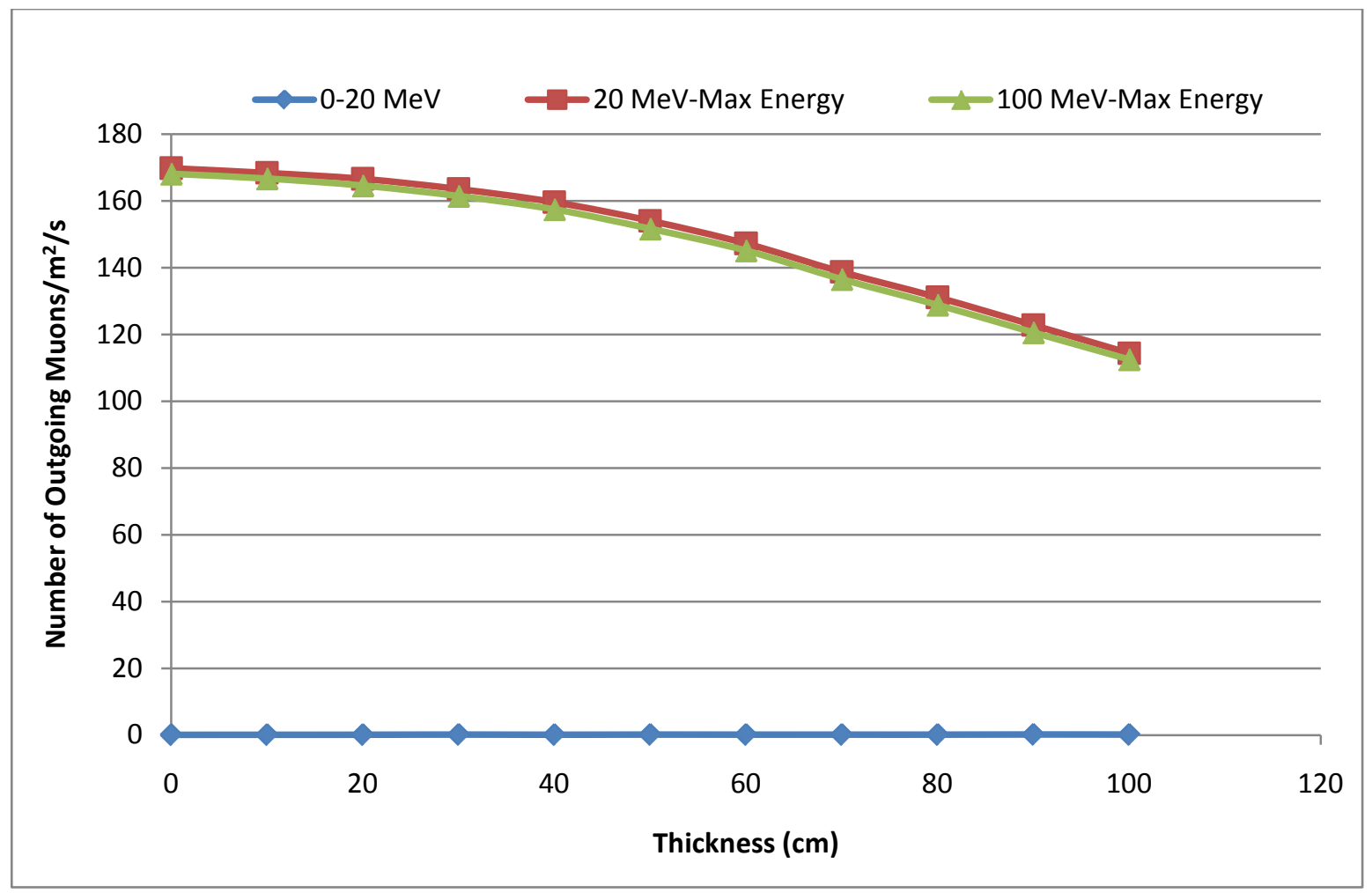

Figure 35: Cosmic Muon Flux through Concrete 
PNNL-20693

Table 22: Cosmic Muon Flux through Concrete

\begin{tabular}{|c|c|c|c|}
\hline Thickness (cm) & $\begin{array}{c}\text { Outbound } \\
\text { Muons/m2/s } \\
0 \mathrm{MeV}-20 \mathrm{MeV}\end{array}$ & $\begin{array}{c}\text { Outbound } \\
\text { Muons/m2/s } \\
20 \mathrm{MeV}-10 \mathrm{GeV}\end{array}$ & $\begin{array}{c}\text { Outbound } \\
\text { Muons/m2/s } \\
100 \mathrm{MeV}-10 \mathrm{GeV}\end{array}$ \\
\hline 0 & $1.23 \mathrm{E}-01$ & $1.70 \mathrm{E}+02$ & $1.68 \mathrm{E}+02$ \\
\hline 10 & $1.39 \mathrm{E}-01$ & $1.68 \mathrm{E}+02$ & $1.67 \mathrm{E}+02$ \\
\hline 20 & $1.47 \mathrm{E}-01$ & $1.67 \mathrm{E}+02$ & $1.65 E+02$ \\
\hline 30 & $1.95 \mathrm{E}-01$ & $1.64 \mathrm{E}+02$ & $1.62 \mathrm{E}+02$ \\
\hline 40 & $1.49 \mathrm{E}-01$ & $1.60 \mathrm{E}+02$ & $1.58 \mathrm{E}+02$ \\
\hline 50 & $1.92 \mathrm{E}-01$ & $1.54 \mathrm{E}+02$ & $1.52 \mathrm{E}+02$ \\
\hline 60 & $1.74 \mathrm{E}-01$ & $1.47 \mathrm{E}+02$ & $1.45 E+02$ \\
\hline 70 & $1.76 \mathrm{E}-01$ & $1.39 \mathrm{E}+02$ & $1.37 \mathrm{E}+02$ \\
\hline 80 & $1.73 \mathrm{E}-01$ & $1.31 \mathrm{E}+02$ & $1.29 \mathrm{E}+02$ \\
\hline 90 & 2.19E-01 & $1.23 \mathrm{E}+02$ & $1.21 \mathrm{E}+02$ \\
\hline 100 & 2.01E-01 & $1.14 \mathrm{E}+02$ & $1.13 E+02$ \\
\hline
\end{tabular}




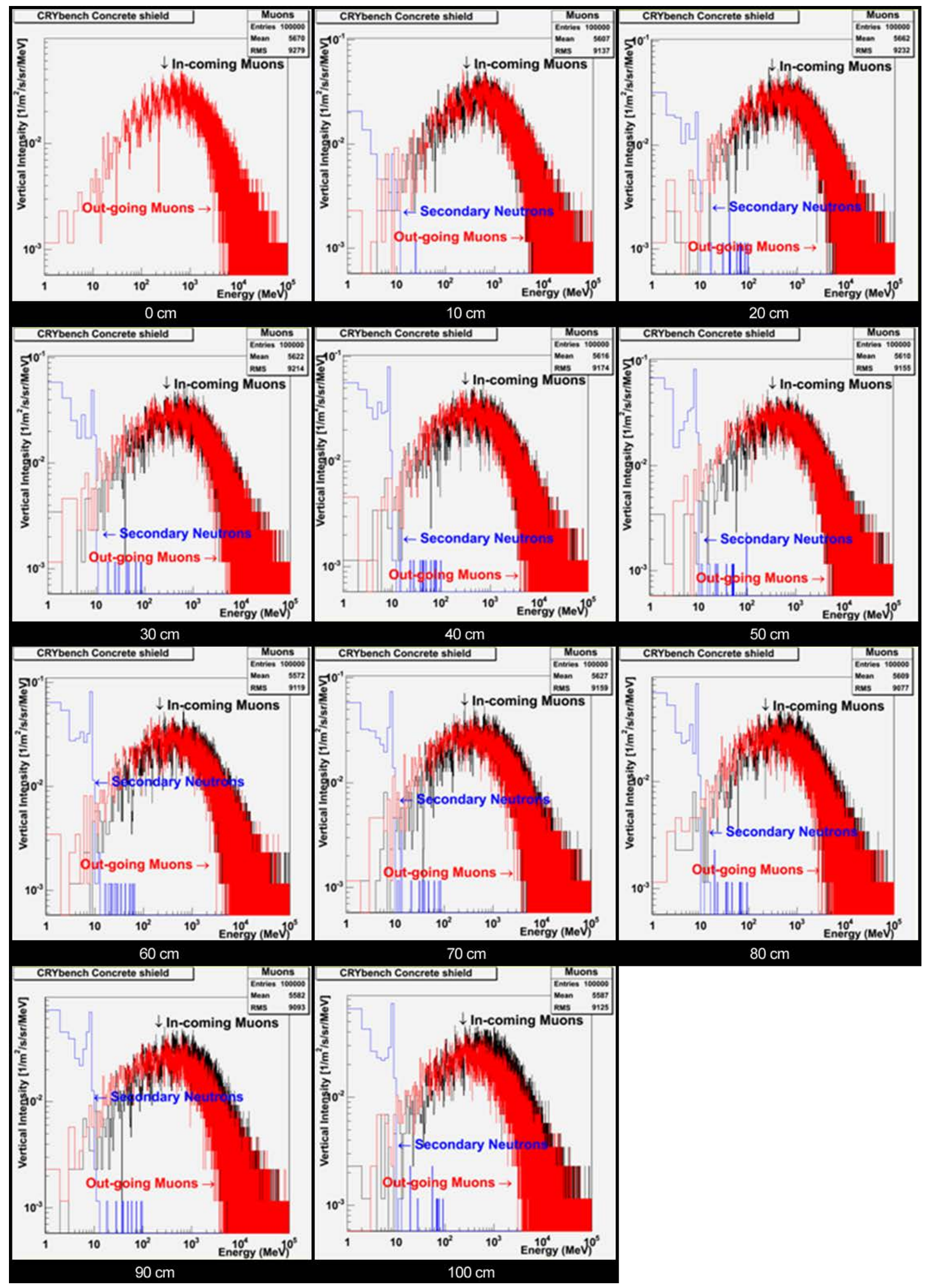

Figure 36: Simulated Spectra for Cosmic Muons through $0 \mathrm{~cm}$ to $100 \mathrm{~cm}$ of concrete 
PNNL-20693

\subsection{Results}

\subsection{Twenty Mega-Electron Volt to Ten Giga-Electron Volt Energy Range of the Cosmic Flux}

This section presents graphs and tables combining all the results presented in the previous sections, in order to facilitate the comparison between cosmic-ray shower shielding materials, in particular the neutronic and protonic components. Figure 37 shows the outbound flux for neutrons above $20 \mathrm{MeV}$, which is the energy range of interest for activation shielding purposes. One can observe that high- $\mathrm{Z}$ materials demonstrate much greater effectiveness. However, iron is considered a superior shielding material because it generates far fewer secondary neutrons than lead. Lead's secondary neutron generation is responsible for the increased flux of outbound neutrons compared to iron at thicknesses greater than $60 \mathrm{~cm}$. The results show that this is not the case with cosmic proton flux. Similar conclusions can be drawn from Figure 38 about high-Z materials, which are the best attenuators for protons above $20 \mathrm{MeV}$. The same data is presented in Table 23, whose statistical calculations yield an accuracy of 3\% due to Monte Carlo methods used. Cosmic neutrons dominate outbound neutrons at energies greater than $20 \mathrm{MeV}$ for all shielding scenarios, while in-bound protons contribute less than $10 \%$ of total outbound neutron flux, and the contribution from muons is negligible.

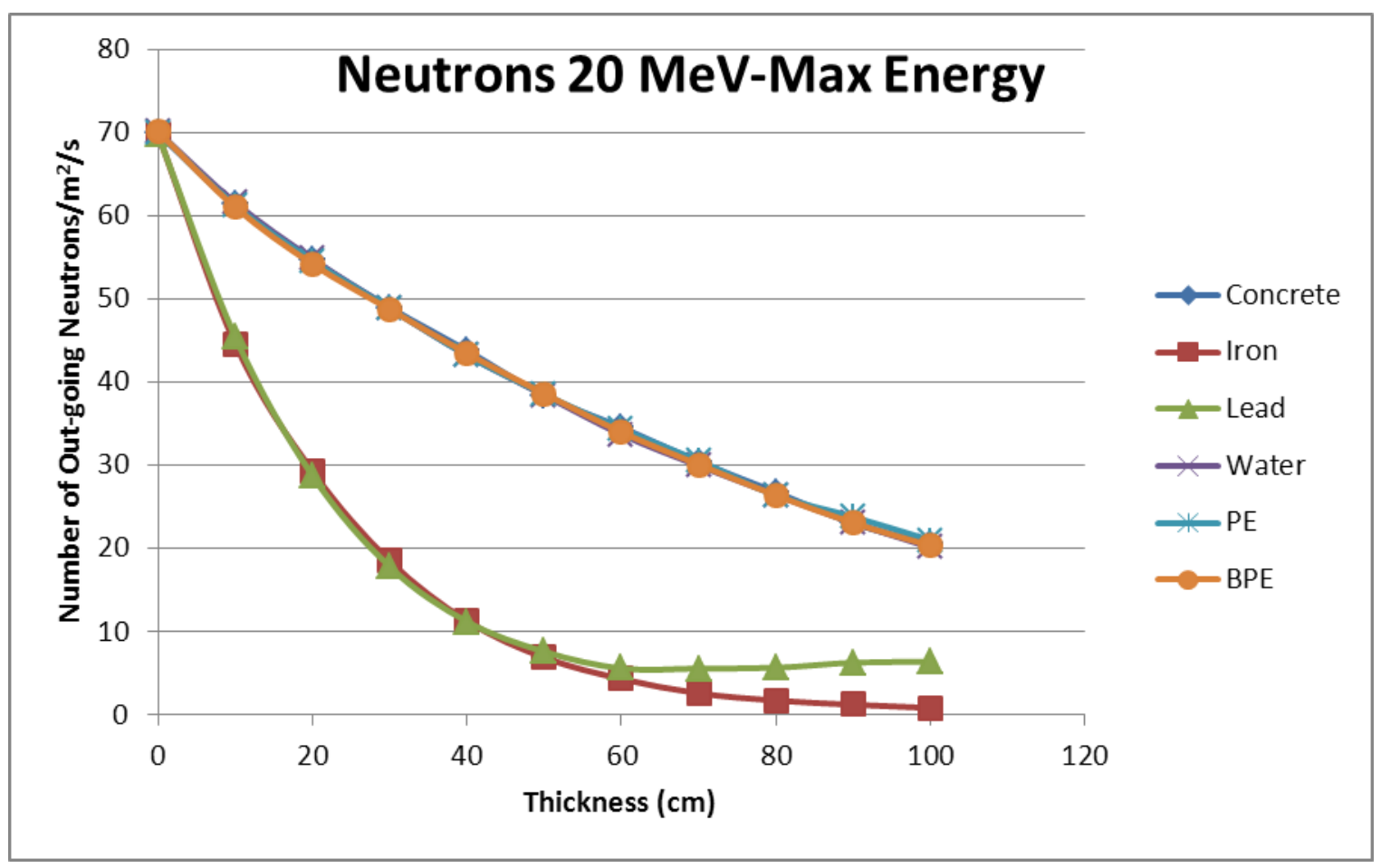

Figure 37: High-Energy Outbound Neutron Flux versus Material Thickness for All Materials Considered in This Study 


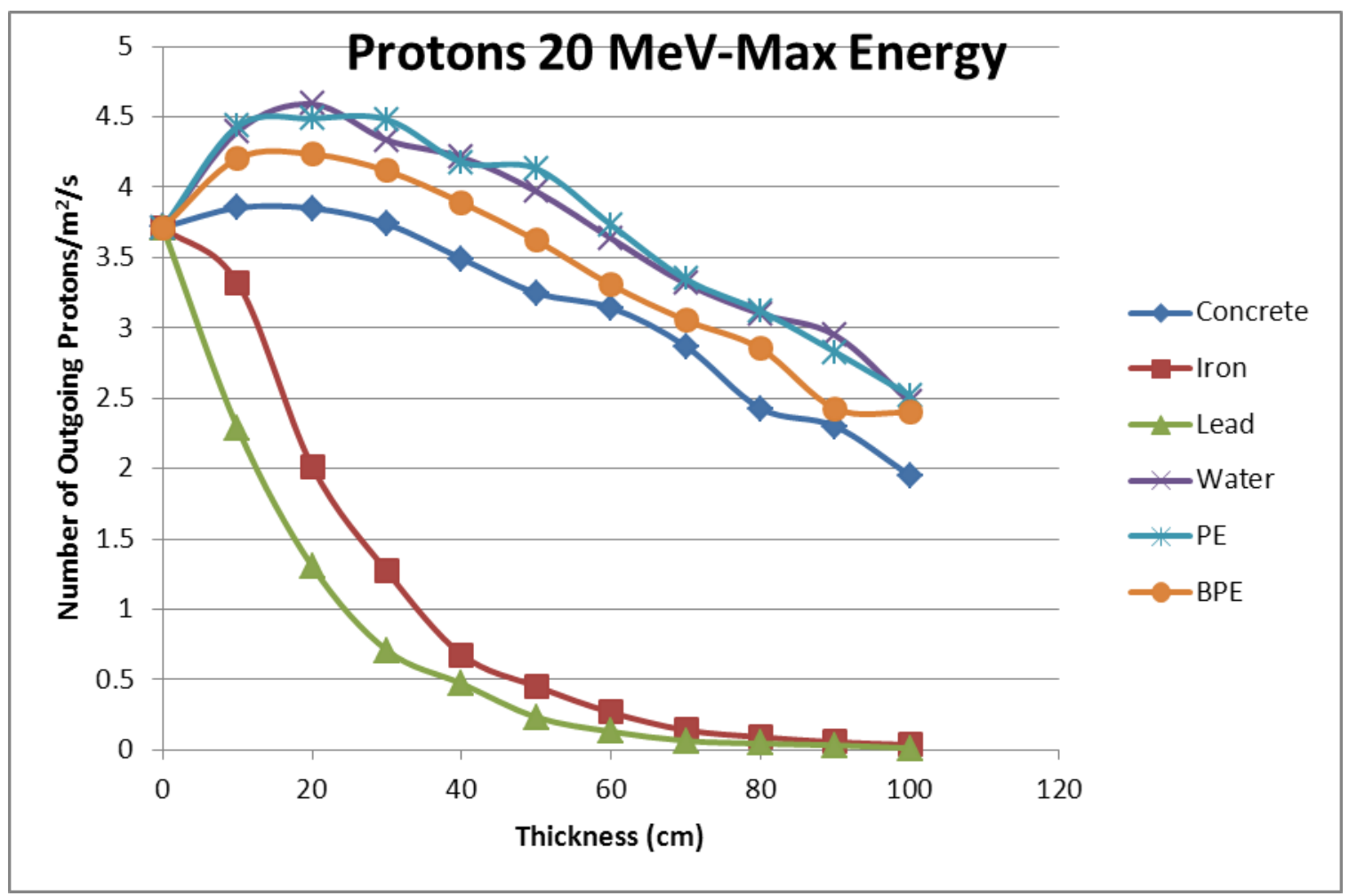

Figure 38: High-Energy Outbound Proton Flux versus Material Thickness for All Materials Considered in This Study 
Table 23: High-Energy Cosmic Particle Flux through Different Materials per Primary Particle

\begin{tabular}{|c|c|c|c|c|c|c|c|}
\hline \multirow[t]{2}{*}{ Material } & \multirow[t]{2}{*}{ Thickness $(\mathrm{cm})$} & \multicolumn{2}{|c|}{20} & \multicolumn{2}{|c|}{50} & \multicolumn{2}{|c|}{100} \\
\hline & & $\begin{array}{c}\text { Outbound } \\
\text { Neutrons } / \mathrm{m}^{2} / \mathrm{s}\end{array}$ & $\begin{array}{c}\text { Outbound } \\
\text { Protons } / \mathrm{m}^{2} / \mathrm{s}\end{array}$ & $\begin{array}{c}\text { Outbound } \\
\text { Neutrons } / \mathrm{m}^{2} / \mathrm{s}\end{array}$ & $\begin{array}{c}\text { Outbound } \\
\text { Protons } / \mathrm{m}^{2} / \mathrm{s}\end{array}$ & $\begin{array}{c}\text { Outbound } \\
\text { Neutrons } / \mathrm{m}^{2} / \mathrm{s}\end{array}$ & $\begin{array}{c}\text { Outbound } \\
\text { Protons } / \mathrm{m}^{2} / \mathrm{s}\end{array}$ \\
\hline \multirow{4}{*}{ Iron } & $\begin{array}{c}\text { Incoming } \\
\text { Protons }\end{array}$ & $1.33 \pm 0.05$ & $0.745 \pm 0.016$ & $0.58 \pm 0.02$ & $0.124 \pm 0.003$ & $0.136 \pm 0.005$ & $0.0177 \pm 0.0004$ \\
\hline & $\begin{array}{l}\text { Incoming } \\
\text { Neutrons }\end{array}$ & 28.229 & 1.42 & 6.37 & 0.35 & 0.65 & 0.02 \\
\hline & $\begin{array}{l}\text { Incoming } \\
\text { Muons }\end{array}$ & 0.02 & 0.00 & 0.05 & 0.00 & 0.08 & 0.00 \\
\hline & Total & 29.56 & 2.17 & 7.01 & 0.48 & 0.87 & 0.04 \\
\hline \multirow{4}{*}{ Lead } & $\begin{array}{l}\text { Incoming } \\
\text { Protons }\end{array}$ & $1.28 \pm 0.05$ & $0.61 \pm 0.01$ & $0.51 \pm 0.02$ & $0.077 \pm 0.00$ & $0.59 \pm 0.02$ & $0.013 \pm 0.00$ \\
\hline & $\begin{array}{l}\text { Incoming } \\
\text { Neutrons }\end{array}$ & 27.71 & 0.85 & 7.14 & 0.17 & 5.86 & 0.00 \\
\hline & $\begin{array}{l}\text { Incoming } \\
\text { Muons }\end{array}$ & 0.020 & 0.00 & 0.06 & 0.00 & 0.05 & 0.00 \\
\hline & Total & 29.01 & 1.43 & 7.72 & 0.25 & 6.50 & 0.02 \\
\hline \multirow{4}{*}{ Concrete } & $\begin{array}{l}\text { Incoming } \\
\text { Protons }\end{array}$ & $0.9 \pm 0.3$ & $1.95 \pm 0.03$ & $1.0 \pm 0.3$ & $0.95 \pm 0.02$ & $0.6 \pm 0.2$ & $0.25 \pm 0.00$ \\
\hline & $\begin{array}{l}\text { Incoming } \\
\text { Neutrons }\end{array}$ & 54.02 & 2.31 & 37.62 & 2.50 & 20.03 & 1.76 \\
\hline & $\begin{array}{c}\text { Incoming } \\
\text { Muons }\end{array}$ & 0.02 & 0.00 & 0.02 & 0.00 & 0.01 & 0.00 \\
\hline & Total & 54.89 & 4.26 & 38.61 & 3.45 & 20.63 & 2.00 \\
\hline \multirow{4}{*}{ Water } & $\begin{array}{l}\text { Incoming } \\
\text { Protons }\end{array}$ & $0.47 \pm 0.02$ & $2.77 \pm 0.01$ & $0.74 \pm 0.04$ & $1.73 \pm 0.01$ & $0.67 \pm 0.03$ & $0.86 \pm 0.00$ \\
\hline & $\begin{array}{l}\text { Incoming } \\
\text { Neutrons }\end{array}$ & 54.42 & 2.40 & 37.85 & 2.60 & 19.61 & 1.79 \\
\hline & $\begin{array}{l}\text { Incoming } \\
\text { Muons }\end{array}$ & 0.00 & 0.00 & 0.00 & 0.00 & 0.01 & 0.00 \\
\hline & Total & 54.89 & 5.17 & 38.59 & 4.33 & 20.28 & 2.65 \\
\hline \multirow{4}{*}{ PE } & $\begin{array}{l}\text { Incoming } \\
\text { Protons }\end{array}$ & $0.41 \pm 0.01$ & $2.79 \pm 0.02$ & $0.69 \pm 0.02$ & $1.75 \pm 0.02$ & $0.76 \pm 0.02$ & $0.88 \pm 0.01$ \\
\hline & $\begin{array}{l}\text { Incoming } \\
\text { Neutrons }\end{array}$ & 54.27 & 2.28 & 37.97 & 2.74 & 20.41 & 1.82 \\
\hline & $\begin{array}{l}\text { Incoming } \\
\text { Muons }\end{array}$ & 0.00 & 0.00 & 0.00 & 0.00 & 0.00 & 0.00 \\
\hline & Total & 54.68 & 5.07 & 38.67 & 4.50 & 21.17 & 2.70 \\
\hline \multirow{4}{*}{ BPE } & $\begin{array}{l}\text { Incoming } \\
\text { Protons }\end{array}$ & $0.53 \pm 0.02$ & $2.40 \pm 0.02$ & $0.90 \pm 0.04$ & $1.31 \pm 0.01$ & $0.83 \pm 0.04$ & $0.61 \pm 0.00$ \\
\hline & $\begin{array}{l}\text { Incoming } \\
\text { Neutrons }\end{array}$ & 53.76 & 2.34 & 37.89 & 2.57 & 19.69 & 1.92 \\
\hline & $\begin{array}{l}\text { Incoming } \\
\text { Muons }\end{array}$ & 0.00 & 0.00 & 0.00 & 0.00 & 0.00 & 0.00 \\
\hline & Total & 54.30 & 4.73 & 38.79 & 3.90 & 20.52 & 2.53 \\
\hline
\end{tabular}


PNNL-20693

Energy ranges below $20 \mathrm{MeV}$ and above $100 \mathrm{MeV}$ were not of direct interest to this study; data for these energy ranges are presented in Appendix A. 
PNNL-20693

\subsection{Conclusions}

The simulations presented herein analyze the shielding properties of six commonly used shield materials against the protonic, neutronic and muonic components of cosmic-ray showers. The analysis is presented in a geometrical progression in terms of thickness, from no material to $100 \mathrm{~cm}$ of material, in increments of $10 \mathrm{~cm}$. The simulations were performed using a simple slab of each material exposed to the simulated cosmic particle shower. The relevant physics processes were considered in the Monte Carlo simulation.

Our analysis concludes that the common belief that more material is better holds up well when considering low-Z hydrogenous materials for cosmic shields. The hydrogenous materials modeled for this study were polyethylene (PE), borated polyethylene (BPE), and water. The effectiveness of each of these materials in shielding cosmic neutrons, protons and muons was similarly poor. None of these is therefore recommended as a material to consider in shielding the detector materials in transport from cosmic rays.

In the case of high-Z materials, such as iron and lead, a significant contribution of secondary neutrons to the total outbound flux begins at $30 \mathrm{~cm}$, the threshold thickness at which attenuation of the outbound neutrons is achieved. Iron proves to be optimum better material than lead since it has a lower rate of secondaryneutron production. Figure 39 shows the total neutron outbound flux in the energy range of interest for all the materials considered in this analysis. For a given thickness, iron outperforms lead by a factor of 5 and hydrogenous materials on average by a factor of 20, making it the shielding material of choice for neutrons above $20 \mathrm{MeV}$. 


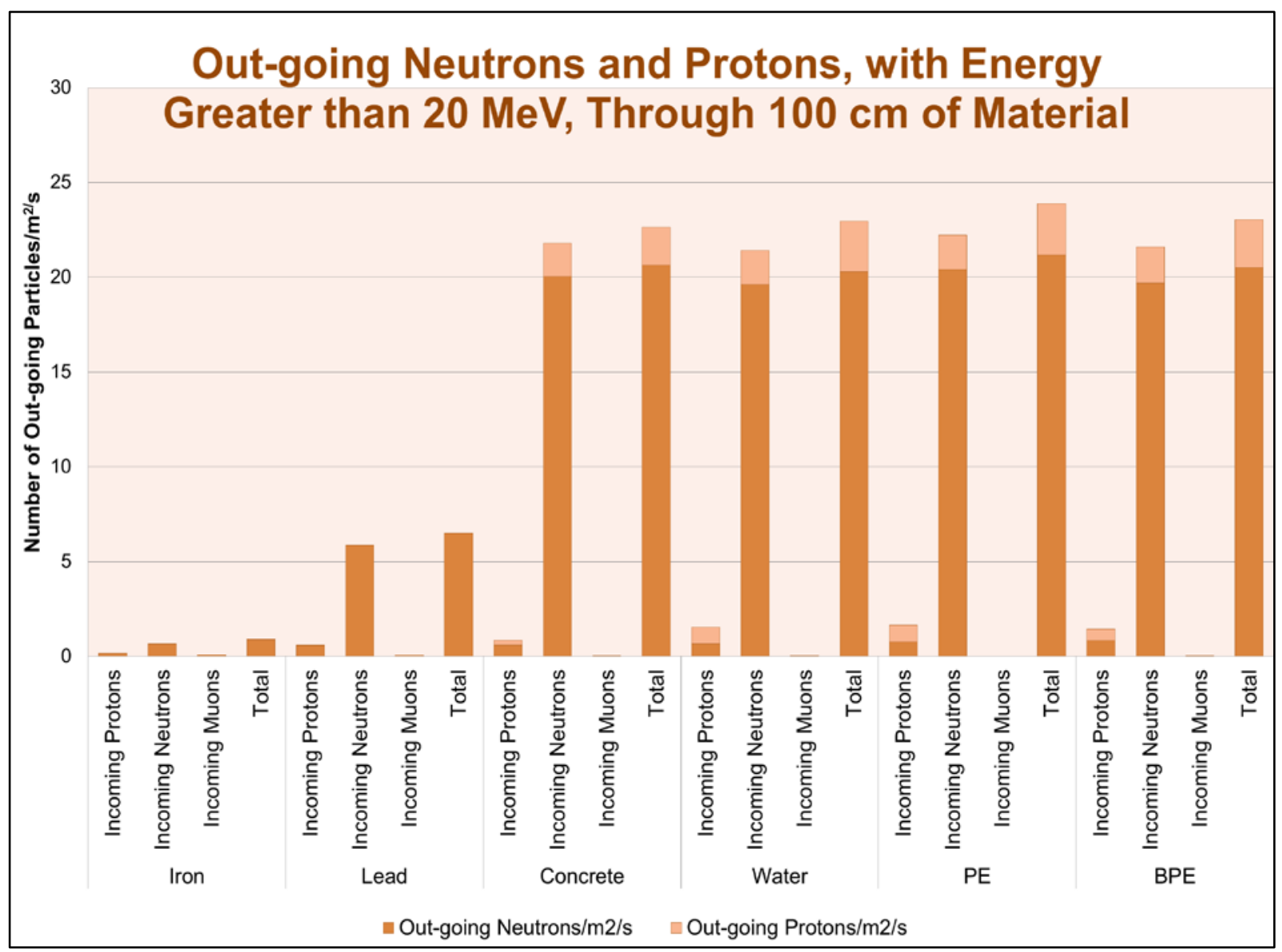

Figure 39: Outbound Total Neutron and Proton Flux through $100 \mathrm{~cm}$ of All Materials Considered in This Study 
PNNL-20693

\subsection{References}

Aalseth, CE, M Amman, JF Amsbaugh, FT Avignone III, HO Backe, AS Barabash, PS Barbeau, JR Beene, M Bergevin, FE Bertrand, M Boswell, V Brudanin, W Bugg, TH Burritt, Y-D Chan, JI Collar, RJ Cooper, R Creswick, JA Detwiler, PJ Doe, Y Efremenko, V Egorov, H Ejiri, SR Elliott, J Ely, J Esterline, H Farach, JE Fast, N Fields, P Finnerty, B Fujikawa, E Fuller, VM Gehman, GK Giovanetti, VE Giuseppe, K Gusey, AL Hallin, R Hazama, R Henning, A Hime, EW Hoppe, TW Hossbach, A Howard, RA Johnson, KJ Keeter, M Keillor, C Keller, JD Kephart, MF Kidd, O Kochetov, SI Konovalov, RT Kouzes, KT Lesko, L Leviner, JC Loach, PN Luke, S MacMullin, MG Marino, DM Mei, HS Miley, ML Miller, L Mizouni, A Montoya, AW Myers, M Nomachi, B Odom, JL Orrell, D Phillips, AWP Poon, G Prior, J Qian, DC Radford, K Rielage, RGH Robertson, L Rodriguez, KP Rykaczewski, AG Schubert, T Shima, M Shirchenko, J Strain, K Thomas, R Thompson, V Timkin, W Tornow, TD Van Welchel, I Vanyushin, K Vetter, R Warner, JF Wilkerson, JM Wouters, E Yakushev, AR Young, C-H Yu, V Yumatov, C Zhang, and S Zimmerman. 2009. The Majorana Demonstrator: An R\&D Project Towards a Tonne-Scale Germanium Neutrinoless Double-Beta Decay Search.”. In Proceedings of Proceedings of the 10th Conference on the Intersections of Particle and Nuclear Physics,V. 1182, pp. 88-91, 4 pp. Springer, San Diego, California,

Agostinelli, S, J Allison, K Amako, J Apostolakis, H Araujo, P Arce, M Asai, D Axen, S Banerjee, G Barrand, F Behner, L Bellagamba, J Boudreau, L Broglia, A Brunengo, H Burkhardt, S Chauvie, J Chuma, R Chytracek, G Cooperman, G Cosmo, P Degtyarenko, A Dell'Acqua, G Depaola, D Dietrich, R Enami, A Feliciello, C Ferguson, H Fesefeldt, G Folger, F Foppiano, A Forti, S Garelli, S Giani, R Giannitrapani, D Gibin, JJG Cadenas, I Gonzalez, GG Abril, G Greeniaus, W Greiner, V Grichine, A Grossheim, S Guatelli, P Gumplinger, R Hamatsu, K Hashimoto, H Hasui, A Heikkinen, A Howard, V Ivanchenko, A Johnson, FW Jones, J Kallenbach, N Kanaya, M Kawabata, Y Kawabata, M Kawaguti, S Kelner, P Kent, A Kimura, T Kodama, R Kokoulin, M Kossov, H Kurashige, E Lamanna, T Lampen, V Lara, V Lefebure, F Lei, M Liendl, W Lockman, F Longo, S Magni, M Maire, E Medernach, K Minamimoto, PM de Freitas, Y Morita, K Murakami, M Nagamatu, R Nartallo, P Nieminen, T Nishimura, K Ohtsubo, M Okamura, S O'Neale, Y Oohata, K Paech, J Perl, A Pfeiffer, MG Pia, F Ranjard, A Rybin, S Sadilov, E Di Salvo, G Santin, T Sasaki, N Savvas, Y Sawada, S Scherer, S Seil, V Sirotenko, D Smith, N Starkov, H Stoecker, J Sulkimo, M Takahata, S Tanaka, E Tcherniaev, ES Tehrani, M Tropeano, P Truscott, H Uno, L Urban, P Urban, M Verderi, A Walkden, W Wander, H Weber, JP Wellisch, T Wenaus, DC Williams, D Wright, T Yamada, H Yoshida, and D Zschiesche. 2003. "Geant4-a Simulation Toolkit." Nuclear Instruments \& Methods in Physics Research Section a-Accelerators Spectrometers Detectors and Associated Equipment 506(3):250-303. 10.1016/s01689002(03)01368-8.

Aguayo-Navarrete, E, RT Kouzes, and JL Orrell. 2010. Monte Carlo Simulations of Cosmic Ray Hadronic Interactions. Report No. PNNL-20401, Pacific Northwest National Laboratory, Richland, Washington.

Detwiler, J. 2011. "Backgrounds and Simulations." Presentation from MJD Annual Review Meeting, 29 Slides. Majorana Collaboration, Washington, D.C.

Elliott, SR. 2011. "Double Beta Decay Science and Context." Presentation from MJD Annual Review Meeting, 31 Slides. Majorana Collaboration, Washington, DC. 
Hagmann, C, D Lange, and D Wright. 2008. "Cosmic-Ray Shower Library (CRY)." Technical Manual, 5 pages. Lawrence Livermore National Laboratory, Livermore, CA. http://nuclear.llnl.gov/simulation/cry.pdf.

Kama, S. 2011. "Introduction to Root." Presentation, 27 Slides. Doğuş University, Acıbadem, Kadıköy, İstanbul. http://indico.cern.ch/getFile.py/access?contribId=49\&resId=1\&materialId=slides\&confId=11551 $\underline{4}$.

The Geant4 Collaboration. Physics Lists - Use Cases. Accessed on July 22, 2011 at http://geant4.org/geant4/support/physicsLists/referencePL/useCases.shtml (last updated July 9, 2011).

Ziegler, JF. 1998. "Terrestrial Cosmic Ray Intensites." IBM Journal of Research and Development 42(1):117. 
PNNL-20693

\section{Appendix A: Low- and Very High-Energy Ranges}




\section{A.1 Low-Energy Range (1 MeV - $20 \mathrm{MeV})$ of Cosmic Flux}

Figure 40 shows the outbound flux for neutrons below $20 \mathrm{MeV}$, which is the energy range of interest for activation shielding purposes. One can observe that high-Z materials do not show much greater efficiency in this energy range. Low $\mathrm{Z}$ materials perform much better in the attenuation of the low-energy components of the cosmic ray shower. This effect is not observed in shielding against the cosmic proton flux. Similar conclusions can be made from Figure 41, which shows that high-Z materials are the best attenuators for protons below $20 \mathrm{MeV}$. The statistics for low energy measurements are poor compared with the rest of data presented in this document. This is obvious, especially for the hydrogenous materials studied. One reason for this decrease in the statistics of the results is that the number of protons at low energies in the cosmic ray shower simulated is lower. The error bar is not shown in this graph but is contained in Table 24.

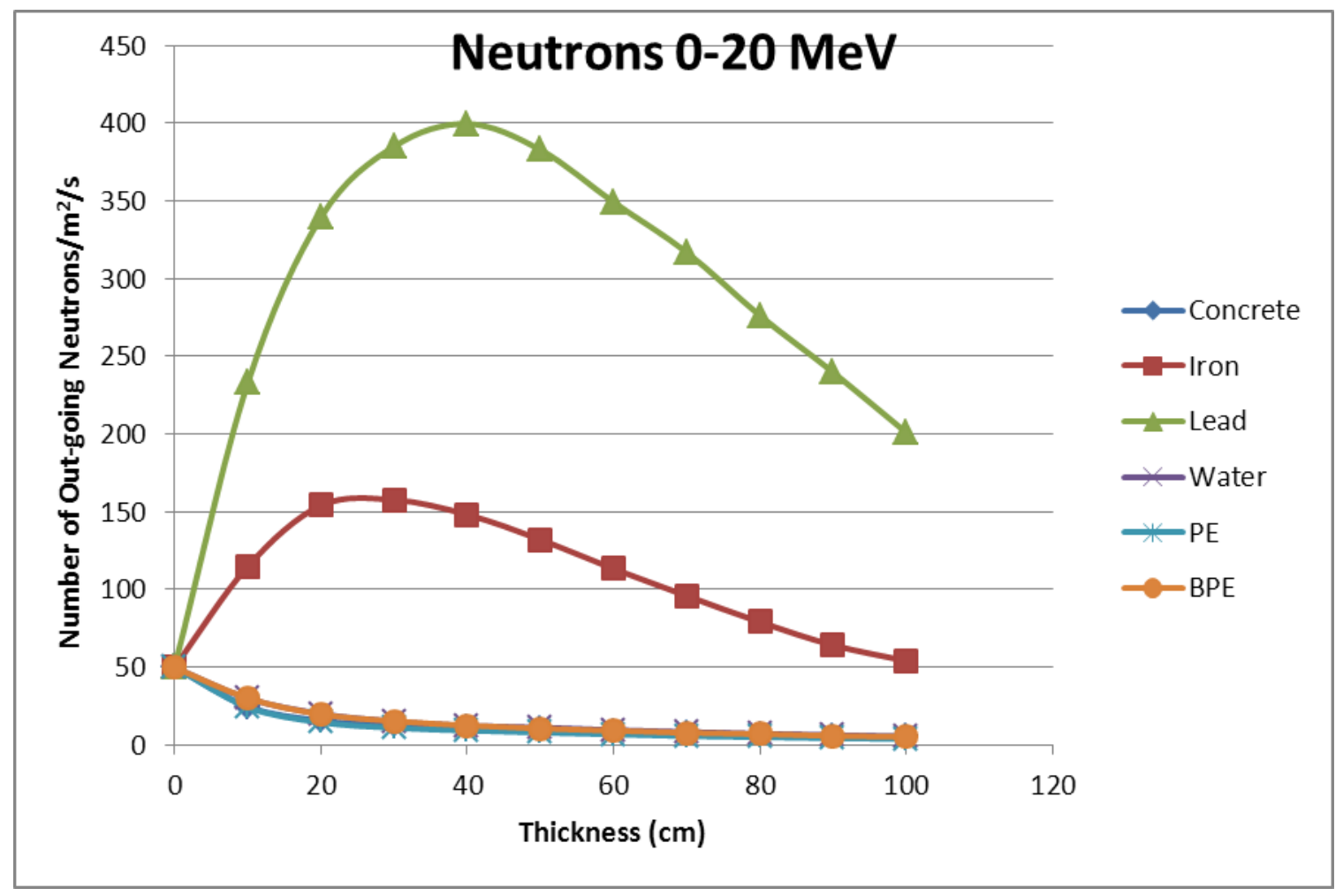

Figure 40: Low-Energy Outbound Neutron Flux versus Material Thickness for All Materials Considered in This Study 


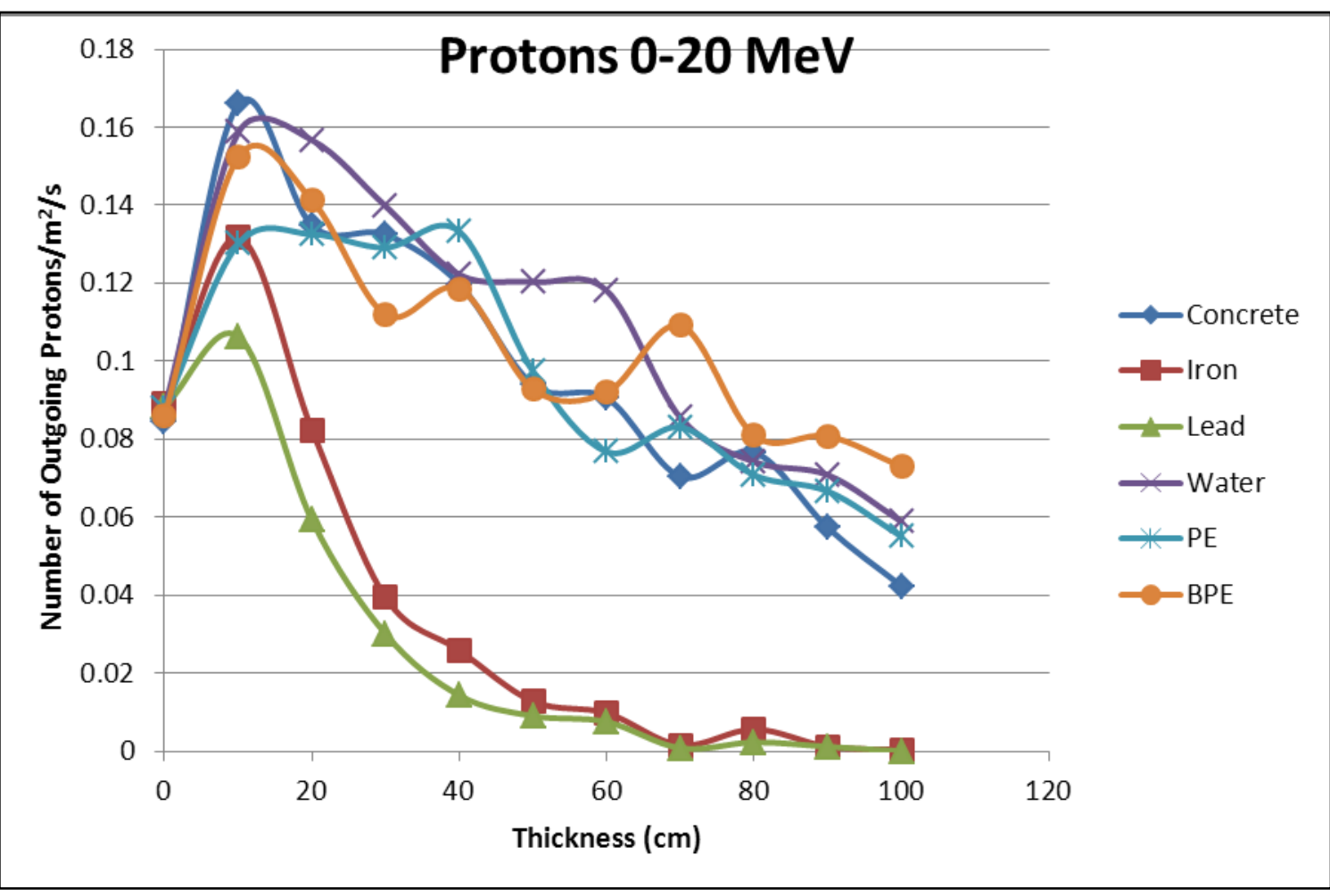

Figure 41: Low-Energy Outbound Proton Flux versus Material Thickness for All Materials Considered in This Study 
Table 24: Low-Energy Cosmic Particle Flux through Different Materials per Primary Particle

\begin{tabular}{|c|c|c|c|c|c|c|c|}
\hline \multirow[t]{2}{*}{ Material } & \multirow[t]{2}{*}{$\begin{array}{l}\text { Thickness } \\
\text { (cm) }\end{array}$} & \multicolumn{2}{|c|}{20} & \multicolumn{2}{|c|}{50} & \multicolumn{2}{|c|}{100} \\
\hline & & $\begin{array}{c}\text { Outbound } \\
\text { Neutrons } / \mathrm{m}^{2} / \mathrm{s}\end{array}$ & $\begin{array}{c}\text { Outbound } \\
\text { Protons } / \mathrm{m}^{2} / \mathrm{s}\end{array}$ & $\begin{array}{c}\text { Outbound } \\
\text { Neutrons } / \mathrm{m}^{2} / \mathrm{s}\end{array}$ & $\begin{array}{c}\text { Outbound } \\
\text { Protons/m2/s }\end{array}$ & $\begin{array}{c}\text { Outbound } \\
\text { Neutrons } / \mathrm{m}^{2} / \mathrm{s}\end{array}$ & $\begin{array}{c}\text { Outbound } \\
\text { Protons } / \mathrm{m}^{2} / \mathrm{s}\end{array}$ \\
\hline \multirow{4}{*}{ Iron } & $\begin{array}{l}\text { Incoming } \\
\text { Protons }\end{array}$ & $8.29 \pm 0.15$ & $0.008 \pm 0.00$ & $9.34 \pm 0.17$ & $0.00 \pm 0.00$ & $5.00 \pm 0.09$ & $0.00 \pm 0.00$ \\
\hline & $\begin{array}{l}\text { Incoming } \\
\text { Neutrons }\end{array}$ & 143.88 & 0.076 & 115.87 & 0.011 & 39.56 & 0.00 \\
\hline & $\begin{array}{l}\text { Incoming } \\
\text { Muons }\end{array}$ & 3.67 & 0.00 & 8.91 & 0.00 & 10.63 & 0.00 \\
\hline & Total & 155.84 & 0.084 & 134.11 & 0.013 & 55.19 & 0.00 \\
\hline \multirow{4}{*}{ Lead } & $\begin{array}{l}\text { Incoming } \\
\text { Protons }\end{array}$ & $24.8 \pm 0.7$ & $0.01 \pm 0.00$ & $30.9 \pm 0.9$ & $0.00 \pm 0.00$ & $18.1 \pm 0.5$ & $0 \pm 0$ \\
\hline & $\begin{array}{l}\text { Incoming } \\
\text { Neutrons }\end{array}$ & 316.52 & 0.06 & 349.62 & 0.01 & 176.58 & 0.00 \\
\hline & $\begin{array}{l}\text { Incoming } \\
\text { Muons }\end{array}$ & 3.284 & 0.00 & 8.81 & 0.00 & 10.12 & 0.00 \\
\hline & Total & 344.64 & 0.060 & 389.33 & 0.01 & 204.79 & 0.00 \\
\hline \multirow{4}{*}{ Concrete } & $\begin{array}{l}\text { Incoming } \\
\text { Protons }\end{array}$ & $1.35 \pm 0.03$ & $0.02 \pm 0.00$ & $1.88 \pm 0.05$ & $0.01 \pm 0.00$ & $1.05 \pm 0.03$ & $0.00 \pm 0.00$ \\
\hline & $\begin{array}{l}\text { Incoming } \\
\text { Neutrons }\end{array}$ & 14.30 & 0.12 & 7.80 & 0.09 & 3.92 & 0.04 \\
\hline & $\begin{array}{l}\text { Incoming } \\
\text { Muons }\end{array}$ & 0.33 & 0.00 & 0.73 & 0.00 & 0.64 & 0.00 \\
\hline & Total & 15.99 & 0.14 & 10.41 & 0.095 & 5.61 & 0.043 \\
\hline \multirow{4}{*}{ Water } & $\begin{array}{l}\text { Incoming } \\
\text { Protons }\end{array}$ & $0.36 \pm 0.02$ & $0.024 \pm 0.00$ & $0.42 \pm 0.02$ & $0.014 \pm 0.00$ & $0.27 \pm 0.01$ & $0.01 \pm 0.00$ \\
\hline & $\begin{array}{l}\text { Incoming } \\
\text { Neutrons }\end{array}$ & 19.80 & 0.14 & 10.95 & 0.11 & 5.22 & 0.055 \\
\hline & $\begin{array}{l}\text { Incoming } \\
\text { Muons }\end{array}$ & 0.045 & 0.00 & 0.04 & 0.00 & 0.02 & 0.00 \\
\hline & Total & 20.21 & 0.16 & 11.41 & 0.12 & 5.51 & 0.06 \\
\hline \multirow{4}{*}{$P E$} & $\begin{array}{l}\text { Incoming } \\
\text { Protons }\end{array}$ & $0.24 \pm 0.02$ & $0.02 \pm 0.00$ & $0.25 \pm 0.02$ & $0.01 \pm 0.00$ & $0.23 \pm 0.02$ & $0.00 \pm 0.00$ \\
\hline & $\begin{array}{l}\text { Incoming } \\
\text { Neutrons }\end{array}$ & 14.42 & 0.12 & 7.80 & 0.09 & 3.78 & 0.053 \\
\hline & $\begin{array}{l}\text { Incoming } \\
\text { Muons }\end{array}$ & 0.00 & 0.00 & 0.02 & 0.00 & 0.01 & 0.00 \\
\hline & Total & 14.65 & 0.14 & 8.06 & 0.10 & 4.02 & 0.06 \\
\hline \multirow{4}{*}{ BPE } & $\begin{array}{l}\text { Incoming } \\
\text { Protons }\end{array}$ & $0.22 \pm 0.01$ & $0.01 \pm 0.00$ & $0.27 \pm 0.02$ & $0.01 \pm 0.00$ & $0.17 \pm 0.01$ & $0.01 \pm 0.00$ \\
\hline & $\begin{array}{l}\text { Incoming } \\
\text { Neutrons }\end{array}$ & 19.65 & 0.13 & 10.41 & 0.09 & 5.13 & 0.068 \\
\hline & $\begin{array}{l}\text { Incoming } \\
\text { Muons }\end{array}$ & 0.00 & 0.00 & 0.00 & 0.00 & 0.00 & 0.00 \\
\hline & Total & 19.87 & 0.14 & 10.68 & 0.09 & 5.31 & 0.07 \\
\hline
\end{tabular}




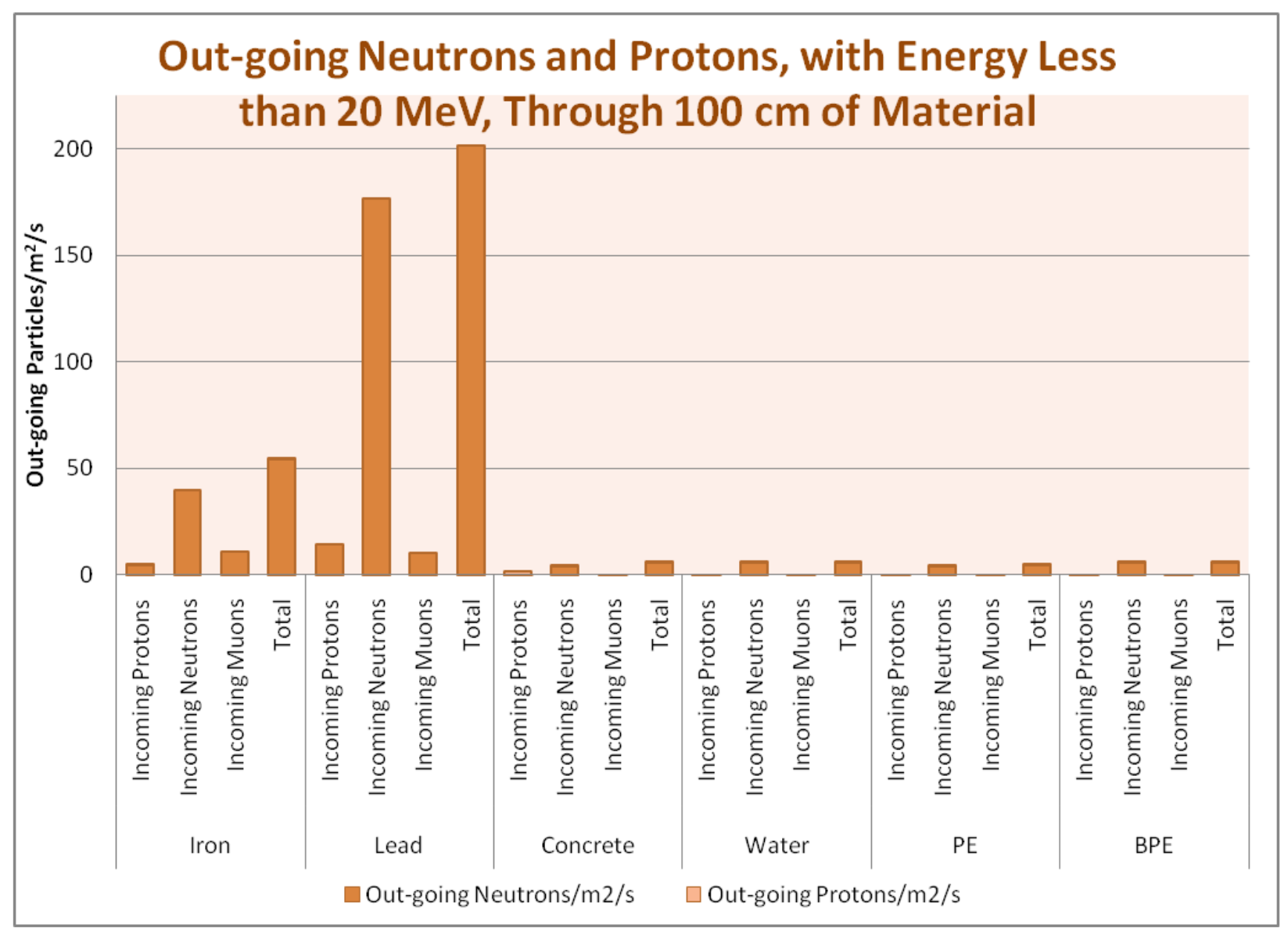

Figure 42: Outbound Total Low-Energy Neutron and Proton Flux through $100 \mathrm{~cm}$ of All Materials Considered in This Study 


\section{A.2 Very High-Energy Range (100 MeV - $10 \mathrm{GeV})$ of the Cosmic Flux}

This section presents graphs and tables combining all the results presented in the previous section, in order to facilitate the comparison between shield materials against cosmic showers, in particular their neutronic and protonic components. Figure 43 shows the outgoing flux for neutrons above $100 \mathrm{MeV}$.

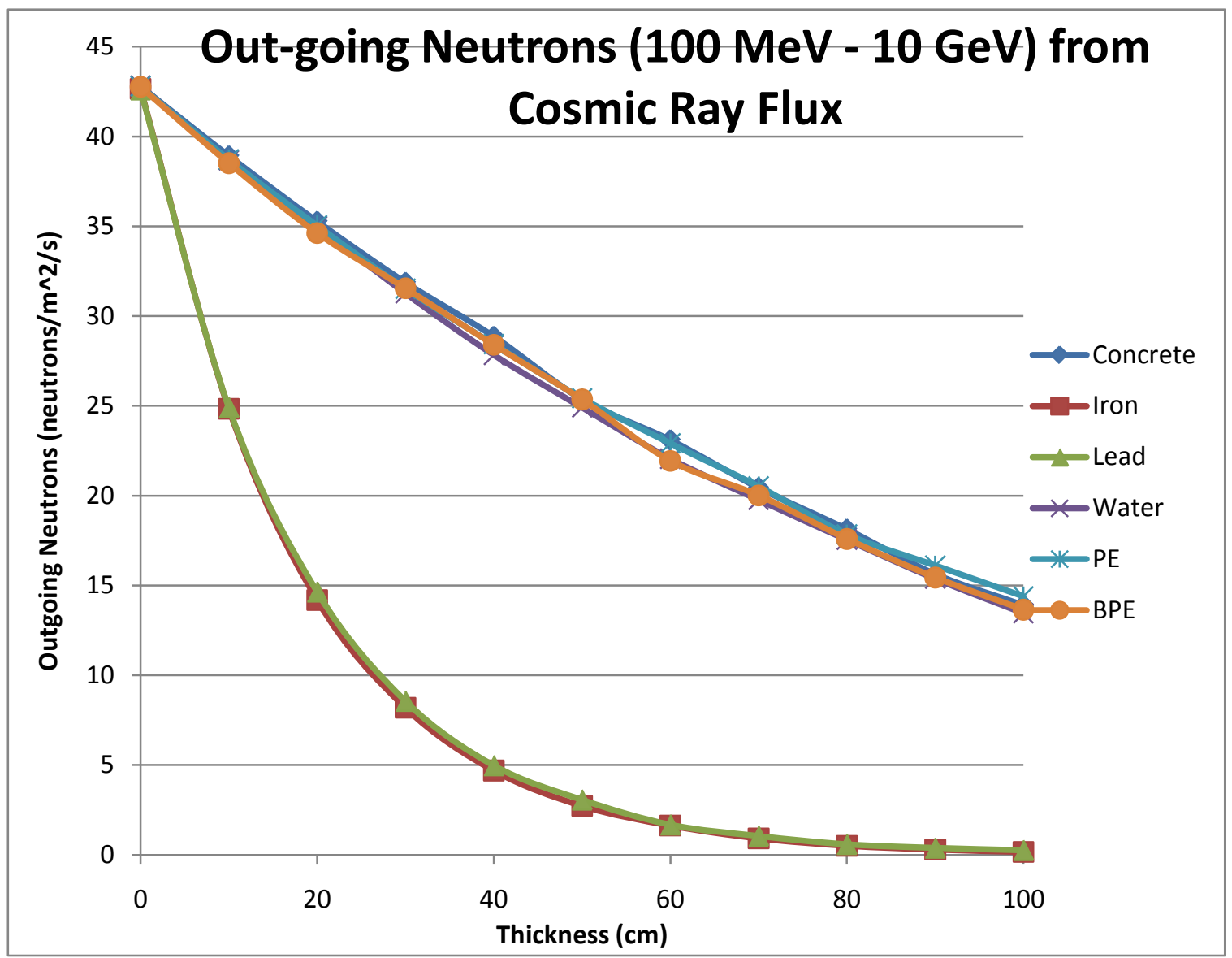

Figure 43: High-Energy Outbound Neutron Flux versus Material Thickness for All Materials Considered in This Study 


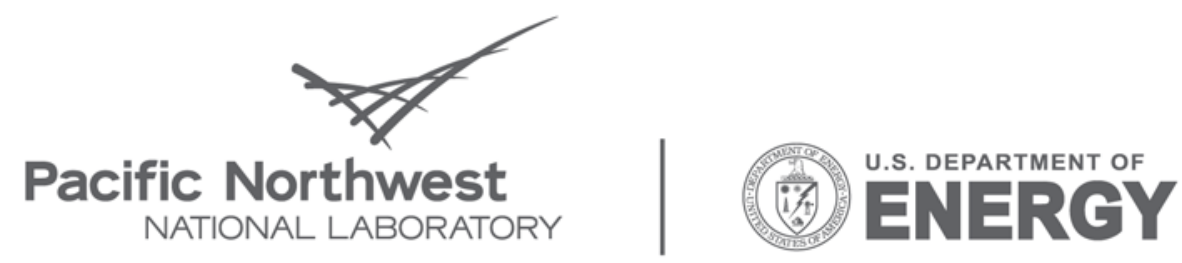

Proudly Operated by Battelle Since 1965

902 Battelle Boulevard

P.O. Box 999

Richland, WA 99352

1-888-375-PNNL (7665)

www.pnl.gov 